University of Massachusetts Amherst

ScholarWorks@UMass Amherst

November 2015

\title{
A Semisynthetic Strategy Leads to Alteration of the Backbone Amidate Ligand in the NiSOD Active Site
}

Julius Omayao Campeciño

University of Massachusetts Amherst

Follow this and additional works at: https://scholarworks.umass.edu/dissertations_2

\section{Recommended Citation}

Campeciño, Julius Omayao, "A Semisynthetic Strategy Leads to Alteration of the Backbone Amidate Ligand in the NiSOD Active Site" (2015). Doctoral Dissertations. 500.

https://doi.org/10.7275/7512646.0 https://scholarworks.umass.edu/dissertations_2/500

This Open Access Dissertation is brought to you for free and open access by the Dissertations and Theses at ScholarWorks@UMass Amherst. It has been accepted for inclusion in Doctoral Dissertations by an authorized administrator of ScholarWorks@UMass Amherst. For more information, please contact scholarworks@library.umass.edu. 


\title{
A SEMISYNTHETIC STRATEGY LEADS TO ALTERATION OF THE BACKBONE AMIDATE LIGAND IN THE NISOD ACTIVE SITE
}

\author{
A Dissertation Presented \\ by \\ JULIUS OMAYAO CAMPECIÑO
}

Submitted to the Graduate School of the University of Massachusetts Amherst in partial fulfillment of the requirements for the degree of

DOCTOR OF PHILOSOPHY

September 2015

Chemistry 
(C) Copyright by Julius Omayao Campeciño

All Rights Reserved 


\title{
A SEMISYNTHETIC STRATEGY LEADS TO ALTERATION OF THE BACKBONE AMIDATE LIGAND IN THE NISOD ACTIVE SITE
}

\author{
A Dissertation Presented \\ by \\ JULIUS OMAYAO CAMPECIÑO
}

Approved as to style and content by:

Michael J. Maroney, Chair

Dhandapani Venkataraman, Member

Patricia A. Bianconi, Member

David J. Gross, Member

Craig T. Martin, Department Head

Chemistry 


\section{DEDICATION}

I dedicate this dissertation to my grandparents, dad, mom, and my siblings. 


\section{ACKNOWLEDGMENTS}

Numerous people, in one way or another, have helped me try to achieve the very goal of obtaining a doctoral degree. It's impossible to name them all here and I would like to apologize to anyone who I might have missed. First, I would like to thank my grandfather, Eufracio Campeciño (dad's), for instilling in us high moral values by going with us to Sunday church service and enrolling us in summer Sunday school every summer. My grandmother, Crecenciana Omayao (mom’s), even though you live far from us and we did not have too many opportunities to share a lot of time with you, thank you for tilling the soil so mom and her siblings will have a chance to live a better life. My mom's very friendly demeanor and a very positive disposition in life, I'm sure she inherited it from you.

I would like to thank my parents, Natividad Omayao and William Campeciño, for molding me into a person that I am today. They certainly did what they could to raise me and my siblings well even when they don't have enough. Where do they get the money to send all of us to school? I had never asked them that question. I just kept taking money. My dear mom and dad, I am sorry it took me so long to finish. Now that it's done, I would like both of you, and grandma and grandpa to enjoy the good life that you deserve. I'll take good care of my siblings and I always felt it's also my duty to look after my nieces and nephews. This I promise.

Next on the list is my adviser, Prof. Michael J. Maroney. I am glad that I ended up in your lab. It was not my intention, at the beginning, to be part of your group but somehow it worked that way. You know my struggles very well and that I even have the intention to quit grad school early on. I could not remember now what you said but you 
convinced me to stay. It was tough grinding but with you being so flexible and tolerant, made it a little easier for me to put my foot in front of the other. It all worked out in the end and it's even better than what I had anticipated.

I would also like to thank my committee: Prof. Patricia Bianconi, Prof. Dhandapani Venkataraman, and Prof. David Gross. Thank you for taking on this responsibility of guiding me through the process until the completion of my degree. I did not have too many opportunities to interact with Prof. David Gross and Prof. Patricia Bianconi but their friendly demeanor took some of the pressure off my shoulders during the qualifying examinations. Prof. Dhandapani Venkataraman has always been a reliable mentor. Be it on the bus, on the street, in the campus, in his office, he is passionate about sharing his wisdom to his mentees. Having received the Campus Distinguished Teaching Award speaks volumes about his dedication. Thanks a lot DV!

I am grateful to my cousins, Adeline Ladion; Adelaida Ladion and her husband Joel Magsayo; and my grandaunt, Florentina Valero; for taking care of my needs when I first came in the US. I would not be able to imagine how difficult it would be to live in a country without knowing anyone. I owe you a lot more than monetary and I would be glad to return the favor if given the opportunity. For similar reason, I am also grateful to Carol Albano and my former housemate, Janet Surprise. It felt like having two moms in one house. I was so naïve back then and I never really prepared for my first winter. Both of you asked if I have a coat and I did not have any. The next few days I had two, one from each of you. To Carol, who volunteered to do my groceries this year to help ease some of the work related pressure off of me, I have so much to thank you for. This 
dissertation is not enough to thank you for all of what you have done. I look forward to your first vacation in the Philippines.

I owe a lot to the past and present members of the Maroney lab (Dr. Crisjoe Joseph, Dr. Robert Herbst, Dr. Vlad-Martin Diaconescu, Dr. Kelly Ryan, Dr. Khadine Higgins, Dr. Nitai Giri, Dr. Roby Kurian, Manju Sharma, Heidi Hu, Hsin-Ting Huang, Priyanka Basak and Zeinab Kaboli). I lacked technical knowledge when I first started working in the lab and it has been a really great help to have this people around. More than the lab help is their company that is a simple cure for insanity. I wish we could play more bocce balls, card games, and chess.

I would like to extend my gratitude to Dr. Rinat Abzalimov and Dr. Stephen Eyles for their help with the mass spectrometry; to Dr. Diane Cabelli for her help with the pulse radiolysis experiments; to Dr. Cornelius Taabazuing for his help with the EPR; to Prof. James Chambers for providing the histidinal and for allowing me to use their UV diode; to Dr. Lech Dudycz and Dr. David Tumelty for synthesizing the pentapeptide; to Prof. Elizabeth Vierling and Dr. Indu Santhanagopalan for providing the thiol sepharose; to the staffs who take care of our equipment repairs (Bob Sabola), glass works (Timothy Landers) and network issues (John Maher) so we may keep working smoothly.

I would also like to thank my inner circle of friends here at UMass (Bernard Matute, Kevin Dagbay, Grazel Dolly Zaballero-Dagbay, Bay Serrano, Mahalia Serrano, Kristine Pobre-Piza, Allan Piza, Cristina Martin and the rest of the Amherst pals) for making my stay here a little bit more comfortable. I’ll see you around. 


\title{
ABSTRACT \\ A SEMISYNTHETIC STRATEGY LEADS TO ALTERATION OF THE BACKBONE AMIDATE LIGAND IN THE NISOD ACTIVE SITE
}

\author{
SEPTEMBER 2015 \\ JULIUS OMAYAO CAMPECIÑO, B.S., MSU-ILIGAN INSTITUTE OF \\ TECHNOLOGY \\ Ph.D., UNIVERSITY OF MASSACHUSETTS-AMHERST
}

Directed by: Professor Michael J. Maroney

\begin{abstract}
Computational investigations have implicated the amidate ligand in nickel superoxide dismutase (NiSOD) in stabilizing Ni-centered redox catalysis and in preventing cysteine thiolate ligand oxidation. To test these predictions, we used an experimental approach utilizing a semisynthetic scheme that employs native chemical ligation of a pentapeptide (HCDLP) to recombinant S. coelicolor NiSOD lacking these N-terminal residues, N $\Delta 5$-NiSOD. Wild-type enzyme produced in this manner exhibits the characteristic spectral properties of recombinant WT-NiSOD and is as catalytically active. The semisynthetic scheme was also employed to construct a variant where the amidate ligand was converted to a secondary amine, H1*-NiSOD, a novel strategy that retains a backbone $\mathrm{N}$-donor atom. The $\mathrm{H} 1{ }^{*}-\mathrm{NiSOD}$ variant was found to have only $1 \%$ of the catalytic activity of the recombinant wild-type enzyme, and have altered spectroscopic properties. X-ray absorption spectroscopy reveals a four-coordinate planar site with $\mathrm{N}_{2} \mathrm{~S}_{2}$-donor ligands, consistent with electronic absorption spectroscopic results indicating that the Ni center in $\mathrm{H} 1 *$-NiSOD is mostly reduced in the as-isolated sample, as opposed to $50: 50 \mathrm{Ni}(\mathrm{II}) / \mathrm{Ni}(\mathrm{III})$ mixture that is typical for the recombinant wild-type enzyme. The EPR spectrum of as-isolated H1*-NiSOD accounts for $\sim 11 \%$ of the $\mathrm{Ni}$ in
\end{abstract}


the sample and is similar to WT-NiSOD, but more axial, with $\mathrm{g}_{\mathrm{z}}<\mathrm{g}_{\mathrm{x}, \mathrm{y}} \cdot{ }^{14} \mathrm{~N}$-hyperfine is observed on $\mathrm{g}_{\mathrm{z}}$, confirming the addition of the apical histidine ligand in the $\mathrm{Ni}(\mathrm{III})$ complex. The altered electronic properties and implications for redox catalysis are discussed in light of predictions based on synthetic and computational models. 
TABLE OF CONTENTS

Page

ACKNOWLEDGMENTS .. $\mathrm{V}$

ABSTRACT. viii

LIST OF TABLES xiii

LIST OF FIGURES xiv

\section{CHAPTER}

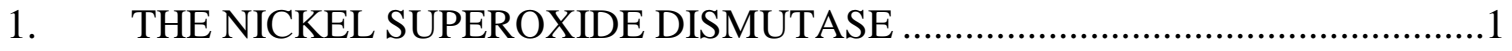

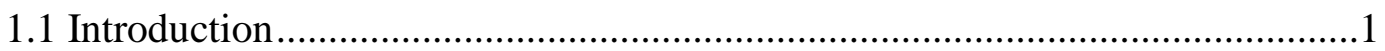

1.1.1 Superoxide Radical: Its Biochemistry and Pathology ......................1

1.1.2 Superoxide Dismutase: Nature's way to regulate the level of superoxide radical.

1.2 Evolution and Genomics.........................................................................

1.3 NiSOD Molecular Structure, Electronic Structure and Catalytic Mechanism ..8

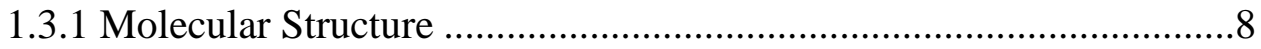

1.3.2 Electronic Structure ...........................................................11

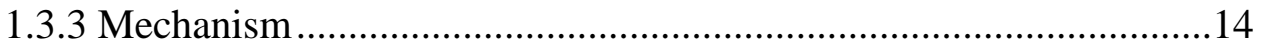

1.3.3.1 Superoxide Self Disproportionation .................................14

1.3.3.2 NiSOD Superoxide Dismutation.....................................15

1.3.3.3 Outer-sphere vs Inner-sphere.......................................17

1.4 The Role of the Nickel Ligands ........................................................21

1.4.1 The Role of the Thiolate Ligands ................................................21

1.4.2 The Role of the Imidazole Ligand ...............................................24

1.4.3 The Role of Mixed Amine/Amide Ligand.......................................28

1.4.4 The Role of the Second Sphere Ligands.......................................31

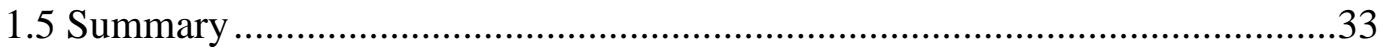

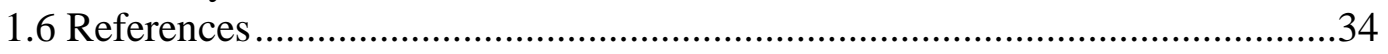

2. SEMISYNTHETIC APPROACH FOR CONSTRUCTING H1*-NISOD ...........42

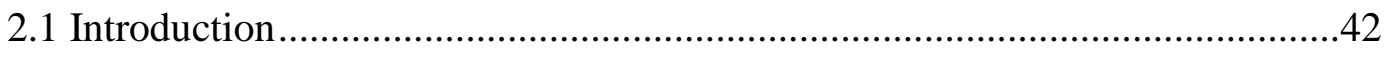


2.2 Materials and Methods

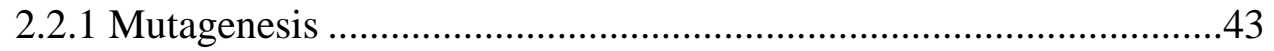

2.2.2 N $\Delta 5$-NiSOD Protein Expression and Purification............................44

2.2.3 N $\Delta 5$-NiSOD Chemical Rescue ......................................................44

2.2.4 His-Cys(o-NBn)-Asp-Leu-Pro-Nbz (Protected Unmodified HCDLP)

2.2.4.1 Synthesis of Alloc-Cys(o-NBn)-OH. Cys(o-NBn)-OH.....47

2.2.4.2 His-Cys(o-NBn)-Asp-Leu-Pro-Nbz SPPS Assembly........47

2.2.5 His- $\psi$-Cys(o-NBn)-Asp-Leu-Pro-SBn Synthesis (Modified H1*-

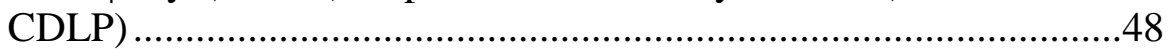

2.2.5.1 Boc-His( $\mathrm{N}^{\pi}$-Adom)-H Synthesis ...................................48

2.2.5.2 His- $\psi$-Cys(o-NBn)-Asp-Leu-Pro-SBn SPPS Assembly....49

2.2.6 Native Chemical Ligation and Product Purification........................51

2.2.7 Cys2 Protective Group Removal, Folding and Metalation ...............52

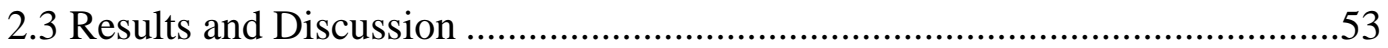

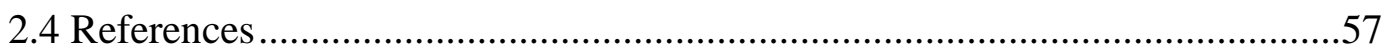

3. REACTION KINETICS AND PHYSICAL CHARACTERIZATION OF H1*-

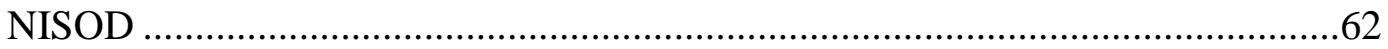

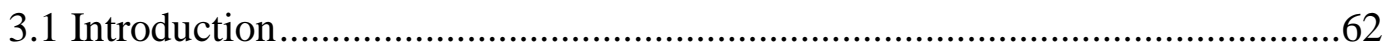

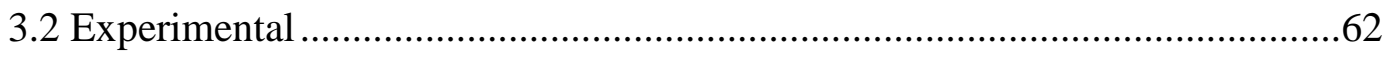

3.2.1 X-ray Absorption Spectroscopy .................................................62

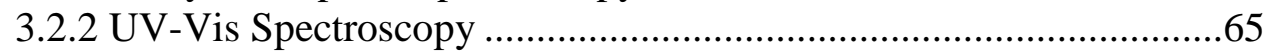

3.2.3 Electron Paramagnetic Resonance Spectroscopy ..........................65

3.2.4 Pulse Radiolysis ...................................................................66

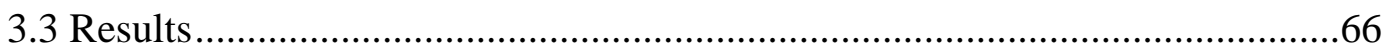

3.3.1 Structural Characterization of the Ni Site in H1*-NiSOD...............66

3.3.2 UV-Vis Spectroscopy ..............................................................68

3.3.3 Electron Paramagnetic Resonance Spectroscopy ...........................69

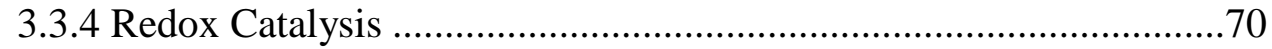

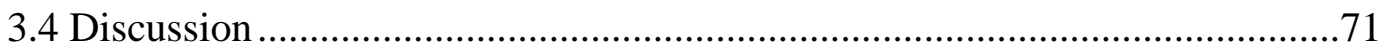

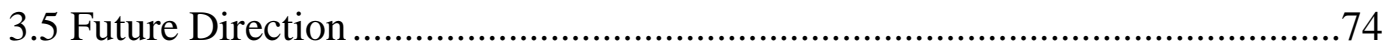

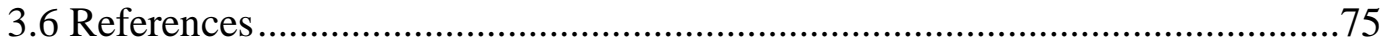




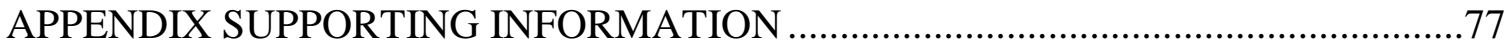

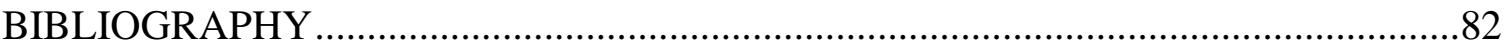




\section{LIST OF TABLES}

Table

Page

3.1 H1*-NiSOD first- and second-coordination sphere EXAFS fit results showing $\mathrm{Ni}-\mathrm{N}$, -S and -C distances, r; threshold energy shift, $\mathrm{E}_{0}$; Debye-Waller factor, $\sigma^{2}$; and statistical parameters. 68

3.2 WT-NiSOD first- and second-coordination sphere EXAFS fit results showing $\mathrm{Ni}-\mathrm{N},-\mathrm{S}$ and $-\mathrm{C}$ distances, $\mathrm{r}$; threshold energy shift, $\mathrm{E}_{0}$; Debye-Waller factor, $\sigma^{2}$; and statistical parameters. .68

A.1 Rates of reactions and [SOD] dependence for H1*-NiSOD.........................77

A.2 $\mathrm{pH}$ dependent activity assay of semisynthetic WT-NiSOD at $2 \mu \mathrm{M}$

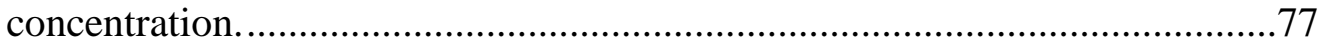

A.3 Extended x-ray absorption fine structure first shell fit results showing Ni-N, -S and $-\mathrm{C}$ distances, $\mathrm{r}$; threshold energy shift, $\mathrm{E}_{0}$; Debye-Waller factor, $\sigma^{2}$; and statistical parameters. Fit highlighted in yellow is the best fit. .78

A.4 XANES analysis for H1*-NiSOD. .80 


\section{LIST OF FIGURES}

Figure

Page

1.1 Model for Nur-dependent inverse regulation of sodN and sodF (reprinted with permission from Oxford University Press) ...............................................

1.2 NiSOD molecular and active site structures. A. 4-helix monomer. B. Tripodlike trimer with C3 rotation. C. Hexamer. D. The active site structure. E. Hexamer C2 relationship.

NiSOD proposed active site channel. ...................................................11

1.4 NiSOD X-band EPR spectra. A. As-isolated WT-NiSOD. B. ${ }^{61}$ Ni labeled WTNiSOD. C. ${ }^{15} \mathrm{~N}$ enriched enzyme. D. ${ }^{33} \mathrm{~S}$ thiolate labeled enzyme (copyright (2004) National Academy of Sciences, U.S.A.).

1.5 A. Molecular orbital energy level diagram for the oxidized (ox) and reduced (red) form of NiSOD. (Adapted with permission from reference 52. Copyright (2005) American Chemical Society.) B. Illustration of the Ni active site $\pi$ orbitals

1.6 Rate contants of superoxide self disproportionation and superoxide dismutation catalyzed by MnSOD (green), CuZnSOD (red) and NiSOD (black) (credit: Dr. Diane Cabelli)..............................................................15

1.7 Proposed catalytic cycle for NiSOD from DFT calculations. (Adapted with permission from reference 59. Copyright (2006) American Chemical Society.). 18

1.8 Proposed outer-sphere mechanism for NiSOD. (Reprinted with permission from reference 49. (Copyright (2009) American Chemical Society.).............20

1.9 A. Sulfur K-edge spectra of radiolitically and chemically reduced WT NiSOD. (Reprinted with permission from reference 67. Copyright (2004) American Chemical Society.) B. Sulfur K-edge spectra of (a) oxidized NiSOD mimic at $\mathrm{pH} 7.4$, (b) reduced mimic at $\mathrm{pH} 9.5$ and (c) reduced mimic at pH 7.4. Inset: structure of the reduced NiSOD mimic, Ni(II) ${ }^{\mathrm{M} 1}-\mathrm{H}$ (copyright (C) 2013 WILEY-VCH Verlag GmbH \& Co. KGaA, Weinheim).

1.10 Spectral data taken during pulse radiolytic catalysis of WT-NiSOD (black) and H1A-NiSOD (red, blue and green). (Reprinted with permission from reference 72. Copyright (2015) American Chemical Society.). 
1.11 Thin film voltammograms and redox mechanisms for [NiII(SOD $\left.{ }^{\mathrm{M} 2}\right)$ ] and [NiII(SOD $\left.\left.{ }^{\mathrm{M} 2} \mathrm{H}(1) \mathrm{A}\right)\right]$. (Adapted with permission from reference 63. Copyright (2007) American Chemical Society.). .26

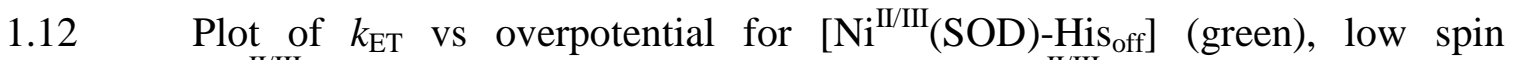
$\left[\mathrm{Ni}^{\mathrm{II} / \mathrm{III}}(\mathrm{SOD})-\mathrm{His}_{\mathrm{on}}\right]$ (red) and high spin [Ni ${ }^{\mathrm{II} / \mathrm{III}}$ (SOD)-His $\left.{ }_{\text {on }}\right]$ (purple). (Reprinted with permission from reference 63. Copyright (2007) American Chemical Society.) $k_{\mathrm{ET}}$ values for $\mathrm{O}_{2}$ (squares) and $\mathrm{H}_{2} \mathrm{O}_{2}$ (circles) generation are: $1.6 \times 10^{5} \mathrm{~s}^{-1}$ (red square), $6.3 \times 10^{5} \mathrm{~s}^{-1}$ (green square), $2.8 \times 10^{4} \mathrm{~s}^{-1}$ (green circle), $4.6 \times 10^{5} \mathrm{~s}^{-1}$ (red circle) and $1.7 \times 10^{6} \mathrm{~s}^{-1}$ (purple circle). The $k_{\mathrm{ET}}$ value at the overpotential required for $\mathrm{O}_{2}$ generation for high spin $\left[\mathrm{Ni}^{\mathrm{II} / \mathrm{III}}\right.$ (SOD)-His $\left.{ }_{\text {on }}\right]$ (purple square) is not provided in the text. ..................................................28

1.13 Complexes A-F used in reference 80 (with kind permission from Springer Science and Business Media (C) 2006).

1.14 Crystal structure for WT-NiSOD (A) and Y9F-NiSOD (B). (Reprinted with permission from 49. Copyright (2009) American Chemical Society.)............31

2.1 The Ni site structures of WT-NiSOD (left) and H1*-NiSOD (right).............42

2.2 The pelB WT-NiSOD amino acid sequence. Highlighted in blue is the pelB sequence. Highlighted in red is the first five amino acids that are deleted to form the $\mathrm{N} \Delta 5$-NiSOD. .44

2.3 ESI-MS for N $\Delta 5$-NiSOD after the Q-sepharose purification. ........................45

2.4 ESI-MS of N $\Delta 5$-NiSOD after the chemical rescue. ...................................46

2.5 A. ESI - MS of H1*-NiSOD after ND5 and H*CDLP-thioester NCL. The peaks under the blue dots are the peaks that correspond to the charge states for H1*-NiSOD. Unlabeled peaks correspond to the charge states of oxidized and

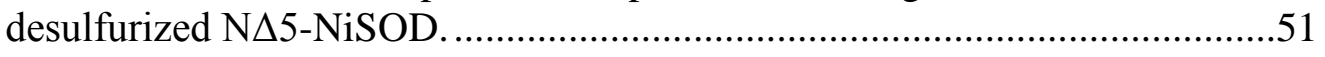

2.6 Semisynthetic approach for constructing H1*-NiSOD................................53

2.7 ESI-mass spectra of the semisynthetic WT-NiSOD (A) and H1*-NiSOD (B) after the removal of the 2-nitrobenzyl Cys2 protective group by UV irradiation. Peaks under the red dots in figure B correspond to a modified $\mathrm{N} \Delta 5$-NiSOD that does not contain a high-affinity nickel binding site............54

2.8 Size exclusion chromatography on the NiSOD variants. The apparent MW determined for all variants is approximately $73 \mathrm{kDa}$ (Calculated: $79 \mathrm{kDa}$ )....56 
3.1 Ni K-edge XANES spectra for dithionite-reduced WT-NiSOD and dithionite reduced H1*-NiSOD. Figure insets: (A) Fourier-transformed $\left(\mathrm{k}=2-12.5 \AA^{-1}\right)$ EXAFS (blue) and fit (red). (B) $k^{3}$-weighted EXAFS data (blue) and fit (red).67

3.2 UV-Vis absorption spectra of the NiSOD variants...........................................69

3.3 EPR spectra of recombinant WT-NiSOD, semisynthetic WT-NiSOD and

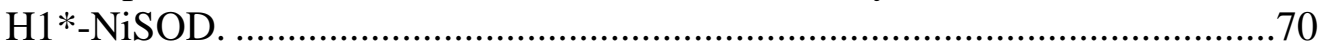

3.4 Catalytic activity $\mathrm{pH}$ dependence of recombinant WT-NiSOD (black square) compared with that of semi-synthetic WT-NiSOD (red circle). The catalytic activity of $\mathrm{H} 1{ }^{*}$-NiSOD at $\mathrm{pH}=7.50$ is shown as a blue triangle......................71

3.5 NiSOD active site diagrams illustrating the different interactions between the $\mathrm{N}$-donor ligands and a Ni $\pi$-symmetry $3 \mathrm{~d}$ orbital in WT-NiSOD with a Cys2 amidate ligand (left), and in $\mathrm{H} 1{ }^{*}$-NiSOD with a Cys2 $2^{\circ}$ amine (right).........73

A.1 XANES spectrum fitted with an error function and two gaussian functions...81 


\section{CHAPTER 1}

\section{THE NICKEL SUPEROXIDE DISMUTASE}

\subsection{Introduction}

\subsubsection{Superoxide Radical: Its Biochemistry and Pathology}

Oxygen is a diatomic molecule that plays an important role in aerobic respiration as the final dumping ground for electrons in the electron transport chain: a cellular process involved in energy production in mitochondria. ${ }^{1}$ The molecular oxygen is reduced to water by cytochrome oxidase using the electrons that are passed down in the electron transport chain from one enzyme complex to another in a tightly choreographed mechanism. In this mechanism, cytochrome oxidase is the last enzyme complex to receive the reducing electrons. ${ }^{2}$ Cytochrome oxidase then reduces molecular oxygen in a stepwise fashion - one electron at a time. Coupled with these electron transfer processes is the pumping of protons from the mitochondrial matrix into the intermembrane space. This creates a proton gradient which drives the synthesis of ATP. ${ }^{2}$ The drawback of the stepwise redox reaction, however, is that it is not foolproof and about $1-2 \%$ of the total daily human oxygen consumption is not completely reduced to water but released as superoxide radical $\left(\mathrm{O}_{2}^{-{ }^{-}}\right)$and it is believed that the electron transport chain in the mitochondria is the main source of superoxide radical. ${ }^{1,2}$

The superoxide radical itself is a benign radical; so low in reactivity that it was

previously argued that a defense mechanism against this radical is not important. However, this benign reactivity makes $\mathrm{O}_{2}{ }^{--}$more dangerous because it can diffuse over long distances, without being quenched, and eventually finds its target. ${ }^{5}$ It has been 
shown that $\mathrm{O}_{2}{ }^{-\bullet}$ could inactivate catalases, ${ }^{6}$ glutathione peroxidases, ${ }^{7}$ and more than a dozen of other enzymes ${ }^{8}$ - most importantly FeS-cluster containing enzymes such as aconitase and dehydratases. ${ }^{5,9}$ The iron ions released from these deactivated FeS-cluster containing enzymes act as catalyst for the Haber-Weiss reaction:

$$
\begin{gathered}
\begin{array}{c}
\mathrm{Fe}^{3+}+\mathrm{O}_{2} \cdot- \\
\rightarrow \mathrm{Fe}^{2+}+\mathrm{O}_{2}(1) \\
\mathrm{Fe}^{2+}+\mathrm{H}_{2} \mathrm{O}_{2} \rightarrow \mathrm{Fe}^{3+}+\mathrm{OH}^{-}+\mathrm{OH}^{\cdot}(2)
\end{array} \\
\mathrm{O}_{2}{ }^{--}+\mathrm{H}_{2} \mathrm{O}_{2} \rightarrow \mathrm{OH}^{\bullet}+\mathrm{OH}^{-}+\mathrm{O}_{2}(3)
\end{gathered}
$$

$\mathrm{O}_{2}{ }^{--}$and $\mathrm{H}_{2} \mathrm{O}_{2}$ from the Haber-Weiss reaction work together to produce an even more toxic reactive oxygen species, hydroxyl radical $\left(\mathrm{OH}^{*}\right)$. The hydroxyl radical is so reactive that it will react with the first molecule it encounters. ${ }^{9,10}$

Since superoxide radical is predominantly produced in mitochondria, the most important target is the mitochondrial DNA (mtDNA). ${ }^{11}$ Damage to mtDNA was one of the bases for the mitochondrial theory of aging. The damage to the mtDNA causes mutations to the encoded proteins; the more important mutations are the ones involving the respiratory complexes. ${ }^{11}$ These mutations decrease the efficiency of the electron transport chain; and as pointed out by Genova et al. (2004), these mutations "lead to further production of reactive oxygen species, thus establishing a vicious cycle of oxidative stress and energetic decline". ${ }^{12}$ This oxidative stress is thought to play a major contribution to all human inflammatory diseases, ischemic diseases, hemochromatosis, and neurologic diseases such as Alzheimer's disease, Parkinson's disease and amyotrophic lateral sclerosis. ${ }^{8}$ 


\subsubsection{Superoxide Dismutase: Nature's way to regulate the level of superoxide radical.}

Energy production (in the form of ATP) via aerobic respiration has the advantage over glycolysis (anaerobic) in that it produces 18 times more ATP per glucose molecule. ${ }^{13}$ However, one trade-off for this advantage is the production of $\mathrm{O}_{2}{ }^{\circ}$. Since $\mathrm{O}_{2}{ }^{\circ-}$ is an inevitable by-product of aerobic respiration and since reactive oxygen species are tremendously destructive, superoxide radical has to be regulated at the cellular level. ${ }^{14}$ To acquire both the advantage of aerobic metabolism as well as the ability to survive against reactive oxygen species, microorganisms and complex organisms had evolved with a defense mechanism using superoxide dismutases (SODs). ${ }^{13}$ The pressure to develop a defense against $\mathrm{O}_{2}{ }^{*}$ is so intense that organisms developed SODs on three separate occasions and these are Fe/MnSOD, CuZnSOD, and NiSOD. ${ }^{13}$

Superoxide dismutases are indispensible for an aerobic lifestyle and are found in all organisms exposed to oxygen. ${ }^{15}$ They are even found in facultative anaerobes with the exception of Neisseria gonorrhoeae, and Lactobacillus plantarum and related lactobacilli which use high concentration of manganese to scavenge $\mathrm{O}_{2} \cdot{ }^{\cdot-16-19}$ Even a few examples of obligate anaerobes harbor this class of enzyme. ${ }^{20,21}$ Microorganisms can possess one, two, or all three classes of SODs to meet their antioxidative demands. ${ }^{22}$ Among SODs, the most ancient is perhaps FeSOD on the basis that it is found in microorganisms that are extremely primitive. This claim is also consistent with the bioavailability of iron prior to the Great Oxidation Event; whereas, $\mathrm{Cu}$ and $\mathrm{Zn}$ were still tied up in insoluble sulfide containing minerals in the crust. ${ }^{23}$ The first superoxide dismutase isolated was CuZnSOD by Mann and Keilin in $1938 .{ }^{24}$ It was then called haemacuprien (isolated from the blood corpuscles and serum of mammals) and hepatocuprien (isolated from the ox liver). Its 
enzymatic activity was unknown until in 1969 when McCord and Fridovich discovered that the enzyme catalyzed the dismutation of superoxide radical to molecular oxygen. ${ }^{25}$ Shortly thereafter, MnSOD and FeSOD were isolated from E. coli, ${ }^{26,27}$ and all three have since been found in a variety of organisms in all three life forms: archea, bacteria and eukarya. ${ }^{23}$

The most recent SOD that has been discovered is one that harbors nickel in its active site - NiSOD. It was first isolated in Streptomyces species; ${ }^{28,29}$ and its encoding gene, sodN, was later found in marine cyanobacteria, actimycetes, gammaproteobacteria, bacteriodetes, planctomycetes and deltaproteobacteria. ${ }^{30,31}$ NiSOD is unique among the superoxide dismutases in that it uses $\mathrm{Ni}(\mathrm{II})$ ions, which are redox inactive in the absence of the protein environment in aqueous media. Unlike aqueous solutions containing $\mathrm{Cu}(\mathrm{II}), \mathrm{Mn}(\mathrm{II})$, and $\mathrm{Fe}(\mathrm{II})$, aqueous $\mathrm{Ni}(\mathrm{II})$ ions do not catalyze the dismutation of superoxide radical. ${ }^{23}$ This is perhaps due to the fact that the redox potential of aqueous $\mathrm{Ni}(\mathrm{II})$ is estimated to be $+2.29 \mathrm{~V},{ }^{32,33}$ hence, it is stable in aqueous medium and renders $\mathrm{Ni}(\mathrm{III})$ unattainable because water can be oxidized at a potential less extreme than $\mathrm{Ni}(\mathrm{II}){ }^{23,33}$ This inaccessible $\mathrm{Ni}(\mathrm{II})$ redox potential is decreased to the optimal redox potential by the redox tuning afforded by the nickel active site ligand environment. ${ }^{33}$

This chapter will examine the structure and function of the nickel active site protein environment in NiSOD with an in-depth review particularly focused on the roles played by the nickel active site ligands in redox catalysis. The roles played by secondsphere residues will also be highlighted. To complete the story on NiSOD, the enzyme evolution and genomics will also be discussed in the section that follows. 


\subsection{Evolution and Genomics}

The sodN gene that encodes the NiSOD enzyme had previously been noted in Synechococcus sp. and Prochlorococcus sp. ${ }^{34}$ Since then, it has been found in a number of organisms; and its phylogenetic distribution has been characterized. ${ }^{31}$ The phylogenetic tree of forty-three fully sequenced genomes of model organisms revealed four major clusters: I. actinomycetes, II. cyanobacteria, III. gammaproteobacteria and bacteriodetes, and IV. planctomycetes, cyanobacteria and deltaproteobacteria. ${ }^{23,31}$ With the exception of cluster IV, each major cluster can be broken down into two or three subclusters. Additional metagenome sequences of forty-one microbes from the Sargasso Sea, ${ }^{35}$ and a full sequence from gutless worm endosymbiont metagenome, ${ }^{36}$ a within the major clusters, form new subclusters within the major clusters, or are simply unassignable. ${ }^{31}$ The phylogenetic tree previously constructed can be found in reference 31.

Using homology modeling and similarity searches, the predicted secondary structures of the post-translationally modified sodN gene products (vide infra) of representative organisms from each of the phylogenetic clusters could be sufficiently aligned to the structure of Streptomyces sp. NiSOD, even though the sequence alignment suggested that some of the genomes are only $30 \%$ similar to the Streptomyces sp sodN. ${ }^{31}$ The sequence alignment revealed that the most conserved region in the Streptomyces sodN gene product after post-translational modification (vide infra) is the $\mathrm{N}$-terminal $\mathrm{Ni}$ -

hook motif (HCDLPCGV-). ${ }^{23,31}$ In this motif only His1, Cys2 and Cys6 are invariant. Tyr9 and Pro5 are highly conserved, with Tyr9 replaced by Phe only in one sequence, and Pro5 is replaced by either Tyr or Phe in only two sodN sequences, both from 
Mycobacterium..$^{23,31}$ The rest of the amino acids are variable, but the variation is phylogenetically consistent. For example, Asp3 is replaced only by glutamine in cluster IV except in the gutless worm endosymbiont where it is replaced by glutamate. Gly7 is replaced by either Ala or Lys in most sequences in cluster III; and Val8 is replaced by Ile in several sequences within clusters III and IV..$^{23,31}$

The $\operatorname{sodN}$ gene is regulated by nickel-uptake regulator, Nur, which is a transcriptional regulator in the Fur (ferric-uptake regulator) family. ${ }^{23,37,38}$ In Streptomyces coelicolor, Nur indirectly regulates sodN through its direct interaction with the promoter region of sodF, a gene that encodes FeSOD. ${ }^{37}$ In the presence of submicromolar Ni(II) concentration, Nur binds to the Nur-consensus sequence (Nur-box), tTGCaa-N5-ttGCAA, that overlaps with sodF promoter region (Figure 1.1). This binding represses sodF and inhibits the production of FeSOD. Since the sodN promoter region is uninhibited, the sodN gene is expressed to produce NiSOD precursor protein. This precursor protein has a 14-amino acid N-terminal prosequence that is proteolytically cleaved by a peptidase $(\operatorname{sodX}) .{ }^{39}$ Proteolysis only commences in the presence of $\mathrm{Ni}(\mathrm{II})^{38}$ to expose the N-terminal Ni-hook region (HCDLPCGVY-) and produce a mature NiSOD. ${ }^{23,39-41}$ Under nickel-limited conditions, apo-Nur loses its ability to bind to the Nur-box, allowing the expression of the sodF gene at the same time repressing the expression of $\operatorname{sodN} .^{37,40}$ The repression of sodN occurs at the level of mRNA translation. It was revealed that a conserved 19 nucleotide upstream of $\operatorname{sodN}$ is complementary to the sodF downstream sequence. Under nickel-limiting conditions, transcription of the sodF gene produces a full length sodF mRNA containing a 90 nucleotide 3'UTR (untranscribed region). From this 3'UTR, a 19 nucleotide anti-sodN mRNA is cleaved off 
and functions as a small regulatory mRNA (s-SodF). The cleaved s-SodF forms a perfect base pairing with the 5 ' end of the sodN mRNA up to 18 base pairs. This base pairing inhibits translation of sodN mRNA and facilitates its degradation (Figure 1.1). ${ }^{40}$ This tight regulation leading up to NiSOD maturation has Ni(II) involved in 3 steps: sodN expression, $\mathrm{N}$-terminal proteolytic processing, and active site constitution. ${ }^{38}$

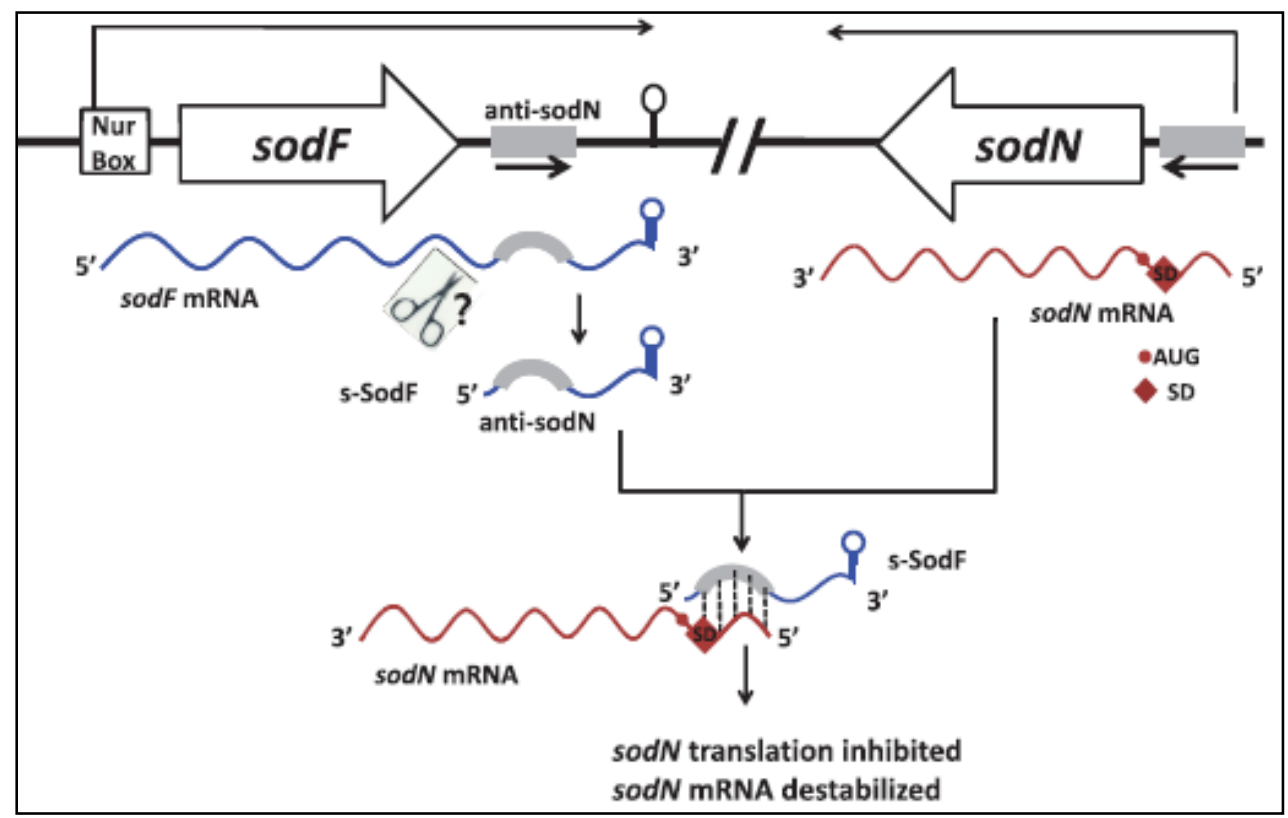

Figure 1.1. Model for Nur-dependent inverse regulation of sodN and sodF (reprinted with permission from Oxford University Press). ${ }^{40}$

While Streptomyces coelicolor contains both FeSOD and NiSOD, in some Streptomyces sp. FeSOD is lost; while NiSOD appears to be ubiquitous within the genus. ${ }^{42}$ It was found that most of the sodN-containing genomes sequenced to date do not have the sodF gene. ${ }^{31}$ It is believed that organisms first acquired MnSOD/FeSOD based on the pervasive presence of sodA (MnSOD) and sodF genes throughout the tree of life and in 'primitive' life forms. ${ }^{31,43}$ Compiled data suggest that ancestral lineages of some bacteria contain either MnSOD or FeSOD, while daughter lineages acquired NiSOD after the invention of oxygenic photosynthesis. ${ }^{31}$ This evolution and its acquisition via 
horizontal gene transfer is a response to the decreased availability of soluble iron as a result of the oxygenation of marine environment. ${ }^{23,31}$ Fe limitation is so pervasive in marine environments that all of sodN-sodF exchanges occurred in marine life forms. ${ }^{31}$

The role of nickel in biological systems is not well understood due to the limited number of Ni-containing enzymes The discovery of Ni-containing superoxide dismutases was totally unexpected and surprised the community studying SODs knowing that the redox potential of aquated nickel is biologically inaccessible and the use of thiolate ligands in the nickel active site is incompatible with superoxide dismutation products (oxygen and hydrogen peroxide). The discovery of NiSOD opened up an exciting era for Ni metallobiochemistry; and since its discovery, much had been understood about NiSOD including its molecular structure, electronic structure, and catalytic mechanism which will be discussed in the next section.

\subsection{NiSOD Molecular Structure, Electronic Structure and Catalytic Mechanism}

\subsubsection{Molecular Structure}

The quaternary structures of mature wild-type NiSOD from Streptomyces coelicor and Streptomyces seoulensis are homohexamers ${ }^{41,44}$ and virtually identical. This is expected since these two enzymes are highly homologous with $90 \%$ sequence identity. ${ }^{23,45}$ The hexamer has a molecular weight of approximately $80 \mathrm{kDa}$ and is composed of $13.2 \mathrm{kDa}$ monomers each containing one $\mathrm{Ni}$ center. The monomeric structure is a 4-helix bundle in an up-and-down topology ${ }^{41,44}$ stabilized by hydrophobic packing at the base of the structure and hydrogen bonding within the loops between

helices (Figure 1.2A). ${ }^{41}$ Interhelical interactions are further stabilized by salt bridges and 
hydrogen bonding. ${ }^{41,44}$ The 4-helix structure is unique from the other SOD structures which feature $\beta$-barrel fold (CuZnSOD) and $\alpha$ - and $\beta$-structure (Fe/MnSOD) and only dimeric or tetrameric as opposed to hexameric for NiSOD. ${ }^{23,46-48}$ The hexamer structure is a hollow sphere with an exterior diameter of about $60 \AA$ and an internal diameter of about $20 \AA$ filled with water and cocrystallized ions. ${ }^{23,41,44}$ Hexamer formation is independent of $\mathrm{N}$-terminal processing or nickel binding, although the active site structure of apo-NiSOD is more disordered than that of the holo-enzmyme. ${ }^{23,41}$

To form the hexameric structure, sets of three subunits come together to form a tripod-like structure through contacts at the N-terminal of the $\alpha 2$ helices (Figure 1.2B). ${ }^{41}$ This tripod-like trimer features a 3-fold axis that relates the three monomers to each other. $^{23,41}$ The hexamer involves locking two tripod-like trimers together so that their legs interdigitate. This is stabilized by hydrophobic interactions, ${ }^{41,44}$ (Figure 1.2C) and features three 2-fold axes perpendicular to the 3-fold axis that relate monomers from two tripod-like trimers (Figure 1.2E). ${ }^{23,41}$ This structure arranges the six nickel ions in a distorted octahedron with Ni-Ni distance of approximately $25 \AA^{23,44}$

The nickel first coordination sphere includes two thiolates from Cys2 and Cys6, the Cys2 amidate backbone $\mathrm{N}$-donor, the His1 imidazole, and the $\mathrm{N}$-terminal amine (Figure 1.2D). ${ }^{23,41,44}$ An interesting feature in the NiSOD active site is the dual conformation of the His1 imidazole ligand. It is bound to nickel in the oxidized state to form a square pyramidal active site while forming an H-bonding interaction with Glu17 which is likewise hydrogen bonded to Arg47. In the reduced state, the imidazole is not a nickel ligand but maintains the His1-Glu17-Arg47 H-bonding network (Figure 1.2D). ${ }^{23,41,44}$ The interconversion between these two conformations involves a rotation at 
the His1 $\mathrm{C}_{\beta}$ - $\mathrm{C}_{\gamma}$, which is the only degree of freedom for His1 side chain. ${ }^{41,44}$ It was revealed that the resting enzyme is a 50:50 mixture of His-on (oxidized) and His-off (reduced) conformation by crystal refinement of His1 side chain occupancy and by EPR spin quantification. ${ }^{41,49}$ This redox dependent His-on/His-off mechanism is also shared by CuZnSOD, and interestingly, the reduction of $\mathrm{Fe}$ in most superoxide reductase is also accompanied by the loss of glutamate ligand. ${ }^{23,41,50}$

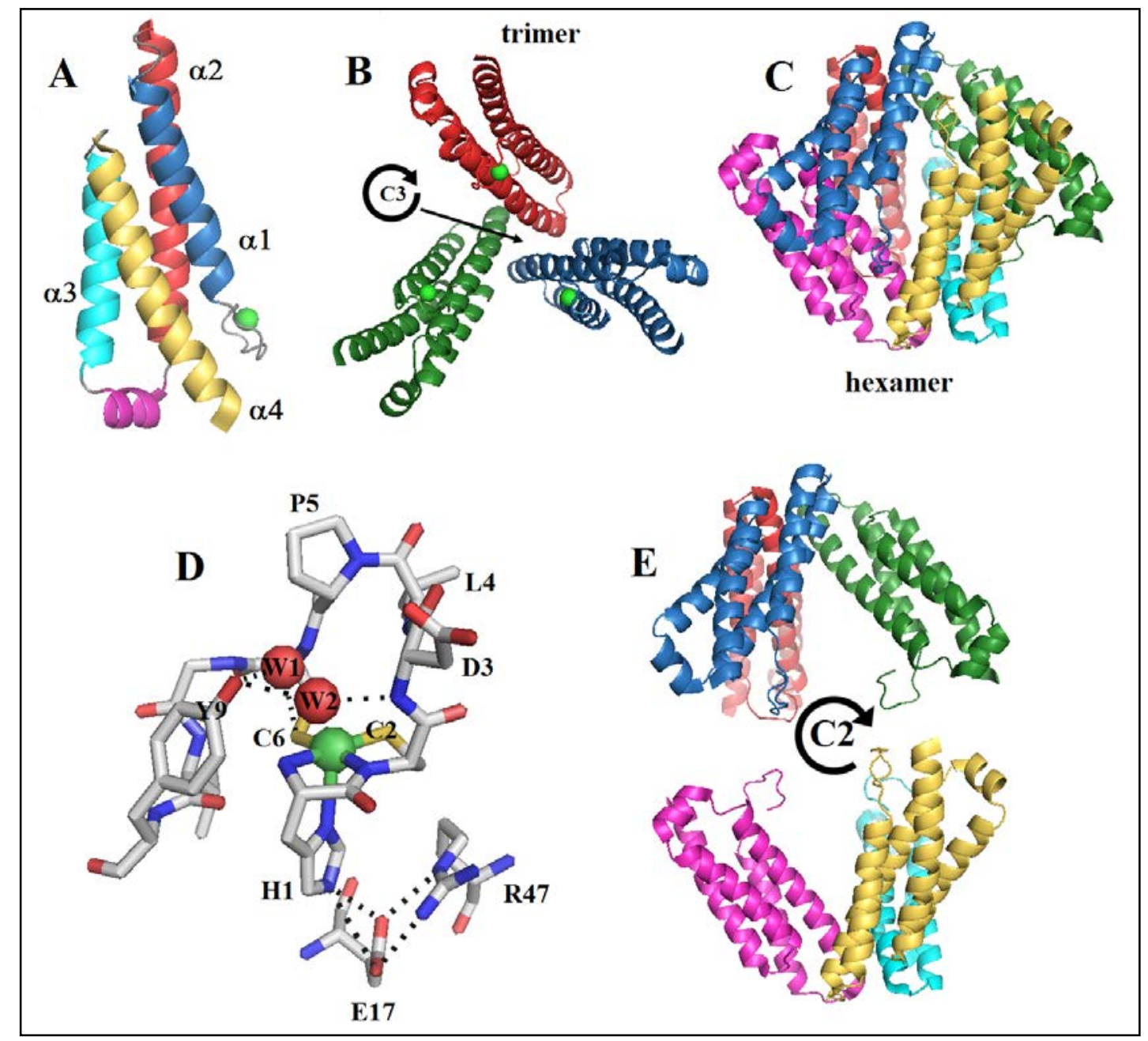

Figure 1.2. NiSOD molecular and active site structures. A. 4-helix monomer. B. Tripodlike trimer with C3 rotation. C. Hexamer. D. The active site structure. E. Hexamer C2 relationship. 
The second sphere ligands also play significant roles in the assembly of the active site structure. Pro5 for example, isomerizes from trans- to cis- conformation in order to properly position Cys6 for nickel binding. ${ }^{23,41,44}$ Together with Tyr9, Pro5 forms a bottleneck at the end of a narrow active site channel (Figure 1.3) and blocks access to the nickel open coordination site, opposite the His1 imidazole, conferring selectivity for the substrate. ${ }^{41,44}$ This also effectively buries the active site from solvent access even though it is located near the surface of the protein. The active site also has two ordered water molecules both hydrogen-bonded to Tyr9, with one of them hydrogen-bonded to the Cys6 amidate proton, while the other is hydrogen bonded to Asp3 amidate proton. ${ }^{23,44,49}$ These water molecules are assumed to be displaced by the superoxide in the proposed outer-sphere mechanism (vide infra). ${ }^{23,49}$

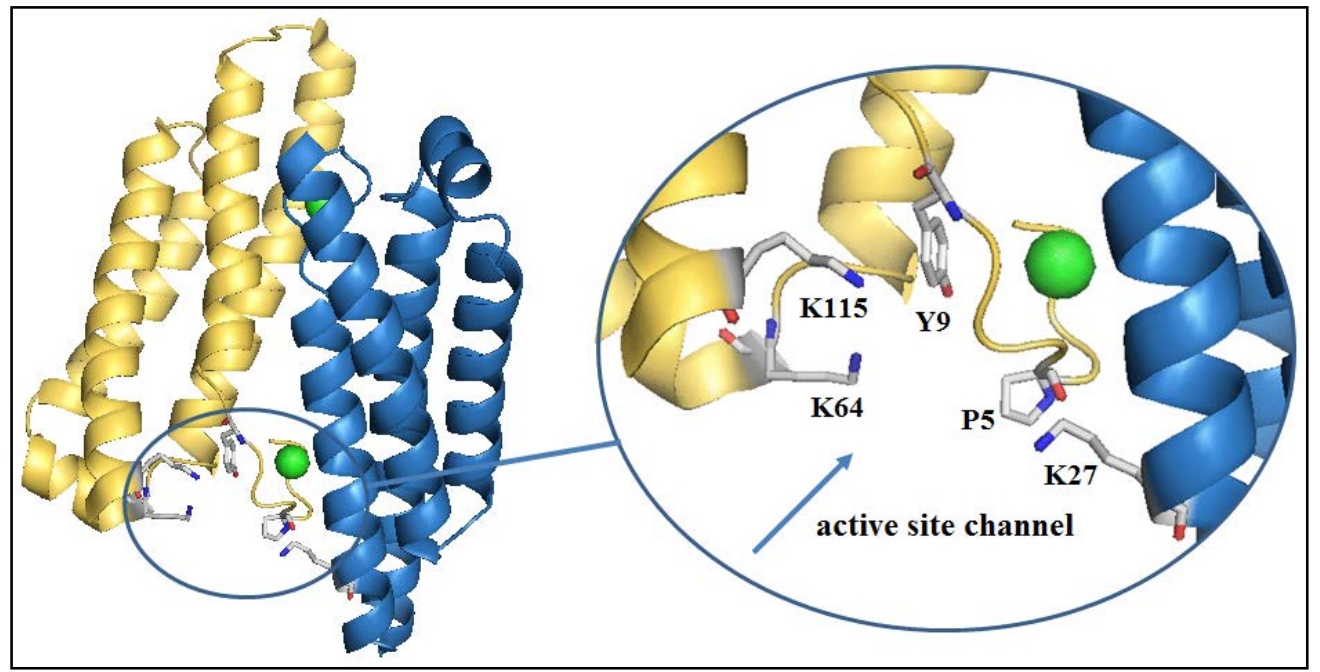

Figure 1.3. NiSOD proposed active site channel.

\subsubsection{Electronic Structure}

The first spectroscopic evidence for the presence of nickel in the active site comes from electron paramagnetic resonance spectroscopy. ${ }^{28,44}$ The rhombic spectrum with $g_{x y z}$ 
values at 2.306, 2.232, and 2.016 $\left(\mathrm{A}_{\mathrm{xyz}}=16.2,17.7,24.6 \mathrm{G}\right)$ is consistent with low-spin, $\left(\mathrm{d}_{\mathrm{z}}^{2}\right)^{1}$, ground state $\mathrm{Ni}(\mathrm{III})$ species in a five-coordinate pyramidal geometry (Figure 1.4a). ${ }^{23,51}$ Isotopic substitution of the naturally abundant metal ion in the active site with ${ }^{61} \mathrm{Ni}(\mathrm{I}=3 / 2)$ gave rise to the expected hyperfine splitting pattern of the highest field signal, giving an unequivocal assignment of the rhombic EPR signal to nickel (Figure 1.4b). ${ }^{23,44}$ The highest field signal shows a hyperfine splitting consistent with an N-donor ( $I=1$ ) ligand. Enrichment of the enzyme with ${ }^{15} \mathrm{~N}(I=1 / 2)$ gave rise to a doublet hyperfine splitting pattern (Figure 1.4c) confirming the presence of an N-donor ligand. This ligand had been assigned to His1 imidazole based on a theoretical model. ${ }^{33,52}$ Isotopic substitution of the thiolate ligands with ${ }^{33} \mathrm{~S}$ (Figure 1.4d) did not show appreciable signal perturbation, only line-broadening, indicating that the unpaired spin is largely nickel centered. ${ }^{23}$

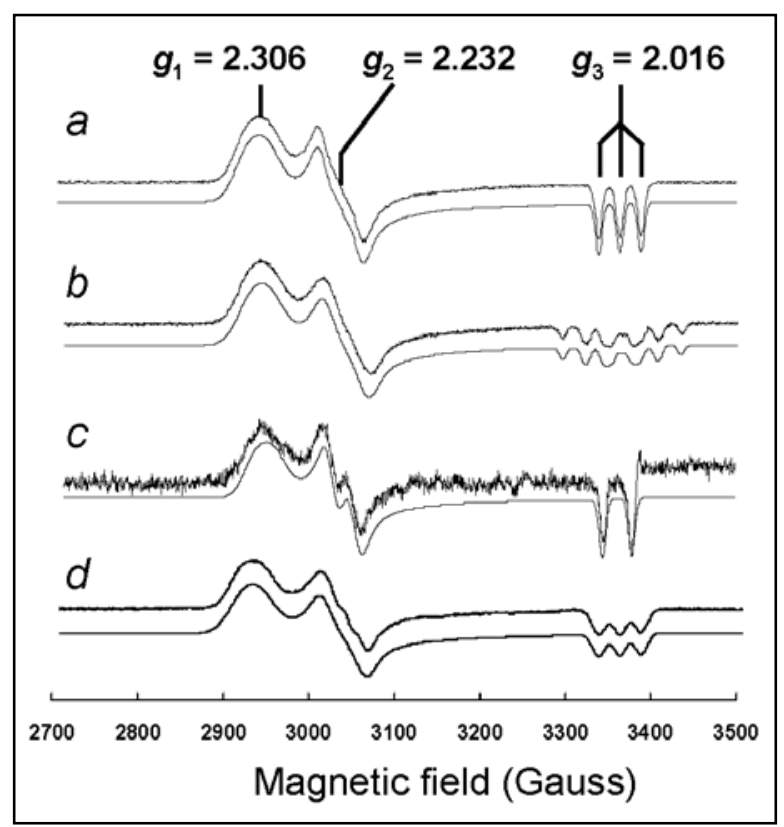

Figure 1.4. NiSOD X-band EPR spectra. A. As-isolated WT-NiSOD. B. ${ }^{61} \mathrm{Ni}$ labeled WT-NiSOD. C. ${ }^{15} \mathrm{~N}$ enriched enzyme. D. ${ }^{33} \mathrm{~S}$ thiolate labeled enzyme (copyright (2004) National Academy of Sciences, U.S.A.). ${ }^{44}$ 
DFT calculation provided a detailed description of the electronic structure of the nickel active site. The result is summarized by the orbital energy diagram in figure 1.5A. ${ }^{23,52}$ The DFT calculation revealed a strongly covalent filled/filled antibonding interaction between $\mathrm{Ni}(\pi)$ and the ligand $(\pi)$ orbitals (Figure 1.5B) that is reflected in the energies of the HOMOs consisting mainly of MOs with $\pi$ symmetry in the NiSOD reduced state. The filled/filled interaction effectively destabilizes the HOMO facilitating electron transfer from $\mathrm{Ni}(\mathrm{II})$ to substrate $\mathrm{O}_{2}{ }^{\cdot-23,52}$ Upon oxidation, the binding of the imidazole ligand strongly destabilizes the $\mathrm{Ni} \mathrm{d}_{\mathrm{z}}{ }^{2}$ orbital and effectively induces the unpaired spin to be on the $\mathrm{d}_{\mathrm{z}}^{2}$ orbital. This mechanism suggests that the redox active MO for NiSOD is different for oxidation and reduction half reactions: $\mathrm{Ni} / \mathrm{N} / \mathrm{S}(\pi)$ based for oxidation and $\mathrm{Ni} \mathrm{d}_{\mathrm{z}}^{2}$ for reduction. ${ }^{52}$

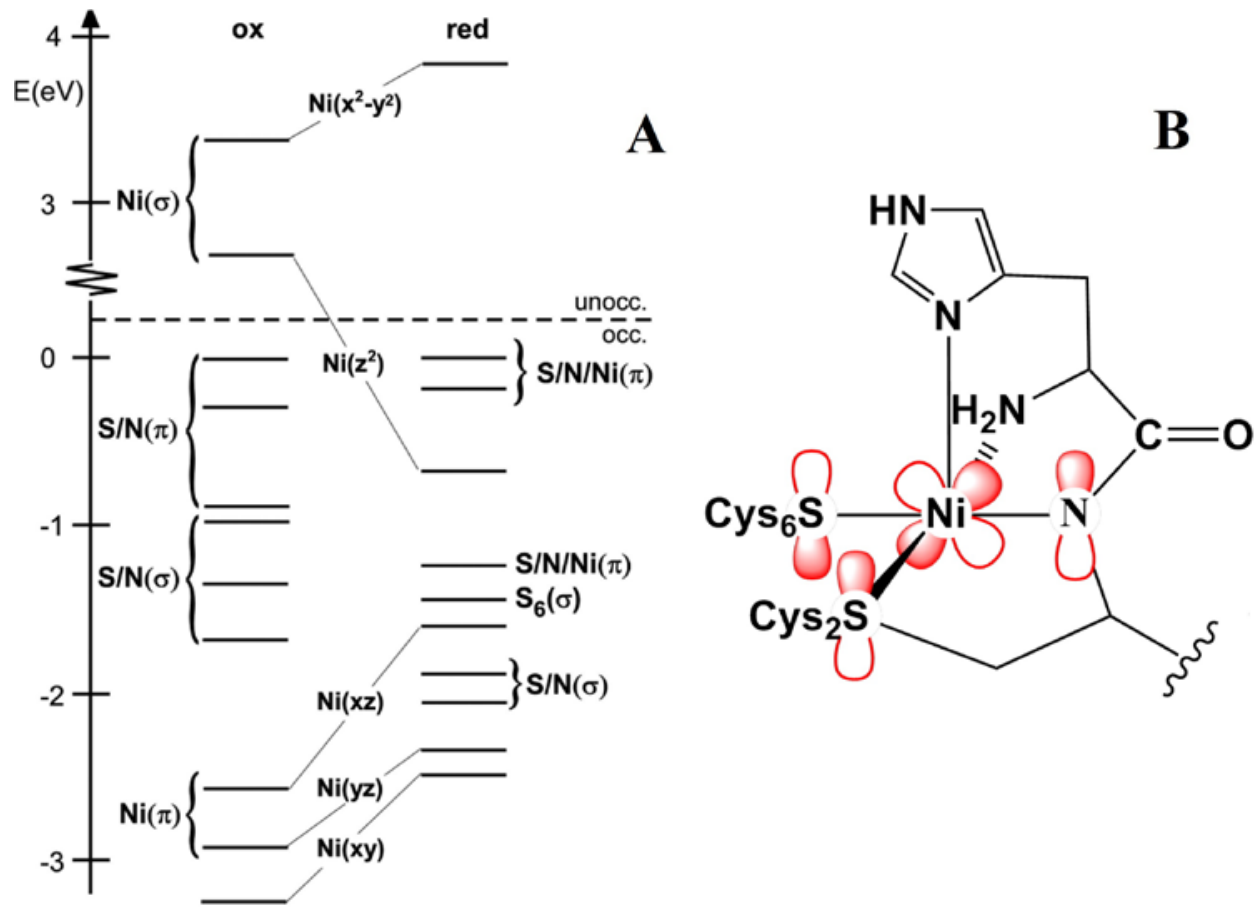

Figure 1.5. A. Molecular orbital energy level diagram for the oxidized (ox) and reduced (red) form of NiSOD. (Adapted with permission from reference 52. Copyright (2005) American Chemical Society.) B. Illustration of the Ni active site $\pi$ orbitals. 
UV-Vis spectroscopy and MCD studies of the as-isolated WT-NiSOD revealed a strong transition at around $380 \mathrm{~nm}\left(\varepsilon=6800 \mathrm{M}^{-1} \mathrm{~cm}^{-1}\right)$, which disappears in the reduced enzyme. This transition is associated with resonance Raman Ni-S vibrations at 349, 365 and $391 \mathrm{~cm}^{-1}$ and had been assigned to a $\mathrm{S}(\mathrm{Cys}) \rightarrow \mathrm{Ni}(\mathrm{III})$ ligand-to-metal charge-transfer transition (LMCT). ${ }^{23,52}$ Upon reduction of the as-isolated WT-NiSOD, the MCD spectrum showed the charge-transfer band shifted to the UV region, and only revealed weak ligand field transitions in the visible region consistent with the spectra of planar $\mathrm{Ni}(\mathrm{II})$ complexes with $\mathrm{N}_{2} \mathrm{~S}_{2}$ coordination. ${ }^{23,52}$

\subsubsection{Mechanism}

\subsubsection{Superoxide Self Disproportionation}

Superoxide is highly soluble in water and can be easily protonated to form hydroperoxide, $\mathrm{HO}_{2}$, which has a pKa $\sim 4.80 .^{53}$ Superoxide undergoes a self disproportionation reaction according to Eq. 4 (inset, Figure 1.6) with an optimal rate constant $k_{\text {cat }}=9.7 \times 10^{7} \mathrm{M}^{-1} \mathrm{~s}^{-1}$ at its $\mathrm{pKa} .^{23,53}$ In this reaction, $\mathrm{HO}_{2}$ serves as a one-electron oxidant due to the fact that it has a proton that can stabilize the additional electron; while $\mathrm{O}_{2}{ }^{\circ-}$ serves as reductant. ${ }^{23}$ At higher $\mathrm{pH}, \mathrm{O}_{2}{ }^{\circ-}$ dominates and the efficiency of superoxide disproportionation decreases. Reaction between two $\mathrm{O}_{2}{ }^{\circ-}$ anions does not occur due to the fact that $\mathrm{O}_{2}{ }^{-}$is quite stable and its negative charge facilitates repulsive interaction. ${ }^{23}$ In the absence of any $\mathrm{O}_{2}{ }^{-}$scavenging mechanism, at physiological $\mathrm{pH}$ the amount of $\mathrm{O}_{2}{ }^{-}$in

cells could go as high as micromolar in concentration. ${ }^{54,55}$ In superoxide bimolecular kinetics, a micromolar concentration has a half-life in the seconds time range. However, as the concentration goes down, the half-life increases, and superoxide at nanomolar 
concentration could persist for hours. ${ }^{23}$ This has biological ramifications that have already been mentioned.

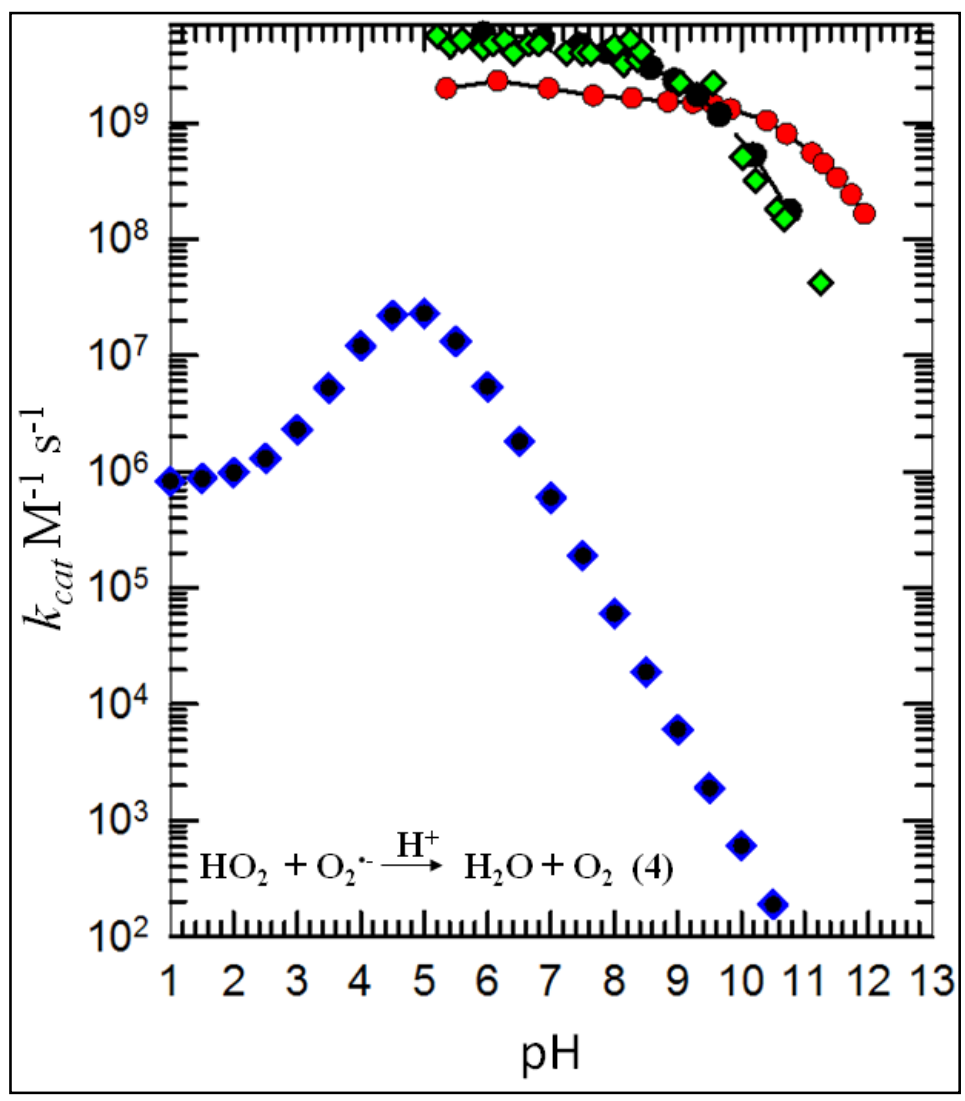

Figure 1.6. Rate contants of superoxide self disproportionation and superoxide dismutation catalyzed by MnSOD (green), CuZnSOD (red) and NiSOD (black) (credit: Dr. Diane Cabelli).

\subsubsection{NiSOD Superoxide Dismutation}

In the presence of superoxide dismutase, the rate of the superoxide disproportionation reaction is essentially $\mathrm{pH}$ independent at physiologically relevant $\mathrm{pH}$ values (Figure 1.6), with a catalytic rate that is essentially diffusion limited, $k \sim 10^{9},{ }^{23}$ and maintains the $\mathrm{O}_{2}{ }^{\cdot-}$ concentration in the picomolar range. ${ }^{23,54,55}$ SODs catalyze the superoxide disproprotionation via a pingpong mechanism that is achieved by alternating 
one-electron oxidation and reduction half-reactions. In the oxidation step, oxygen is produced concomitant with the reduction of the metal ion. In the reduction step, hydrogen peroxide, $\mathrm{H}_{2} \mathrm{O}_{2}$, is produced concomitant with the oxidation of the metal ion. In NiSOD this metal ion redox pair involves $\mathrm{Ni}(\mathrm{II}) / \mathrm{Ni}(\mathrm{III})$ tuned at $\sim 0.29 \mathrm{~V}$ potential, a potential close to the optimal redox potential. ${ }^{23,33}$ However, in NiSOD, the nickel ion can be fully reduced but could only be oxidized up to $50 \%$. This may indicate an inter-subunit communication between the nickel sites that still remains to be uncovered.

The redox reaction in NiSOD appears to involve proton-coupled electron transfer (PCET). This was observed using a NiSOD mimic made of the first $12 \mathrm{~N}$-terminal amino acids (Figure 1.9B). ${ }^{56,57}$ The mimic is catalytically active towards superoxide dismutation at a reasonably slow rate $\left(k=6 \times 10^{6} \mathrm{M}^{-1} \mathrm{~s}^{-1}\right)$, and kinetic studies in $\mathrm{D}_{2} \mathrm{O}(\mathrm{pH}$ 8) at room temperature showed a kinetic isotope effect (KIE) of 20(4) which is suggestive of a PCET event. ${ }^{57}$ To further explore this phenomenon, the mimic was treated with ascorbate and TEMPO; both of which have an abstractable proton with moderate X-H bonddissociation free energies (BDFE) of $\sim 70 \mathrm{kcal} / \mathrm{mol}$ and both were able to reduce the mimic. In contrast, no reduction was observed using reductants with slightly stronger X$\mathrm{H}$ bonds such as 1,4-dihydroquinone (first $\mathrm{BDFE}=81.5 \mathrm{kcal} / \mathrm{mol}$ ) and hydrazine (first BDFE $=83.4 \mathrm{kcal} / \mathrm{mol})$. The calculated BDFE for the mimic was estimated to be $\sim 79$ $\mathrm{kcal} / \mathrm{mol}^{57}$ and this value is more than the BDFE for $\mathrm{HO}_{2}(48.2 \mathrm{kcal} / \mathrm{mol})^{58}$ allowing a thermodynamically favorable oxidation of superoxide to oxygen. This is also less than the BDFE for $\mathrm{H}_{2} \mathrm{O}_{2}(89.5 \mathrm{kcal} / \mathrm{mol})^{58}$ allowing a thermodynamically favorable superoxide reduction. It has to be noted that since the mimic showed a kinetic isotope effect and that NiSOD had diffusion limited catalysis, the two might have distinctly 
different mechanisms and this has to be borne in mind for the rest of the chapter; nonetheless, mimics provide useful insights on NiSOD catalysis. With this in mind, the redox half reactions can now be written as:

$$
\begin{aligned}
& \text { Oxidation: } \mathrm{Ni}(\mathrm{III})^{\mathrm{SOD}}+\mathrm{O}_{2}{ }^{--}+\mathrm{H}^{+}->\mathrm{Ni}(\mathrm{II})^{\mathrm{SOD}}-\mathrm{H}+\mathrm{O}_{2}(5) \\
& \text { Reduction: } \mathrm{Ni}(\mathrm{II})^{\mathrm{SOD}}-\mathrm{H}+\mathrm{O}_{2}{ }^{--}+\mathrm{H}^{+}->\mathrm{Ni}(\mathrm{III}) \mathrm{SOD}+\mathrm{H}_{2} \mathrm{O}_{2}(6)
\end{aligned}
$$

\subsubsection{Outer-sphere vs Inner-sphere}

The most controversial aspect of the mechanism is the disagreement over whether the catalysis proceeds via an inner-sphere or outer-sphere mechanism. The open coordination in the nickel active site suggests an inner-sphere mechanism and has led theoretical calculations to assume such is the case. ${ }^{23,59,60}$ One mechanism proposed, shown in Figure 1.7, ${ }^{59}$ suggested that the oxidation half-reaction involves an end-on binding of a protonated superoxide (the proton could be from a group within the active site which is reprotonated later by the solvent) to the $\mathrm{Ni(III)}$ ion forming an antiferromagnetically coupled nickel and substrate, while a simultaneous hydrogen-bond formation occurs between the substrate and Cys2 thiolate. This then led to a transition state that involves proton transfer from the substrate to the Cys2 thiolate followed by subsequent reduction of the metal site and release of $\mathrm{O}_{2} \cdot{ }^{59}$ The reduction half-reaction again involves an end-on binding of a protonated superoxide, which is immediately followed by the oxidation of the metal site. This then led to a transition state that involves

proton transfer from Cys2 thiolate to the substrate and the subsequent release of $\mathrm{H}_{2} \mathrm{O}_{2} .{ }^{59}$ In this mechanism, it is suggested that the preferred site of protonation is Cys2 rather than the Cys6 thiolate or His1 imidazole on the basis that the Cys2 thiolate has a larger 
electron density at the solvent accessible face compared to Cys6 thiolate. ${ }^{59}$ Protonation of His1 imidazole, on the other hand, led to paths that are energetically unfavorable. The other feature in this mechanism is that the $\mathrm{Ni}-\mathrm{N}_{\text {His }}^{\delta}$ axial remains intact throughout the catalytic cycle (see section 1.4.2). ${ }^{59}$

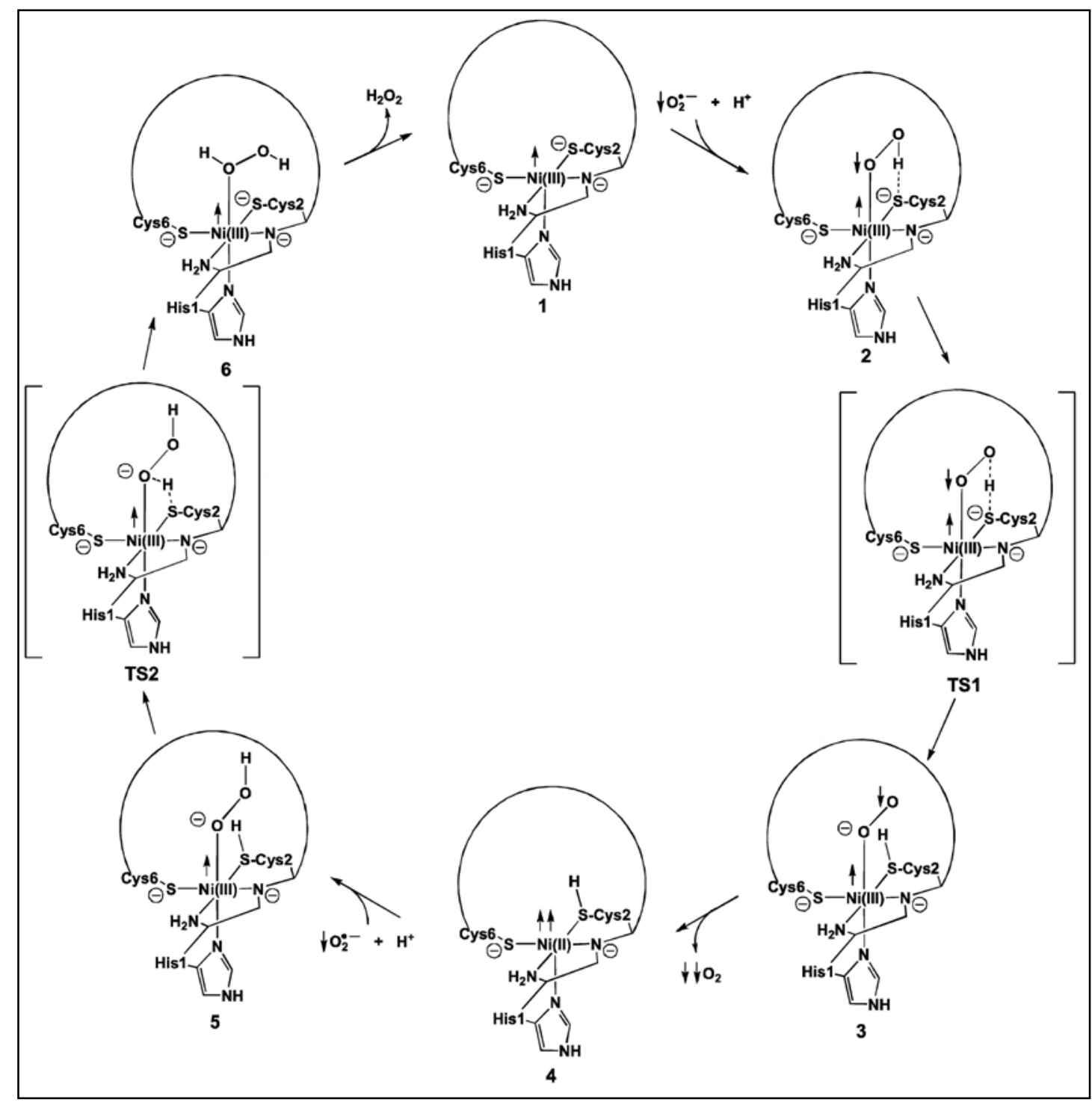

Figure 1.7. Proposed catalytic cycle for NiSOD from DFT calculations. (Adapted with permission from reference 59. Copyright (2006) American Chemical Society.)

The presence of an active site channel (Figure 1.3) that leads directly towards the open coordination site appears to support the inner-sphere mechanism. The channel 
which has three conserved lysine residues (Lys64, Lys115 and Lys27 from a neighboring subunit), is proposed to provide the substrate electrostatic guidance towards the active site in the same manner as in CuZnSOD and Mn/FeSOD. ${ }^{41,44}$ DFT calculation, however, showed that the electrostatic potential on the surface of the presumed channel does not show significant positively charged areas. This lack of strong surface potential leading to the active site is in agreement with the low ionic strength dependence for NiSOD. ${ }^{44,45}$ It appears that perhaps electrostatic steering, although important for the other SODs, is not so important in NiSOD and the open coordination site might reflect the need for low-spin electronic configuration. ${ }^{23}$

Recent experimental data appears to favor an outer-sphere mechanism. It has been well established that NiSOD, like all other SODs, can be inhibited by small molecules such as azide, cyanide and hydrogen peroxide. ${ }^{28}$ EPR data of azide-treated NiSOD shifted and introduced a hyperfine splitting to the gy tensor. The altered spectral property is the same whether the azide is ${ }^{14} \mathrm{~N}$ - or ${ }^{15} \mathrm{~N}$-labeled suggesting that the inhibitor may not be directly bound to the metal ion but rather introduced the hyperfine interaction through structural perturbation. ${ }^{41}$ Azide-treated NiSOD also showed minor perturbation on the MCD spectrum complimenting the EPR data. ${ }^{52}$ On the other hand, Tietze et al. claimed that $\mathrm{CN}^{-}$binds to the $\mathrm{Ni}$ site in a NiSOD metallopeptide mimic. ${ }^{61,62}$ It is a claim contradictory to what has been found by Shearer et al. ${ }^{63}$ using a similar metallopeptide mimic which showed that $\mathrm{CN}^{-}$strips off the $\mathrm{Ni}$ ion from the peptide, and not to mention the fact that active site mimics do not have the anion binding pocket (see below).

The case for the outer-sphere mechanism has also been fortified by crystallographic data from a Y9F-NiSOD mutant. ${ }^{49}$ The crystal structure revealed that the 
conservative Tyr9 $\rightarrow$ Phe substitution opens up the binding pocket and allows the replacement of one of the two ordered water molecules in the active site (Figure 1.2D) by a small anion $\left(\mathrm{Cl}^{-}\right.$or $\left.\mathrm{Br}^{-}\right)$from the buffer solution. The Ni-Cl has a nonbonded distance of $3.5 \AA$ and does not result in the observation of $\mathrm{Cl}^{-}$hyperfine splitting in the EPR spectrum. ${ }^{49}$ This has led to the proposal that during catalysis, superoxide replaces both the ordered water molecules and hydrogen bond with Asp3 and Cys6 amide backbones similar to the displaced water molecules. The superoxide is then reduced or oxidized according to Eqs. 5 and 6 (section 1.3.3.2) in an outer-sphere mechanism (Figure 1.8). ${ }^{49}$

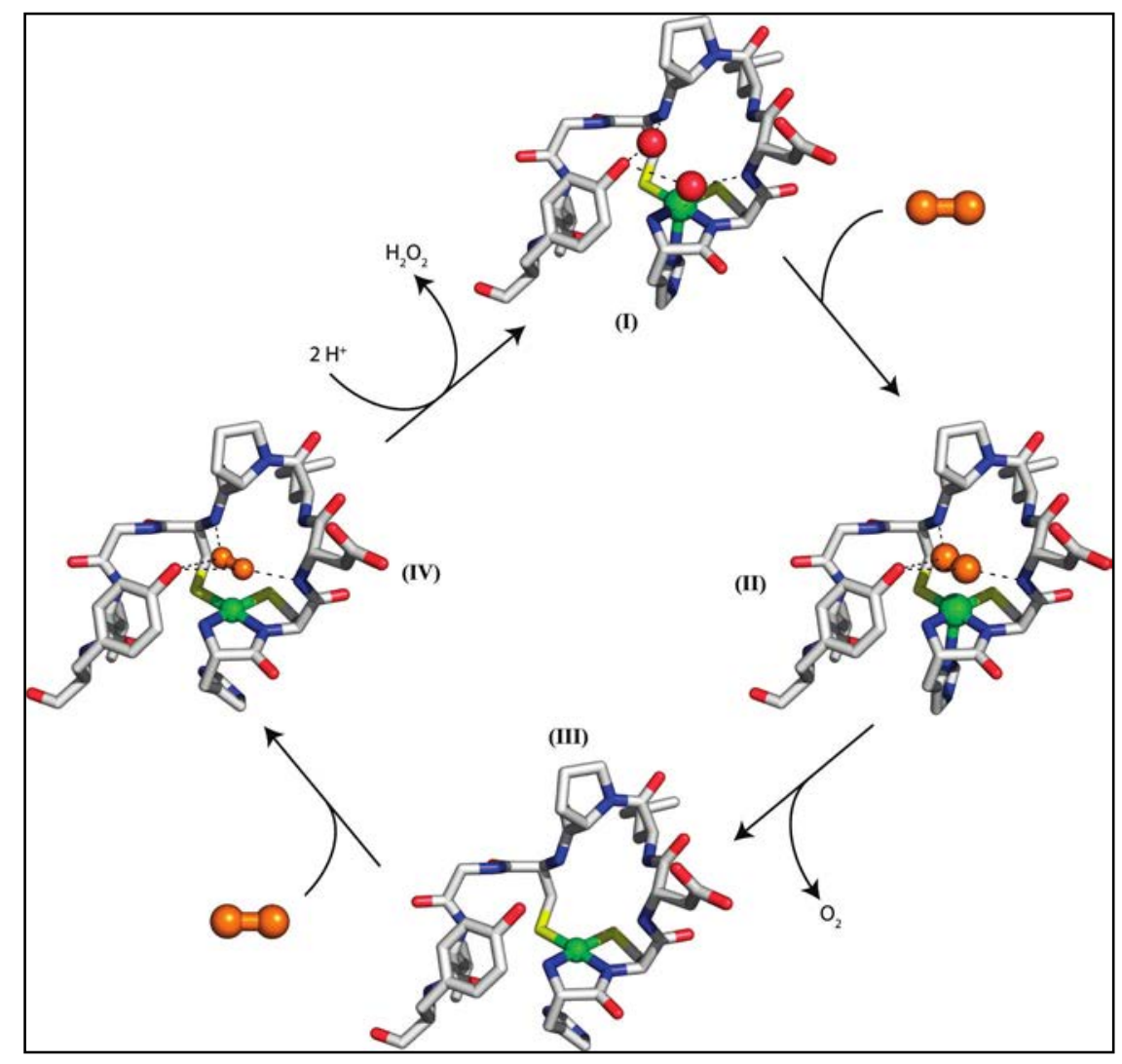

Figure 1.8. Proposed outer-sphere mechanism for NiSOD. (Reprinted with permission from reference 49. (Copyright (2009) American Chemical Society.) 


\subsection{The Role of the Nickel Ligands}

\subsubsection{The Role of the Thiolate Ligands}

Among the Ni-containing enzymes known so far, only redox active enzymes feature thiolate ligation. This includes NiFe-hydrogenase, CO dehydrogenase, acetylCoA synthase, methyl coenzyme $\mathrm{M}$ reductase and Ni superoxide dismutase. ${ }^{64}$ With the exception of methyl coenzyme $M$ reductase, it appears that thiolate ligation is a prerequisite for any redox-active nickel enzyme; perhaps it is a primary mechanism to tune the active site nickel to biologically relevant potentials. ${ }^{23,45}$ In NiSOD, Cys2 and Cys6 provide the necessary thiolate ligation, and together with the rest of the ligands, the redox potential is reduced from $+2.29 \mathrm{~V}^{32,33}$ for aqueous $\mathrm{Ni}$ (II) to just $+0.29 \mathrm{~V}^{49}$ for NiSOD. Mutation of Cys2 and Cys6 to Ser, individually or in tandem, produces mutants that can still bind nickel but are catalytically inactive and have a high spin ( $\mathrm{S}=1$ ) Ni(II) center that gave rise to EPR silent species. ${ }^{23,65}$ None of the single Cys $\rightarrow$ Ser mutants involved thiolate ligation, which suggests that mutation of any of the thiolate ligands precludes the other Cys thiolate from binding to the Ni site. All these suggest that both of these thiolates are important for tuning the redox potential of the nickel active site and are required for the low spin electronic configuration. ${ }^{23,65}$

The thiolate ligands also appeared to undergo protonation during the oxidation half reaction and were implicated as the proton source during the reduction half reaction to produce $\mathrm{H}_{2} \mathrm{O}_{2}$. The evidence comes primarily from sulfur K-edge X-ray absorption spectroscopy of as isolated enzyme as well as peptide mimics. ${ }^{56,66,67}$ The sulfur K-edge data for the as isolated enzyme revealed two pre-edge features, $2469.7 \mathrm{eV}$ and $2470.9 \mathrm{eV}$, (Figure 1.9 $)^{23,67}$; and were assigned to $\mathrm{S}_{1 \mathrm{~s}} \rightarrow \mathrm{Ni}\left(\mathrm{d}_{\mathrm{z}}{ }^{2}\right)$ and $\mathrm{S}_{1 \mathrm{~s}} \rightarrow \mathrm{Ni}\left(\mathrm{d}_{\mathrm{x}}{ }^{2}-\mathrm{y}^{2}\right)$, respectively. ${ }^{23}$ The 
lower energy transition gradually disappeared upon continuous X-ray beam exposure of the sample as the Ni site is progressively photoreduced. In comparison, the peroxidereduced NiSOD (blue line, Figure 1.9) displayed a broad structureless S K-edge with the pre-edge at $2470.9 \mathrm{eV}$ significantly decreased. This broad feature was interpreted to be

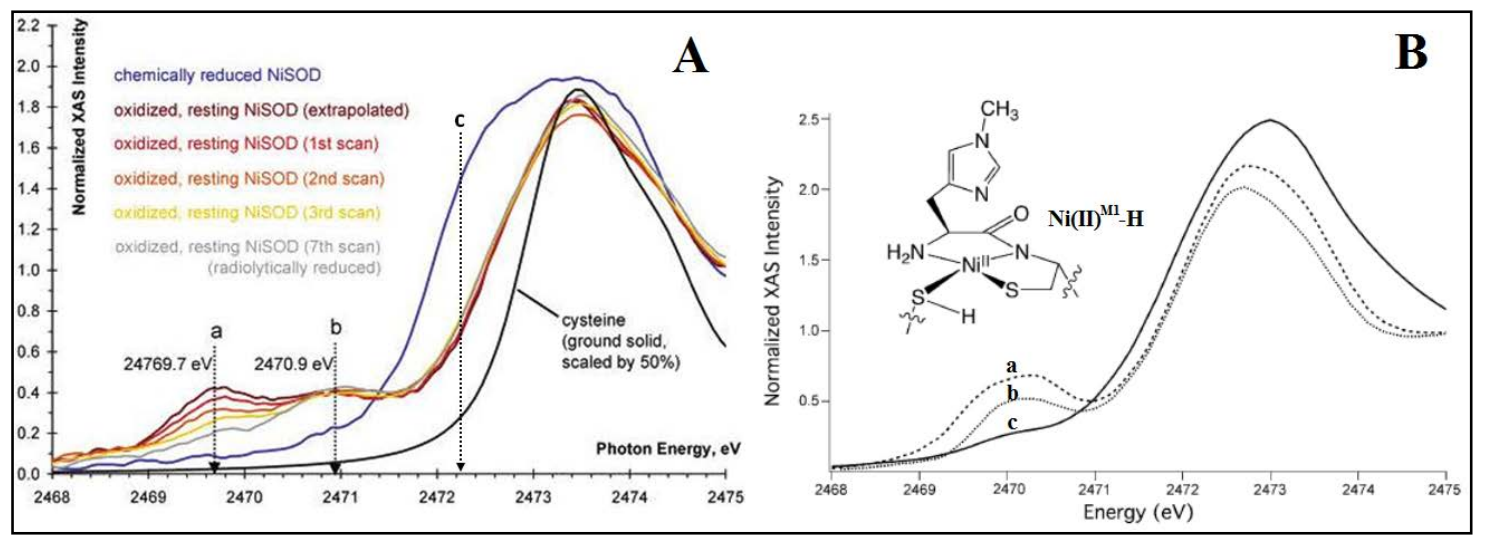

Figure 1.9. A. Sulfur K-edge spectra of radiolitically and chemically reduced WT NiSOD. (Reprinted with permission from reference 67. Copyright (2004) American Chemical Society.) B. Sulfur K-edge spectra of (a) oxidized NiSOD mimic at pH 7.4, (b) reduced mimic at $\mathrm{pH} 9.5$ and (c) reduced mimic at $\mathrm{pH}$ 7.4. Inset: structure of the reduced NiSOD mimic, Ni(II) ${ }^{\mathrm{M} 1}$-H (copyright (C) 2013 WILEY-VCH Verlag GmbH \& Co. KGaA, Weinheim). ${ }^{56}$

consistent with thiolate protonation, which is expected to shift the pre-edge transition to higher energy and overlap with the edge energy (Figure 1.9A arrow c). ${ }^{23,67}$ The above finding was complemented by using a NiSOD peptide mimic made of the first $12 \mathrm{~N}$ terminal amino acids. This is the same mimic described earlier (section 1.3.3.2) and is known to undergo chemical reduction via proton-coupled electron transfer (PCET). ${ }^{56}$ The sulfur K-edge spectrum of the reduced mimic at $\mathrm{pH} 7.4$ (Figure 1.9B (c)) displayed a weak transition at $\sim 2470 \mathrm{eV}$ in contrast to the oxidized mimic at $\mathrm{pH} 7.4$ (Figure 1.9B (a)) and to the reduced mimic at $\mathrm{pH} 9.5$ (Figure 1.9B (b)). These observations were consistent with the interpretations that (1) the strong intensity of the transition at $2470 \mathrm{eV}$ in the oxidized mimic at $\mathrm{pH} 7.4$ is consistent with the increase in the number of holes in 
the 3d manifold, (2) the decrease in intensity of the transition at $2470 \mathrm{eV}$ and the broadening of the edge transition in the reduced mimic at $\mathrm{pH} 7.4$ is consistent with thiolate protonation, and (3) the recurrence of the same transition for the reduced mimic at $\mathrm{pH} 9.5$ suggests deprotonation of the thiolate ligand at this $\mathrm{pH}^{56}$

Nickel K-edge XAS data for the same complex mimic described above further strengthened the argument that the thiolate ligands are the possible proton source. ${ }^{56}$ The average Ni-S bond length derived from the Ni K-edge XAS for the reduced mimic, $\mathrm{Ni}(\mathrm{II})^{\mathrm{M} 1}-\mathrm{H}$, at $\mathrm{pH} 7.4$ is shorter $(2.18 \AA)$ compared to the average bond length for the same reduced mimic, $\mathrm{Ni}(\mathrm{II})^{\mathrm{M} 1}$, at $\mathrm{pH} 9.5(2.20 \AA) .{ }^{56}$ This increase in bond length at elevated $\mathrm{pH}$ is consistent with a thiolate deprotonation event and this phenomenon has also been observed in planar $\mathrm{NiN}_{2} \mathrm{~S}_{2}$ complexes. ${ }^{52,56,68-70}$ The protonation of the thiolate ligand relieve the unfavorable $\mathrm{Ni}(\pi) / \mathrm{S}(\pi)$ interaction (Figure 1.5B), and leads to Ni-S bond contraction. ${ }^{52,56}$

As mentioned earlier in the text (section 1.3.3.3), the role of the thiolate ligands as possible proton sources was initially tagged to Cys2 on the basis that Cys2 thiolate has a larger electronic density at the solvent accessible face compared to Cys6 thiolate. ${ }^{59}$ However, a recent result using a NiSOD mimic with methylation (as a proton substitute) at one or both thiolate ligands showed that only the mimic with Cys6 methylation is capable of binding nickel. The Cys6 methylated mimic also showed a sulfur K-edge spectrum reminiscent that of the $\mathrm{Ni}(\mathrm{II})^{\mathrm{M} 1}-\mathrm{H}$ at $\mathrm{pH}$ 7.4. ${ }^{66}$ This suggested that Cys6 is the probable protonation site. 


\subsubsection{The Role of the Imidazole Ligand}

Histidine is a very common ligand in superoxide dismutases, where it is actively involved in redox tuning in Fe/MnSOD and as a proton donor/acceptor in CuZnSOD. ${ }^{23}$ The first evidence that revealed the importance of the His1 imidazole ligand in NiSOD came from the H1Q-NiSOD mutation. ${ }^{71}$ It was demonstrated that the mutant is predominantly in the reduced state and has a catalytic activity of two orders of magnitude lower than WT-NiSOD. In a recently published result, H1A-NiSOD showed a similar decrease in catalytic activity and displayed a unique spectral behavior (Figure 1.10),

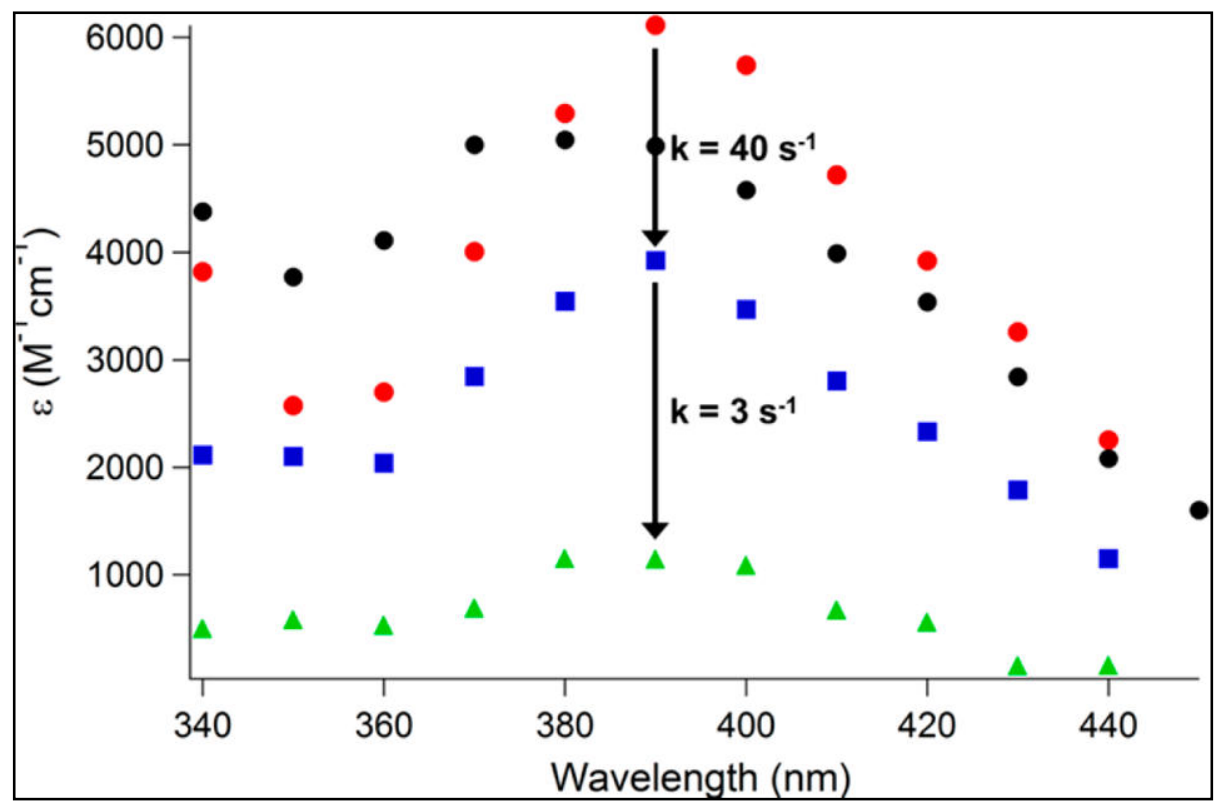

Figure 1.10. Spectral data taken during pulse radiolytic catalysis of WT-NiSOD (black) and H1A-NiSOD (red, blue and green). (Reprinted with permission from reference 72. Copyright (2015) American Chemical Society.)

suggesting a transient species during catalysis that is not observed in WT-NiSOD. ${ }^{72}$ Kinetics employing pulse radiolytic generation of $\mathrm{O}_{2}{ }^{-}$and reduced WT-NiSOD showed the rapid appearance of the absorption maximum at $\sim 380 \mathrm{~nm}$ that has been assigned to $\mathrm{S}_{\mathrm{Cys}} \rightarrow \mathrm{Ni}(\mathrm{III})$ charge transfer and its persistence during subsequent turnovers. In the H1A- 
NiSOD mutant, however, the spectral behavior shows a rapid increase in absorbance at $\sim 390 \mathrm{~nm}$ followed by a decay that is much slower than catalysis. This decay is independent of $\left[\mathrm{O}_{2}^{-}\right]$and occurs in two steps, one with a rate constant $k=40 \mathrm{~s}^{-1}$ and the other at $k=3 \mathrm{~s}^{-1} .{ }^{72}$ A possible rationale for this observation is the possibility of an internal redox process where the oxidized H1A-NiSOD decays via reduction of Ni(III) by the thiolate ligands. ${ }^{72}$

Most of our understanding about the role of His1 imidazole comes from the NiSOD metallopeptide-based mimic, $\left[\mathrm{Ni}^{\mathrm{II}}\left(\mathrm{SOD}^{\mathrm{M} 2}\right)\right]$, consisting of the NiSOD first seven N-terminal amino acids ${ }^{63}$ and its variant, [ $\left.\mathrm{Ni}^{\mathrm{II}}\left(\mathrm{SOD}^{\mathrm{M} 2} \mathrm{H}(1) \mathrm{A}\right)\right]$, where His1 is mutated to Ala (Figure 1.11). Thin-film voltammetry of $\left[\mathrm{Ni}^{\mathrm{II}}\left(\mathrm{SOD}^{\mathrm{M} 2} \mathrm{H}(1) \mathrm{A}\right)\right]$ showed an increased peak to peak separation as the scan rate is increased from $5 \mathrm{mV} / \mathrm{s}$ to $50 \mathrm{~V} / \mathrm{s}$. The voltammogram displayed quasireversible behavior and the peak separation, as a function of scan rate, has an exponential behavior. ${ }^{63}$ In contrast, thin-film voltammetry of $\left[\mathrm{Ni}^{\mathrm{II}}\left(\mathrm{SOD}^{\mathrm{M} 2}\right)\right]$ showed a far more complex behavior as a function of scan rate. At lower scan rates $(<500 \mathrm{mV} / \mathrm{s})$, the voltammogram displayed a large peak-to-peak separation of $\sim 120 \mathrm{mV}$. At intermediate scan rates, the cathodic wave disappears into the baseline and reappears at faster scan rates (>10 V/s) with smaller peak separations of $\sim 30 \mathrm{mV}$ and with significant broadening relative to the lower scan rates. ${ }^{63}$ This was interpreted in terms of the His-on/His-off mechanism. At slower scan rates, His-on/His-off appears to be the main mechanism during the redox process. At very fast scan rates, however, the imidazole likely remained ligated throughout the redox process. Whereas, at the intermediate scan rates the two mechanisms are possibly occurring simultaneously resulting to a broad oxidation wave that blurred into the background. ${ }^{63}$ 


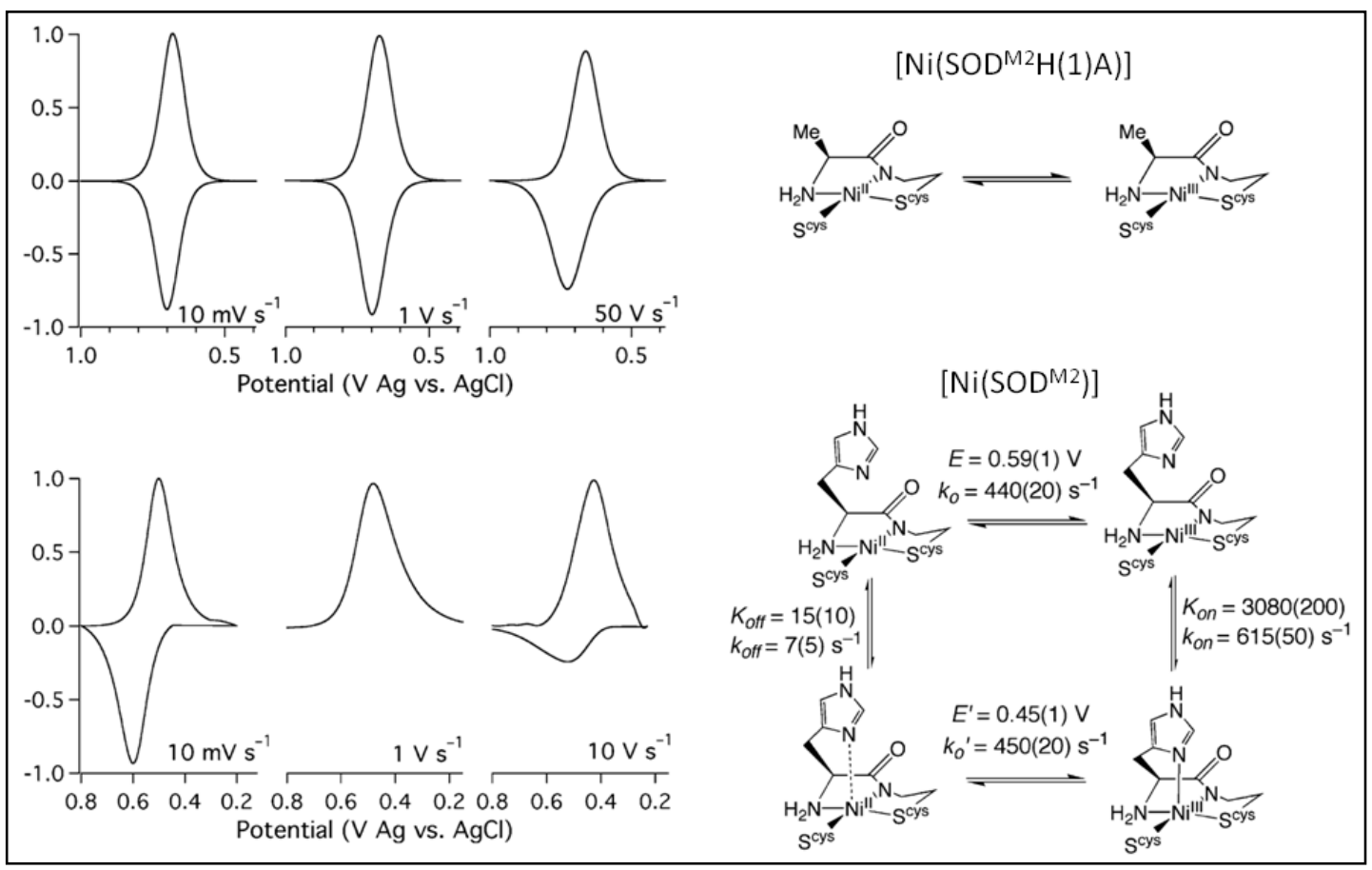

Figure 1.11. Thin film voltammograms and redox mechanisms for [NiII(SOD $\left.\left.{ }^{\mathrm{M} 2}\right)\right]$ and [NiII(SOD $\left.\left.{ }^{\mathrm{M} 2} \mathrm{H}(1) \mathrm{A}\right)\right]$. (Adapted with permission from reference 63. Copyright (2007) American Chemical Society.)

Although the modeled electrochemical data using a square kinetics scheme ${ }^{73,74}$ revealed oxidation and reduction rate constants $\left(k_{o}\right)$ that are nearly identical $\left(440 \mathrm{~s}^{-1} \mathrm{vs}\right.$ $450 \mathrm{~s}^{-1}$, Figure 1.11), the reduction half-reaction involving a five-coordinate complex occurs at a much lower potential at $0.45 \mathrm{~V}$. This potential is closer to the optimal SOD potential compared to the potential of the oxidation half-reaction of the four-coordinate planar complex, which is at $0.59 \mathrm{~V} .{ }^{63}$ Also, comparison of the His-on/His-off rate constants, $k_{\text {on }}$ vs $k_{\text {off, }}$, and the equilibrium constants, $K_{\text {on }}$ vs $K_{\text {off, revealed a strong }}$ preference of the mimic towards His-on structure. These data implied that, at the diffusion limited catalytic rate, the His1 imidazole likely remained ligated during SOD catalysis. ${ }^{63}$ This finding is in line with the DFT calculation done by Pelminschikov et al. (Figure 1.7). ${ }^{59}$ If His1 imidazole remained ligated throughout the catalysis, it appears that 
the redox active $\mathrm{MO}$ is the same for both oxidation and reduction and involves only the $\mathrm{Ni}\left(\mathrm{d}_{\mathrm{z}}{ }^{2}\right)$ orbital. This would ensure a Ni-centered redox process. ${ }^{63}$

Using $k_{\mathrm{o}}$ from the electrochemical data described above, and DFT calculated values of the reorganization energy $(\lambda)$, the rate of electron transfer $\left(k_{\mathrm{ET}}\right)$ during $\mathrm{O}_{2}{ }^{*}$ oxidation and reduction by the mimic can be calculated. From this, a plot of oxidationreduction overpotential vs $k_{\mathrm{ET}}$ for $\left[\mathrm{Ni}^{\mathrm{II} / \mathrm{III}}(\mathrm{SOD})-\mathrm{His}_{\text {off }}\right]$ as well as for [ $\left[\mathrm{Ni}^{\mathrm{II} / I I I}(\mathrm{SOD})-\mathrm{His}_{\text {on }}\right.$ ] (in both high-spin and low-spin $\mathrm{Ni}^{\mathrm{II}}$ ) were obtained (Figure 1.12). At the overpotential required for $\mathrm{O}_{2}$ generation (negative overpotential), the ET rate constants differ by no more than a factor of 4 with $k_{\mathrm{ET}}$ for $\left[\mathrm{Ni}^{\mathrm{IIIIII}}(\mathrm{SOD})-\mathrm{His}_{\text {off }}\right]$ being the fastest (green square, Figure 1.12). However, at the overpotential required for $\mathrm{H}_{2} \mathrm{O}_{2}$ generation (positive overpotential), the $k_{\mathrm{ET}}$ for both low-spin and high-spin [ $\left.\mathrm{Ni}^{\mathrm{II/III}}(\mathrm{SOD})-\mathrm{His}_{\text {on }}\right]$ are larger by at least an order of magnitude (purple and red circles vs green circle). These data suggested that imidazole coordination to the $\mathrm{Ni}$ ion is important in $\mathrm{Ni}$ active site redox tuning so that ET is optimized.

Taking all these observations together, it appears that His1 imidazole enhances SOD catalysis in a number of ways. First, by maintaining the coordination throughout the catalysis, the reorganization energy is minimized; thereby facilitating a faster ET process, which is in line with the diffusion limited SOD catalysis. Secondly, the imidazole coordination forces the redox active MO to be metal based ensuring Ni-centered oxidation. Finally, a five-coordinate Ni site has a potential shifted to a more negative value (relative to a four-coordinate Ni center) and is closer to the optimal redox potential for SOD catalysis. ${ }^{63}$ 


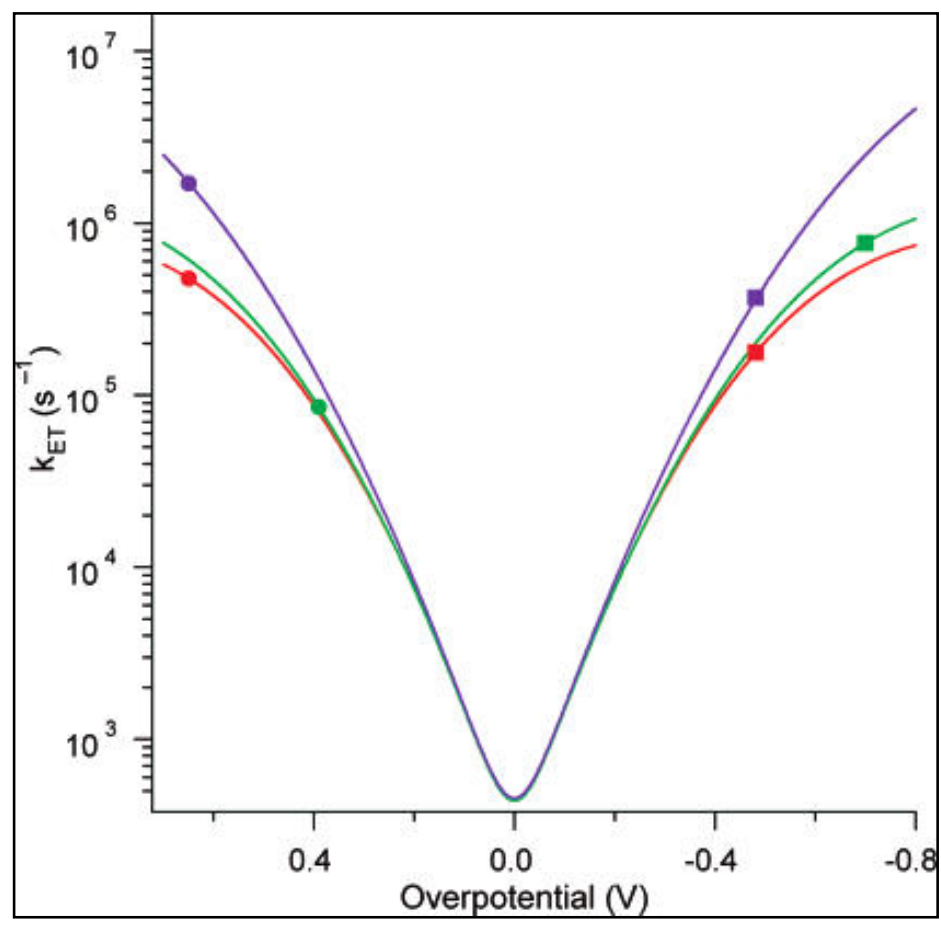

Figure 1.12. Plot of $k_{\mathrm{ET}}$ vs overpotential for [Ni ${ }^{\mathrm{I} / \mathrm{III}}(\mathrm{SOD})-\mathrm{His}_{\text {off }}$ (green), low spin $\left[\mathrm{Ni}^{\mathrm{II} / \mathrm{III}}(\mathrm{SOD})-\mathrm{His}_{\mathrm{on}}\right]$ (red) and high spin $\left[\mathrm{Ni}^{\mathrm{I} / \mathrm{III}}(\mathrm{SOD})-\mathrm{His}_{\text {on }}\right]$ (purple). (Reprinted with permission from reference 63. Copyright (2007) American Chemical Society.) $k_{\mathrm{ET}}$ values for $\mathrm{O}_{2}$ (squares) and $\mathrm{H}_{2} \mathrm{O}_{2}$ (circles) generation are: $1.6 \times 10^{5} \mathrm{~s}^{-1}$ (red square), $6.3 \times 10^{5} \mathrm{~s}^{-1}$ (green square), $2.8 \times 10^{4} \mathrm{~s}^{-1}$ (green circle), $4.6 \times 10^{5} \mathrm{~s}^{-1}$ (red circle) and $1.7 \times 10^{6}$ $\mathrm{s}^{-1}$ (purple circle). The $k_{\mathrm{ET}}$ value at the overpotential required for $\mathrm{O}_{2}$ generation for high spin $\left[\mathrm{Ni}^{\mathrm{II} / \mathrm{III}}(\mathrm{SOD})-\mathrm{His}_{\mathrm{on}}\right]$ (purple square) is not provided in the text.

\subsubsection{The Role of Mixed Amine/Amide Ligand}

A survey of redox active Ni-containing enzymes, with the exception of methyl coenzyme $\mathrm{M}$ reductase, reveals a possible role of $\mathrm{Ni}$ amidate ligands. Ni-enzymes featuring amidate ligands, such as acetyl-coenzyme synthase ${ }^{75}$ and $\mathrm{Ni}$ superoxide dismutase, ${ }^{23}$ are oxygen tolerant. Whereas, redox active Ni-enzymes that do not have any amidate ligation, such as NiFe-hydrogenase ${ }^{76}$ and carbon monoxide dehydrogenase, ${ }^{77}$ are oxygen-sensitive. The functional role of amidate ligation is experimentally challenging to investigate because of the fact that it is not accessible through point mutation. In NiSOD, 
the functional role of the amidate ligand was investigated both by performing DFT calculations and by using enzyme mimics characterized primarily by sulfur K-edge XAS and electrochemistry. ${ }^{52,78-82}$ It was revealed in these studies that in going from bisamine, mixed amine/amidate, to bisamidate, the sulfur character in the HOMO and LUMO frontier orbitals decreases and the nickel character increases. ${ }^{52,78-82}$ This suggested that the amidate ligand is crucial in tuning the redox potential so that the redox reaction is $\mathrm{Ni}$ centered rather than S-centered, thus protecting the thiolate ligands from being oxidized.

In line with the above observation, is the decreasing redox potential in going from bisamine to bisamidate, with the bisamine complexes generally having irreversible redox potentials compared to mixed amine/amidate and bisamidate complexes. A likely explanation for this is that a bisamine complex has a significant sulfur character in the HOMO making it less stable towards oxidation. ${ }^{78,79,81}$ It is also interesting to note that bisamidate complexes are significantly reactive towards oxygen giving rise to sulfur oxygenated products. ${ }^{79,80,83}$ This is due to the fact that an additional amidate anion further raises the energy of the $\mathrm{Ni} \mathrm{d}$ orbitals, relative to bisamine and mixed amine/amidate, through filled/filled interaction (Figure 1.5), which results in an "activated" HOMO that is now more susceptible to oxidation by oxygen. ${ }^{79,80,83}$ From these observations, it appears that the mixed amine/amidate ligand combination is ideal so that the redox potential in NiSOD is at the optimum and the system is still stable to reaction with oxygen.

Mullins et al. ${ }^{80}$ argued that amidate ligation might not be the only factor responsible for the robustness of the NiSOD active site against thiolate oxidation. Their argument is based on the fact that $\mathrm{NiN}_{2} \mathrm{~S}_{2}$ bisamine and bisamidate complexes readily 
react with oxygen forming thiolate oxidized products, albeit at different rates with bisamine complexes having the slower rate. ${ }^{80}$ A structurally similar mixed amine/amidate complex will likely react similarly with oxygen at a rate that is more or less halfway between that of a bisamine and a bisamidate. They also argued that an oxidation of one of the thiolate ligands in $\mathrm{Ni}(\mathrm{bmmp}-\mathrm{dmed})$ (Figure $1.13 \mathrm{~A} \& \mathrm{D}$ ), a bisamine, led to a significant "deactivation" toward oxidation of the other thiolate ligand. They found that

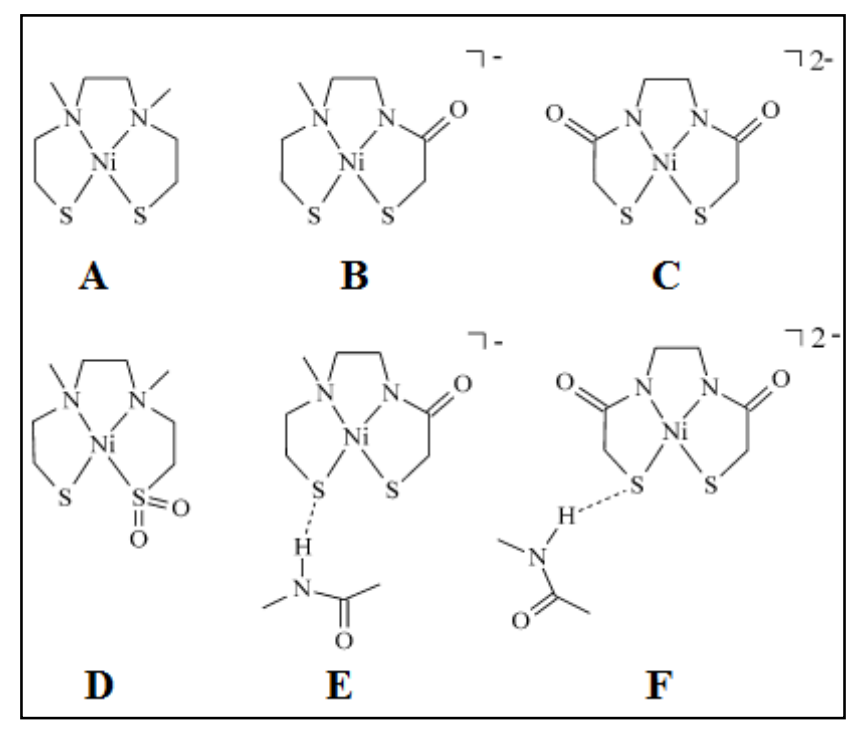

Figure 1.13. Complexes A-F used in reference 80 (with kind permission from Springer Science and Business Media ( 2006).

oxygenation of the thiolate led to a decrease in the negative potential in both thiolate ligands, which suggests that oxygenation in one of the thiolate ligands relieves both thiolates of their nucleophilicity. ${ }^{80}$ The same effect was found when complexes B and C (Figure 1.13) had H-bonding at one of their thiolate ligands ( $\mathrm{E}$ and $\mathrm{F}$ ). The molecular electrostatic potentials calculated for complexes $\mathrm{E}$ and $\mathrm{F}$ revealed that $\mathrm{H}$-bonding removes electron density from both sulfur atoms nearly equally and with the nickel center having the highest electron density in both complexes compared to their parent complexes. ${ }^{80}$ This suggested that in addition to the mixed amine/amidate ligation, $\mathrm{H}$ - 
bonding or protonation is a possible mechanism in stabilizing the nickel active site against deactivation by thiolate oxidation. Inspection of the resting nickel active site shows Cys6 H-bonded to a water molecule (Figure 1.2D), and Cys2 is protonated during catalysis (section 1.4.1).

\subsubsection{The Role of the Second Sphere Ligands}

The protein environment in NiSOD serves at least three roles: (1) to tune the redox potential of the nickel active site, (2) to provide a source of protons for the formation of $\mathrm{H}_{2} \mathrm{O}_{2}$ and (3) to control the access of small anions to the nickel site. Tyr9 in NiSOD appears to fulfill the third role much in the same way as the "gateway" tyrosine found in $\mathrm{MnSOD}^{84}$ and FeSOD. ${ }^{13,85} \mathrm{Tyr} 9$ is positioned close to the vacant site of the $\mathrm{Ni}$ ion (Figure 1.2D) with Ni-O(Tyr9) distance of approximately $5.47 \AA$ and it is H-bonded to two ordered water molecules. ${ }^{49}$ In Tyr9 $\rightarrow$ Phe-NiSOD mutant, as described previously, the loss of the phenol group led to the opening of the binding pocket (Figure 1.14) and allowed the replacement of one of the two ordered water molecules with a small anion $\left(\mathrm{Cl}^{-}\right.$and $\left.\mathrm{Br}^{-}\right)$. The $\mathrm{Cl}^{-}$is positioned such that it could interact with the phenol group in WT-NiSOD which suggest that Tyr could be involved both in controlling the access of small anions to the active site as well as the release of $\mathrm{H}_{2} \mathrm{O}_{2}{ }^{49}$

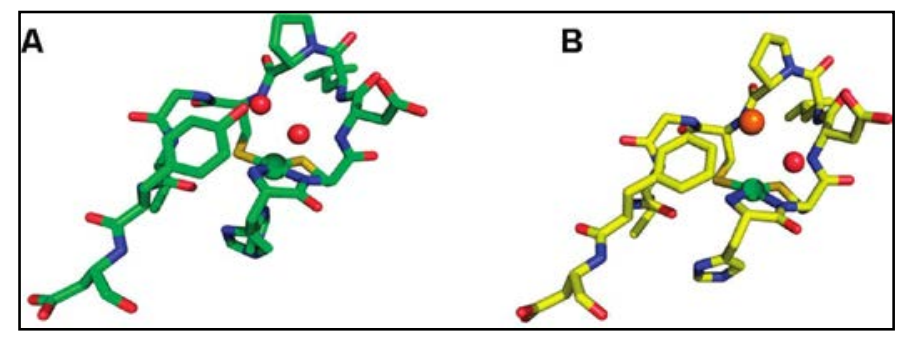

Figure 1.14. Crystal structure for WT-NiSOD (A) and Y9F-NiSOD (B). (Reprinted with permission from 49. Copyright (2009) American Chemical Society.) 
The proper positioning of Tyr9 in the active site appears to be modulated by Asp3. Mutation of Asp3 to alanine led to a perturbation in the Ni active site, most notably the Tyr9 residue moved $\sim 1 \AA$ closer to the nickel site, which results in the displacement of one of the two ordered water molecules. ${ }^{49}$ Asp3 also appears to be involved in stabilizing the WT-NiSOD structure through ionic interaction with Lys89. In the D3A mutation, the loss of the salt bridge between Asp3 and Lys89 led the disruption of the salt bridge network across the interface between monomers in the hexamer. The movement of Lys89 due to the mutation caused the neighboring Glu49 to be displaced by $\sim 2.0 \AA$ (toward Lys89) which in turn weakens the Glu49 and His53 ionic interaction. ${ }^{49}$ Thus, the loss of Asp3 residue led to the loss of two monomer interface salt bridges (Asp3/Lys89 and Glu49/His53) which translates to 12-ion pairs per hexamer. This disruption is manifested in the decrease of the melting point of the mutant from $84.8^{\circ} \mathrm{C}$ to $73.9^{\circ} \mathrm{C} .{ }^{49}$

The other two second-sphere residues that are essential for proper folding and redox tuning of the nickel active site are Glu17 and Arg47. As mentioned earlier (section 1.3.1), the two second-sphere residues form a hydrogen-bonding network with the His1 imidazole. The His1 imidazole is hydrogen bonded to Glu17, which is likewise hydrogen- bonded to Arg47 (Figure 1.2D). The role of this hydrogen-bonding network was studied by altering this network using H1A, R47A, E17A/R47A, E17R/R47E mutants. ${ }^{72}$ Metal analysis using ICP-OES showed that these mutants are still capable of binding nickel; and EXAFS analysis showed that the Ni binds in the same site in these mutants as in WT-NiSOD. The mutants displayed decreased thermal stability, which is more pronounced for the ones with altered His1/Glu17 hydrogen bonding. ${ }^{72}$ The mutants that are EPR active (R47A and E17R/R47E) displayed similar hyperfine splitting at the $\mathrm{g}_{z}$ 
peak indicating that the mutants retain the His-on structure. However, the EPR intensities in these two mutants are significantly decreased compared to WT-NiSOD with the intensities being $\sim 15 \%$ for R47A and $\sim 8 \%$ for E17R/R47E. The other two mutants (H1A and E17A/R47A) are EPR silent. This suggests that the hydrogen-bonding network is also important in redox tuning of the Ni active site. ${ }^{72}$

\subsection{Summary}

It has been over a decade since Ni-containing superoxide dismutase was first isolated. Since then, much has been uncovered about this enzyme after years of investigation which includes the phylogeny of this enzyme in archea and bacteria, its regulation in response to nickel availability, and how the protein scaffold folds and provides the essential ligands to prime its nickel active site for redox catalysis. Many aspects of the reaction mechanism still have to be elucidated with the outer-sphere vs. inner-sphere processes being the most controversial aspect. From the total amount of work dedicated to this enzyme, it is tempting to draw a picture of how the first- and second-sphere residues achieved the robustness of the $\mathrm{Ni}$ active site and how it achieved the optimum state at which it is able to sequester superoxide in the same efficiency as other SODs. Thiolate ligation deserves much of the credit for bringing the nickel redox potential down to a biologically relevant value. The mixed amine/amide ligation, along with hydrogen bonding and thiolate ligand protonation, stabilize the thiolate ligands against oxygen deactivation. The His1 imidazole, which appears to remain bound to the nickel site during catalysis, ensures that the redox active MO during turnovers is $\mathrm{Ni}$ centered. A second-sphere residue, Tyr9, controls the access of small anions to the active 
site rendering the enzyme ion selectivity. Its proper positioning, on the other hand, is modulated by another second-sphere residue, Asp3, which also appears to be essential for the inter-subunit stability. Finally, the His1-Glu17-Arg47 hydrogen-bonding network appears to be essential for fine tuning the enzyme redox potential as well as the proper folding of the active site and the overall protein stability.

\subsection{References}

1. Cadenas, E.; Davies, K. J. Mitochondrial free radical generation, oxidative stress, and aging. Free Radical Biology and Medicine 2000, 29, 222-230.

2. Bhagavan, N. V. Medical biochemistry; Academic press: 2002; .

3. Fee, J. A. Is superoxide toxic. Dev.Biochem 1980, 11, 41-48.

4. Sawyer, D. T.; Valentine, J. S. How super is superoxide? Acc. Chem. Res. 1981, 14, 393-400.

5. Fridovich, I. Oxygen toxicity: a radical explanation. J. Exp. Biol. 1998, 201, 12031209.

6. Kono, Y.; Fridovich, I. Superoxide radical inhibits catalase. J. Biol. Chem. 1982, 257, 5751-5754.

7. Blum, J.; Fridovich, I. Inactivation of glutathione peroxidase by superoxide radical. Arch. Biochem. Biophys. 1985, 240, 500-508.

8. McCord, J. M. The evolution of free radicals and oxidative stress. Am. J. Med. 2000, 108, 652-659.

9. Benov, L. How superoxide radical damages the cell. Protoplasma 2001, 217, 33-36.

10. Fridovich, I. Superoxide radical and superoxide dismutases. Annu. Rev. Biochem. 1995, 64, 97-112.

11. Miquel, J.; Economos, A.; Fleming, J.; Johnson Jr, J. Mitochondrial role in cell aging. Exp. Gerontol. 1980, 15, 575-591.

12. Genova, M. L.; Pich, M. M.; Bernacchia, A.; Bianchi, C.; Biondi, A.; Bovina, C.; Falasca, A. I.; Formiggini, G.; Castelli, G. P.; Lenaz, G. The mitochondrial production of 
reactive oxygen species in relation to aging and pathology. Ann. N. Y. Acad. Sci. 2004, 1011, 86-100.

13. Miller, A. Superoxide dismutases: ancient enzymes and new insights. FEBS Lett. 2012, 586, 585-595.

14. Fridovich, I. Superoxide radical: an endogenous toxicant. Annu. Rev. Pharmacol. Toxicol. 1983, 23, 239-257.

15. Fridovich, I. Superoxide radicals, superoxide dismutases and the aerobic lifestyle. Photochem. Photobiol. 1978, 28, 733-741.

16. Archibald, F. S.; Fridovich, I. Manganese and defenses against oxygen toxicity in Lactobacillus plantarum. J. Bacteriol. 1981, 145, 442-451.

17. Archibald, F. S.; Fridovich, I. Manganese, superoxide dismutase, and oxygen tolerance in some lactic acid bacteria. J. Bacteriol. 1981, 146, 928-936.

18. Tseng, H.; Srikhanta, Y.; McEwan, A. G.; Jennings, M. P. Accumulation of manganese in Neisseria gonorrhoeae correlates with resistance to oxidative killing by superoxide anion and is independent of superoxide dismutase activity. Mol. Microbiol. 2001, 40, 1175-1186.

19. Hayaishi, O. Molecular mechanisms of oxygen activation; Elsevier: 2012; .

20. Hewitt, J.; Morris, J. Superoxide dismutase in some obligately anaerobic bacteria. FEBS Lett. 1975, 50, 315-318.

21. Fridovich, I. Superoxide dismutases. Adv. Enzymol. Relat. Areas Mol. Biol. 1986, 58, 61-97.

22. Hassan, H. Cytotoxicity of oxyradicals and the evolution of superoxide dismutases. LUNG BIOLOGY IN HEALTH AND DISEASE 1997, 105, 27-48.

23. Sheng, Y.; Abreu, I. A.; Cabelli, D. E.; Maroney, M. J.; Miller, A.; Teixeira, M.; Valentine, J. S. Superoxide Dismutases and Superoxide Reductases. Chem. Rev. 2014, 114, 3854-3918.

24. Mann, T.; Keilin, D. Haemocuprein and hepatocuprein, copper-protein compounds of blood and liver in mammals. Proceedings of the Royal Society of London.Series B, Biological Sciences 1938, 126, 303-315.

25. McCord, J. M.; Fridovich, I. Superoxide dismutase. An enzymic function for erythrocuprein (hemocuprein). J. Biol. Chem. 1969, 244, 6049-6055. 
26. Keele, B. B.,Jr; McCord, J. M.; Fridovich, I. Superoxide dismutase from escherichia coli B. A new manganese-containing enzyme. J. Biol. Chem. 1970, 245, 6176-6181.

27. Yost, F. J.,Jr; Fridovich, I. An iron-containing superoxide dismutase from Escherichia coli. J. Biol. Chem. 1973, 248, 4905-4908.

28. Youn, H.; Kim, E.; Roe, J.; Hah, Y.; Kang, S. A novel nickel-containing superoxide dismutase from Streptomyces spp. Biochem. J. 1996, 318, 889-896.

29. Youn, H.; Youn, H.; Lee, J.; Yim, Y.; Lee, J. K.; Hah, Y. C.; Kang, S. Unique Isozymes of Superoxide Dismutase inStreptomyces griseus. Arch. Biochem. Biophys. 1996, 334, 341-348.

30. Dupont, C. L.; Barbeau, K.; Palenik, B. Ni uptake and limitation in marine Synechococcus strains. Appl. Environ. Microbiol. 2008, 74, 23-31.

31. Dupont, C.; Neupane, K.; Shearer, J.; Palenik, B. Diversity, function and evolution of genes coding for putative Ni-containing superoxide dismutases. Environ. Microbiol. 2008, 10, 1831-1843.

32. Uudsemaa, M.; Tamm, T. Density-functional theory calculations of aqueous redox potentials of fourth-period transition metals. The Journal of Physical Chemistry A 2003, 107, 9997-10003.

33. Bryngelson, P. A.; Maroney, M. J. Nickel superoxide dismutase. Nickel and its Surprising Impact in Nature.John Wiley and Sons 2007, 417-444.

34. Palenik, B.; Brahamsha, B.; Larimer, F.; Land, M.; Hauser, L.; Chain, P.; Lamerdin, J.; Regala, W.; Allen, E.; McCarren, J. The genome of a motile marine Synechococcus. Nature 2003, 424, 1037-1042.

35. Venter, J. C.; Remington, K.; Heidelberg, J. F.; Halpern, A. L.; Rusch, D.; Eisen, J. A.; Wu, D.; Paulsen, I.; Nelson, K. E.; Nelson, W.; Fouts, D. E.; Levy, S.; Knap, A. H.; Lomas, M. W.; Nealson, K.; White, O.; Peterson, J.; Hoffman, J.; Parsons, R.; BadenTillson, H.; Pfannkoch, C.; Rogers, Y. H.; Smith, H. O. Environmental genome shotgun sequencing of the Sargasso Sea. Science 2004, 304, 66-74.

36. Woyke, T.; Teeling, H.; Ivanova, N. N.; Huntemann, M.; Richter, M.; Gloeckner, F. O.; Boffelli, D.; Anderson, I. J.; Barry, K. W.; Shapiro, H. J. Symbiosis insights through metagenomic analysis of a microbial consortium. Nature 2006, 443, 950-955.

37. Ahn, B.; Cha, J.; Lee, E.; Han, A.; Thompson, C. J.; Roe, J. Nur, a nickel-responsive regulator of the Fur family, regulates superoxide dismutases and nickel transport in Streptomyces coelicolor. Mol. Microbiol. 2006, 59, 1848-1858. 
38. Kim, E.; Chung, H.; Suh, B.; Hah, Y. C.; Roe, J. Transcriptional and post-transcriptional regulation by nickel of sodN gene encoding nickel-containing superoxide dismutase from Streptomyces coelicolor Müller. Mol. Microbiol. 1998, 27, 187-195.

39. Eitinger, T. In vivo production of active nickel superoxide dismutase from Prochlorococcus marinus MIT9313 is dependent on its cognate peptidase. J. Bacteriol. 2004, 186, 7821-7825.

40. Kim, H. M.; Shin, J. H.; Cho, Y. B.; Roe, J. H. Inverse regulation of Fe- and Nicontaining SOD genes by a Fur family regulator Nur through small RNA processed from 3'UTR of the sodF mRNA. Nucleic Acids Res. 2014, 42, 2003-2014.

41. Barondeau, D. P.; Kassmann, C. J.; Bruns, C. K.; Tainer, J. A.; Getzoff, E. D. Nickel superoxide dismutase structure and mechanism. Biochemistry (N. Y. ) 2004, 43, 80388047.

42. Leclere, V.; Boiron, P.; Blondeau, R. Diversity of superoxide-dismutases among clinical and soil isolates of Streptomyces species. Curr. Microbiol. 1999, 39, 365-368.

43. Kirschvink, J. L.; Gaidos, E. J.; Bertani, L. E.; Beukes, N. J.; Gutzmer, J.; Maepa, L. N.; Steinberger, R. E. Paleoproterozoic snowball earth: extreme climatic and geochemical global change and its biological consequences. Proc. Natl. Acad. Sci. U. S. A. 2000, 97, 1400-1405.

44. Wuerges, J.; Lee, J. W.; Yim, Y. I.; Yim, H. S.; Kang, S. O.; Djinovic Carugo, K. Crystal structure of nickel-containing superoxide dismutase reveals another type of active site. Proc. Natl. Acad. Sci. U. S. A. 2004, 101, 8569-8574.

45. Choudhury, S. B.; Lee, J.; Davidson, G.; Yim, Y.; Bose, K.; Sharma, M. L.; Kang, S.; Cabelli, D. E.; Maroney, M. J. Examination of the nickel site structure and reaction mechanism in Streptomyces seoulensis superoxide dismutase. Biochemistry (N. Y. ) 1999, 38, 3744-3752.

46. Wagner, U. G.; Frolow, F.; Sussman, J. L.; Pattridge, K. A.; Ludwig, M. L.; Stallings, W. C.; Werber, M. M.; Oefner, C. Comparison of the crystal structures of genetically engineered human manganese superoxide dismutase and manganese superoxide dismutase from Thermus thermophilus: differences in dimer-dimer interaction. Protein Science 1993, 2, 814-825.

47. Ringe, D.; Petsko, G. A.; Yamakura, F.; Suzuki, K.; Ohmori, D. Structure of iron superoxide dismutase from Pseudomonas ovalis at 2.9-A resolution. Proc. Natl. Acad. Sci. U. S. A. 1983, 80, 3879-3883. 
48. Tainer, J. A.; Getzoff, E. D.; Beem, K. M.; Richardson, J. S.; Richardson, D. C. Determination and analysis of the $2 \AA$ structure of copper, zinc superoxide dismutase. $J$. Mol. Biol. 1982, 160, 181-217.

49. Herbst, R. W.; Guce, A.; Bryngelson, P. A.; Higgins, K. A.; Ryan, K. C.; Cabelli, D. E.; Garman, S. C.; Maroney, M. J. Role of Conserved Tyrosine Residues in NiSOD Catalysis: A Case of Convergent Evolution†. Biochemistry (N. Y. ) 2009, 48, 3354-3369.

50. Murphy, L. M.; Strange, R. W.; Hasnain, S. S. A critical assessment of the evidence from XAFS and crystallography for the breakage of the imidazolate bridge during catalysis in CuZn superoxide dismutase. Structure 1997, 5, 371-379.

51. Lee, H.; Lee, J.; Yang, T.; Kang, S.; Hoffman, B. M. ENDOR and ESEEM investigation of the Ni-containing superoxide dismutase. JBIC Journal of Biological Inorganic Chemistry 2010, 15, 175-182.

52. Fiedler, A. T.; Bryngelson, P. A.; Maroney, M. J.; Brunold, T. C. Spectroscopic and computational studies of $\mathrm{Ni}$ superoxide dismutase: electronic structure contributions to enzymatic function. J. Am. Chem. Soc. 2005, 127, 5449-5462.

53. Bielski, B. H.; Cabelli, D. E.; Arudi, R. L.; Ross, A. B. Reactivity of HO2/O- 2 radicals in aqueous solution. Journal of Physical and Chemical Reference Data 1985, 14, 1041-1100.

54. Brawn, K.; Fridovich, I. Superoxide radical and superoxide dismutases: threat and defense; Springer: 1980; .

55. Imlay, J. A.; Fridovich, I. Assay of metabolic superoxide production in Escherichia coli. J. Biol. Chem. 1991, 266, 6957-6965.

56. Shearer, J. Use of a Metallopeptide-Based Mimic Provides Evidence for a Proton-Coupled Electron-Transfer Mechanism for Superoxide Reduction by Nickel-Containing Superoxide Dismutase. Angewandte Chemie International Edition 2013, 52, 2569-2572.

57. Shearer, J.; Neupane, K. P.; Callan, P. E. Metallopeptide based mimics with substituted histidines approximate a key hydrogen bonding network in the metalloenzyme nickel superoxide dismutase. Inorg. Chem. 2009, 48, 10560-10571.

58. Stans, M. H. Bond dissociation energies in simple molecules. NIST Special Publication 1970, 1, 58.

59. Pelmenschikov, V.; Siegbahn, P. E. Nickel superoxide dismutase reaction mechanism studied by hybrid density functional methods. J. Am. Chem. Soc. 2006, 128, 7466-7475. 
60. Prabhakar, R.; Morokuma, K.; Musaev, D. G. A DFT study of the mechanism of Ni superoxide dismutase (NiSOD): Role of the active site cysteine-6 residue in the oxidative half-reaction. Journal of computational chemistry 2006, 27, 1438-1445.

61. Tietze, D.; Voigt, S.; Mollenhauer, D.; Tischler, M.; Imhof, D.; Gutmann, T.; González, L.; Ohlenschläger, O.; Breitzke, H.; Görlach, M. Revealing the position of the substrate in nickel superoxide dismutase: A model study. Angewandte Chemie International Edition 2011, 50, 2946-2950.

62. Tietze, D.; Breitzke, H.; Imhof, D.; Kothe, E.; Weston, J.; Buntkowsky, G. New insight into the mode of action of nickel superoxide dismutase by investigating metallopeptide substrate models. Chemistry-A European Journal 2009, 15, 517-523.

63. Neupane, K. P.; Gearty, K.; Francis, A.; Shearer, J. Probing variable axial ligation in nickel superoxide dismutase utilizing metallopeptide-based models: insight into the superoxide disproportionation mechanism. J. Am. Chem. Soc. 2007, 129, 14605-14618.

64. Maroney, M. J. Structure/function relationships in nickel metallobiochemistry. Curr. Opin. Chem. Biol. 1999, 3, 188-199.

65. Ryan, K. C.; Johnson, O. E.; Cabelli, D. E.; Brunold, T. C.; Maroney, M. J. Nickel superoxide dismutase: structural and functional roles of Cys2 and Cys6. JBIC Journal of Biological Inorganic Chemistry 2010, 15, 795-807.

66. Shearer, J.; Peck, K. L.; Schmitt, J. C.; Neupane, K. P. Cysteinate Protonation and Water Hydrogen Bonding at the Active-Site of a Nickel Superoxide Dismutase Metallopeptide-Based Mimic: Implications for the Mechanism of Superoxide Reduction. J. Am. Chem. Soc. 2014, 136, 16009-16022.

67. Szilagyi, R. K.; Bryngelson, P. A.; Maroney, M. J.; Hedman, B.; Hodgson, K. O.; Solomon, E. I. S K-edge X-ray absorption spectroscopic investigation of the $\mathrm{Ni}$ containing superoxide dismutase active site: New structural insight into the mechanism. J. Am. Chem. Soc. 2004, 126, 3018-3019.

68. Grapperhaus, C. A.; Darensbourg, M. Y. Oxygen capture by sulfur in nickel thiolates. Acc. Chem. Res. 1998, 31, 451-459.

69. Gale, E. M.; Narendrapurapu, B. S.; Simmonett, A. C.; Schaefer III, H. F.; Harrop, T. C. Exploring the effects of $\mathrm{H}$-bonding in synthetic analogues of nickel superoxide dismutase (Ni-SOD): experimental and theoretical implications for protection of the $\mathrm{Ni}-$ SCys bond. Inorg. Chem. 2010, 49, 7080-7096.

70. Allan, C. B.; Davidson, G.; Choudhury, S. B.; Gu, Z.; Bose, K.; Day, R. O.; Maroney, M. J. Protonation and alkylation of a dinuclear nickel thiolate complex. Inorg. Chem. 1998, 37, 4166-4167. 
71. Bryngelson, P. A.; Arobo, S. E.; Pinkham, J. L.; Cabelli, D. E.; Maroney, M. J. Expression, Reconstitution, and Mutation of Recombinant Streptomyces c oelicolor NiSOD. J. Am. Chem. Soc. 2004, 126, 460-461.

72. Ryan, K. C.; Guce, A. I.; Johnson, O. E.; Brunold, T. C.; Cabelli, D. E.; Garman, S. C.; Maroney, M. J. Nickel Superoxide Dismutase: Structural and Functional Roles of His1 and its H-bonding Network. Biochemistry (N. Y. ) 2015, 54, 1016-1027.

73. Boll, M.; Fuchs, G.; Tilley, G.; Armstrong, F. A.; Lowe, D. J. Unusual spectroscopic and electrochemical properties of the 2 [4Fe-4S] ferredoxin of Thauera aromatica. Biochemistry (N. Y. ) 2000, 39, 4929-4938.

74. Jeuken, L. J.; van Vliet, P.; Verbeet, M. P.; Camba, R.; McEvoy, J. P.; Armstrong, F. A.; Canters, G. W. Role of the surface-exposed and copper-coordinating histidine in blue copper proteins: The electron-transfer and redox-coupled ligand binding properties of His117Gly azurin. J. Am. Chem. Soc. 2000, 122, 12186-12194.

75. Starai, V.; Escalante-Semerena, J. Acetyl-coenzyme A synthetase (AMP forming). Cellular and Molecular Life Sciences CMLS 2004, 61, 2020-2030.

76. Goris, T.; Wait, A. F.; Saggu, M.; Fritsch, J.; Heidary, N.; Stein, M.; Zebger, I.; Lendzian, F.; Armstrong, F. A.; Friedrich, B. A unique iron-sulfur cluster is crucial for oxygen tolerance of a [NiFe]-hydrogenase. Nature chemical biology 2011, 7, 310-318.

77. Diekert, G. B.; Graf, E. G.; Thauer, R. K. Nickel requirement for carbon monoxide dehydrogenase formation in Clostridium pasteurianum. Arch. Microbiol. 1979, 122, 117120.

78. Shearer, J.; Zhao, N. [Me4N](NiII (BEAAM)): A Synthetic Model for Nickel Superoxide Dismutase That Contains $\mathrm{Ni}$ in a Mixed Amine/Amide Coordination Environment. Inorg. Chem. 2006, 45, 9637-9639.

79. Mathrubootham, V.; Thomas, J.; Staples, R.; McCraken, J.; Shearer, J.; Hegg, E. L. Bisamidate and Mixed Amine/Amidate $\mathrm{NiN}_{2} \mathrm{~S}_{2}$ Complexes as Models for NickelContaining Acetyl Coenzyme A Synthase and Superoxide Dismutase: An Experimental and Computational Study. Inorg. Chem. 2010, 49, 5393-5406.

80. Mullins, C.; Grapperhaus, C.; Kozlowski, P. Density functional theory investigations of $\mathrm{NiN}_{2} \mathrm{~S}_{2}$ reactivity as a function of nitrogen donor type and $\mathrm{N}-\mathrm{H} \cdots \mathrm{S}$ hydrogen bonding inspired by nickel-containing superoxide dismutase. JBIC Journal of Biological Inorganic Chemistry 2006, 11, 617-625.

81. Shearer, J.; Dehestani, A.; Abanda, F. Probing variable amine/amide ligation in $\mathrm{NiIIN}_{2} \mathrm{~S}_{2}$ complexes using sulfur K-edge and nickel L-edge $\mathrm{X}$-ray absorption spectroscopies: implications for the active site of nickel superoxide dismutase. Inorg. Chem. 2008, 47, 2649-2660. 
82. Neupane, K. P.; Shearer, J. The influence of amine/amide versus bisamide coordination in nickel superoxide dismutase. Inorg. Chem. 2006, 45, 10552-10566.

83. Shearer, J. Dioxygen and superoxide stability of metallopeptide based mimics of nickel containing superoxide dismutase: The influence of amine/amidate vs. bis-amidate ligation. J. Inorg. Biochem. 2013, 129, 145-149.

84. Guan, Y.; Hickey, M. J.; Borgstahl, G. E.; Hallewell, R. A.; Lepock, J. R.; O'Connor, D.; Hsieh, Y.; Nick, H. S.; Silverman, D. N.; Tainer, J. A. Crystal structure of Y34F mutant human mitochondrial manganese superoxide dismutase and the functional role of tyrosine 34. Biochemistry (N. Y. ) 1998, 37, 4722-4730.

85. Hunter, T.; Ikebukuro, K.; Bannister, W. H.; Bannister, J. V.; Hunter, G. J. The conserved residue tyrosine 34 is essential for maximal activity of iron-superoxide dismutase from Escherichia coli. Biochemistry (N. Y. ) 1997, 36, 4925-4933. 


\section{CHAPTER 2}

\section{SEMISYNTHETIC APPROACH FOR CONSTRUCTING H1*-NISOD}

\subsection{Introduction}

Prior computational investigations of the NiSOD active site ${ }^{1}$ as well as experimental and DFT calculations on model complexes, ${ }^{2-6}$ predicted that the amidate ligand in NiSOD plays a role in the electronic structure of the Ni(III) site by keeping the oxidation product $\mathrm{Ni}$-centered rather than S-centered, in contrast to the oxidation products of planar $\mathrm{Ni}(\mathrm{II})$ complexes with amine and thiolate ligation. ${ }^{7-10}$ To study the functional role of the amidate ligand, however, is challenging due to the fact that it is not accessible through site directed mutagenesis. To test the predictions mentioned above, herein we describe a semisynthetic strategy employing native chemical ligation (NCL) of a pentapeptide (HCDLP) to recombinant Streptomyces coelicolor NiSOD that lacks these five $\mathrm{N}$-terminal residues and features an $\mathrm{N}$-terminal Cys residue ( $\mathrm{N} \Delta 5-\mathrm{NiSOD}$ ) to produce a variant (H1*-NiSOD, Figure 2.1) wherein the backbone Cys2 amidate N-donor ligand is altered to a secondary amine.

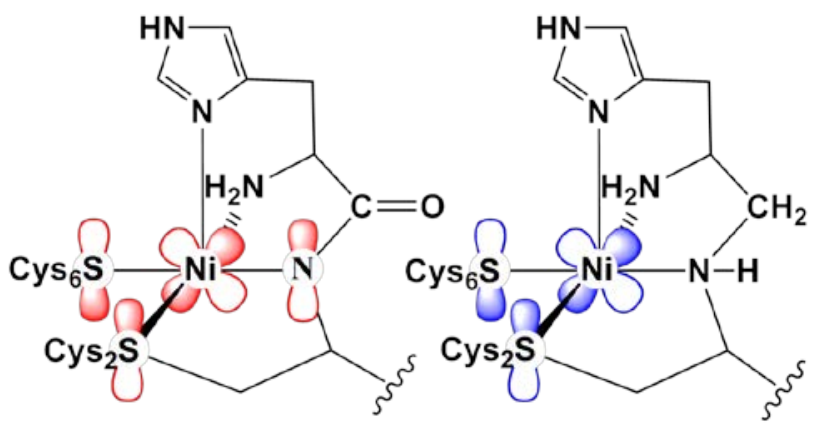

Figure 2.1. The Ni site structures of WT-NiSOD (left) and H1*-NiSOD (right). (Reprinted with permission from reference 11. Copyright (2015) American Chemical Society.) 


\subsection{Materials and Methods}

\subsubsection{Mutagenesis}

The deletion mutant, $\mathrm{N} \Delta 5$-NiSOD, was expressed using the pelB expression system. ${ }^{12}$ The pelB WT-NiSOD construct was designed by isolating the WT-NiSOD gene previously inserted in $\mathrm{pET}-30 \mathrm{Xa} / \mathrm{LIC}$ vector $^{13}$ and re-inserting the gene into the pET22b(+) upstream of the pelB sequence (Novagen protocol). This construct was then used as a template to construct a plasmid containing the $\mathrm{N} \Delta 5-\mathrm{NiSOD}$ deletion mutant using the polymerase chain reaction (PCR). To delete the first five amino acids of the WT-NiSOD sequence (Figure 2.2) the following primers were used: 5'TGCGGCGTGTACGACCCTGC-3' (forward primer) and 5'GGCCATCGCCGGCTGGGC-3' (reverse primer) with melting temperatures of 74 and $77^{\circ} \mathrm{C}$, respectively. The PCR was performed using Q5 high fidelity DNA polymerase (New England Biolabs Inc., Ipswich, MA) and only 1 pg of the template DNA. The denaturation temperature was $98{ }^{\circ} \mathrm{C}$, and the annealing and extension temperature was 72 ${ }^{\circ} \mathrm{C}$ (NEB protocol). The PCR product was ligated without further purification by first adjusting the buffer using $5 \mu \mathrm{L}$ of the $10 \mathrm{X}$ T4PNK reaction buffer (NEB) for every $45 \mu \mathrm{L}$ of the PCR product. The sample was then treated with T4 DNA kinase followed by T4 DNA ligase (NEB protocol). To isolate the N $\triangle 5$-NiSOD plasmid, the ligated PCR product was transformed in NovaBlue cells and selection was performed using an LB agar plate containing $100 \mu \mathrm{g} / \mathrm{mL}$ ampicillin. Single colonies were picked and each colony was grown in $5 \mathrm{~mL} \mathrm{LB}$ media with ampicillin for $16 \mathrm{~h}$ at $37^{\circ} \mathrm{C}$. The cultures were harvested, and plasmid preparation was performed using a Qiagen (Valencia, CA) kit. 
The sample plasmids were then submitted to Genewiz (South Plainfield, NJ) for sequencing. The plasmids with the correct sequence were stored at $-20^{\circ} \mathrm{C}$ for future use. \begin{tabular}{|l|} 
MKYLLPTAAAGLLLLAA PAMAHCD LPCGVYDPA \\
QARIEAESVKAVQEKMAGNDDPHFQTRATVIKEQR \\
AELAKHHVSVLWSDYFKPPHFEKYPELHQLVNDTL \\
KALSAAKGSKDPATGQKALDYIAQIDKIFWETKKA
\end{tabular}

Figure 2.2. The pelB WT-NiSOD amino acid sequence. Highlighted in blue is the pelB sequence. Highlighted in red is the first five amino acids that are deleted to form the $\mathrm{N} \Delta 5$-NiSOD. (Reprinted with permission from reference 11. Copyright (2015) American Chemical Society.)

\subsubsection{N $\Delta 5$-NiSOD Protein Expression and Purification}

The pelB N $\Delta 5$-NiSOD plasmid was transformed into BL21 (DE3) and selected for ampicillin resistance on an LB agar plate supplemented with ampicillin. Single colonies were selected and grown in $5 \mathrm{~mL}$ LB media for $16 \mathrm{~h}$ at $37^{\circ} \mathrm{C} @ 200 \mathrm{rpm}$ and used to prepare frozen stocks by storing $1 \mathrm{~mL}$ aliquots in $50 \%$ glycerol at $-80{ }^{\circ} \mathrm{C}$. From a frozen stock, cultures were prepared in $150 \mathrm{~mL}$ LB medium supplemented with ampicillin and grown for $16 \mathrm{~h}$ at $37^{\circ} \mathrm{C} @ 200 \mathrm{rpm}$. Aliquots $(20 \mathrm{~mL})$ from the culture were used to inoculate flasks containing $2 \mathrm{~L}$ of LB medium supplemented with ampicillin (total of six) and grown at $25{ }^{\circ} \mathrm{C}$ until $0.5 \mathrm{OD}$ is reached. At this point, $200 \mu \mathrm{L}$ of $1 \mathrm{M}$ IPTG was added to each $2 \mathrm{~L}$ culture, and they were incubated for another $12 \mathrm{~h}$ at $25{ }^{\circ} \mathrm{C}$. The culture was then harvested by centrifugation. To extract N $\Delta 5-\mathrm{NiSOD}$, the cells were disrupted by osmotic shock. This was done by resuspending the cells in $30 \mathrm{mM}$ Tris buffer at $\mathrm{pH}=8.00$ containing $20 \%$ sucrose (50 mL total volume of per $2 \mathrm{~L}$ cell culture). After $10 \mathrm{~min}$, the cells were centrifuged, the supernatant was discarded, and the cells were resuspended in water (50 mL total volume per $2 \mathrm{~L}$ culture) at $4{ }^{\circ} \mathrm{C}$ for another 10 
min. The cells were again centrifuged, the pellet was discarded, and $200 \mu \mathrm{L}$ of $200 \mathrm{mM}$ PMSF was added per $50 \mathrm{~mL}$ of the supernatant. After $30 \mathrm{~min}$, cysteine was added to the supernatant to a final concentration of $100 \mathrm{mM}$, and the solution was stored at $4{ }^{\circ} \mathrm{C}$ overnight to allow the cysteine to form a disulfide bond with the cysteine $\mathrm{N}$-terminus of the $\mathrm{N} \Delta 5$-NiSOD, thereby protecting the $\mathrm{N}$-terminal cysteine from oxidation. The $\mathrm{N} \Delta 5$ NiSOD was purified using Q-sepharose resin packed in XK 16 column with resin height of $41 \mathrm{~cm}$. The buffer used was $50 \mathrm{mM}$ Tris at $\mathrm{pH} 8.50$ and the $\mathrm{NaCl}$ concentration was linearly increased from 0 to $200 \mathrm{mM}$ over 1500 at $3 \mathrm{~mL} / \mathrm{min}$. PAGE was performed to determine the fractions that contain pure N $\Delta 5-\mathrm{NiSOD}$. The purified protein was characterized by mass spectroscopy (Figure 2.3), which showed the presence of $\mathrm{N} \Delta 5$ NiSOD (12634 Da) and impurities that correspond to $\mathrm{N}$-terminally modified forms of $\mathrm{N} \Delta 5$-NiSOD,

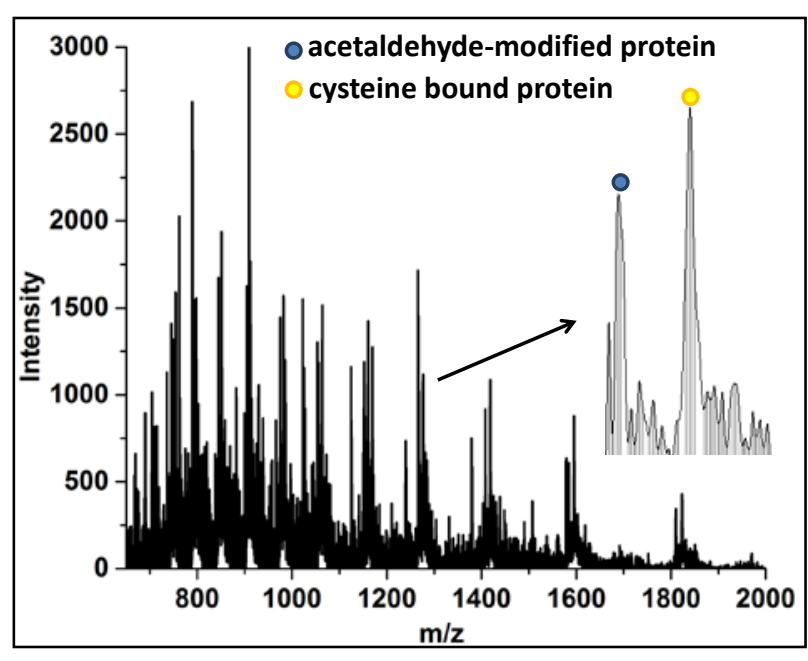

Figure 2.3. ESI-MS for $\mathrm{N} \Delta 5-\mathrm{NiSOD}$ after the Q-sepharose purification. (Reprinted with permission from reference 11. Copyright (2015) American Chemical Society.)

principally the thiazolidine modification resulting from reaction with acetaldehyde (12661 Da).

\subsubsection{N $\Delta 5-N i S O D$ Chemical Rescue}

Almost half of the $\mathrm{N} \Delta 5-\mathrm{NiSOD}$ isolated as described above has the cysteine $\mathrm{N}$ terminus reacted with endogenous acetaldehyde forming a thiazolidine ring structure. ${ }^{14}$ 
To rescue the modified N-terminal cysteine, the protein was incubated at $37^{\circ} \mathrm{C}$ at a final concentration of $1 \mathrm{mM}$ in a solution containing $100 \mathrm{mM}$ semicarbazide in $6 \mathrm{M}$ guanidine $\mathrm{HCl}$ with $30 \mathrm{mM}$ TCEP unbuffered at $\mathrm{pH} 4.00$ for $1-2 \mathrm{~h}^{15}$ This procedure reverses the thiazolidine cyclization. The sample was then added to an equivalent volume of $1 \mathrm{M}$ cysteine in $50 \mathrm{mM}$ Tris buffer with $6 \mathrm{M}$ guanidine hydrochloride at $\mathrm{pH} 7.50$ and left for 4 h to overnight to allow the cysteine to replace the bound aldehyde via nucleophilic substitution. This procedure was done twice to remove most of the aldehyde. Prior to the native chemical ligation, the cysteine bound at the N-terminus was removed by buffer exchanging the sample with 50 $\mathrm{mM}$ Tris $\mathrm{pH} 7.50$ containing $30 \mathrm{mM}$ TCEP at room temperature. The sample buffer was then exchanged with the ligation buffer (section 2.2.6) and stored at $-20^{\circ} \mathrm{C}$ for future use. The molecular weight of the product was determined by ESI-mass spectrometry:

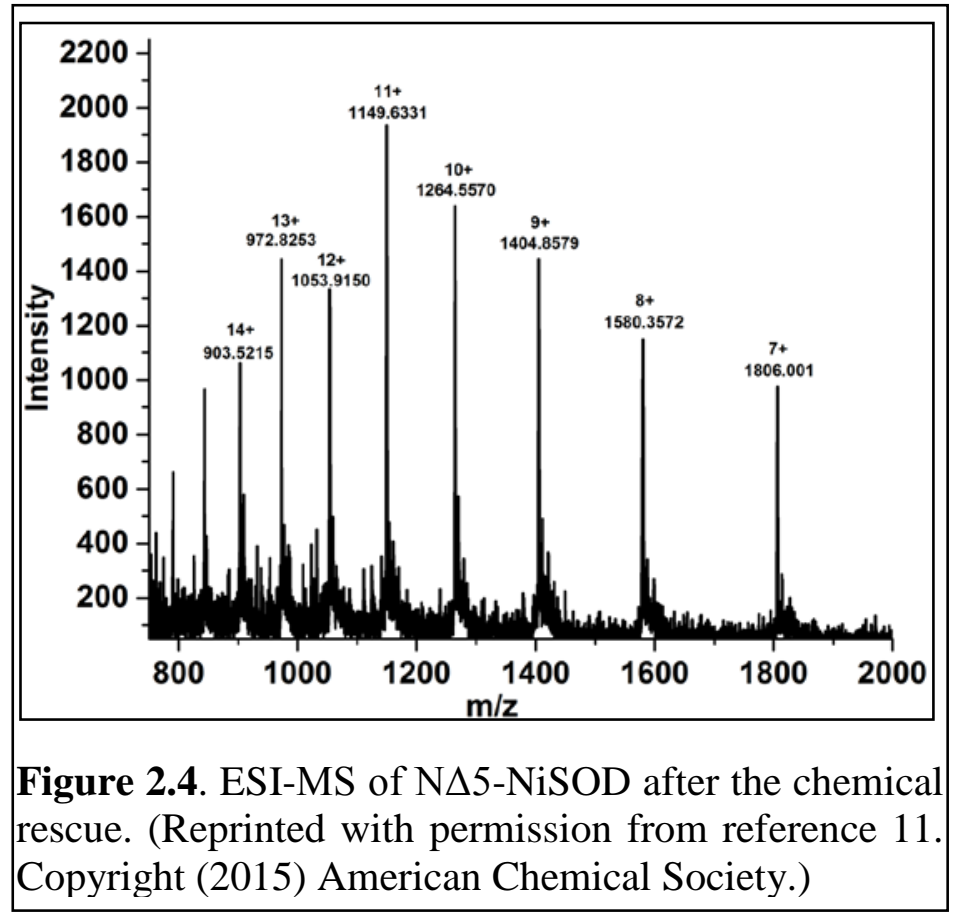

Found: 12634 Da. Calculated for NA5-NiSOD: 12635 Da (Figure 2.4). Yield: 50\% of the protein from section 2.2.2 is recovered. 


\subsubsection{His-Cys(o-NBn)-Asp-Leu-Pro-Nbz (Protected Unmodified HCDLP)}

\subsubsection{Synthesis of Alloc-Cys(o-NBn)-OH. Cys(o-NBn)-OH}

Cys(o-NBn)-OH was first synthesized by dissolving $15 \mathrm{mmol}$ cysteine in deaerated aqueous solution of $10 \mathrm{mmol}$ potassium carbonate in $20 \mathrm{~mL}$ water $/ 10 \mathrm{~mL}$ dioxane and treated with $10 \mathrm{mmol}$ o-nitrobenzyl chloride. Formation of a crystalline product was observed after $30 \mathrm{~min}$, and after $4 \mathrm{~h}$ the $\mathrm{pH}$ of the reaction mixture was adjusted to 5.9 with acetic acid. The product was collected by filtration and washed with water, isopropanol, and ether. The solids were dried under vacuum and a yield of $2.06 \mathrm{~g}$ (79\%) of the product was obtained at $99 \%$ purity.

Alloc-Cys(o-NBn)-OH was then synthesized as previously described. ${ }^{16}$ About $100 \mathrm{mmol}$ of cysteine was dissolved in $2 \mathrm{~mL}$ of $4 \mathrm{~N} \mathrm{NaOH}$. The solution was cooled in an ice-bath and treated with $10.6 \mathrm{~mL}$ of allyl chloroformate and $25 \mathrm{~mL}$ of $4 \mathrm{~N}$ sodium hydroxide, added in eight equal portions with vigorous shaking for a few minutes after each addition and intermittent cooling. The reaction mixture was kept alkaline to phenolphthalein throughout. After the last addition, the mixture was shaken vigorously, allowed to stand for 15 min at room temperature, extracted with ether, and then acidified to congo red with concentrated hydrochloric acid. After cooling for several hours, the product that crystallized was collected, dried, and recrystallized.

\subsubsection{His-Cys(o-NBn)-Asp-Leu-Pro-Nbz SPPS Assembly}

The pentapeptide His-Cys(o-NBn)-Asp-Leu-Pro-Nbz was assembled by Fmoc SPPS using $0.2 \mathrm{mmol}$ of the commercially available Dawson Dbz AM resin. The Cterminal Pro was loaded onto the resin via two 1-h couplings using $1.2 \mathrm{mmol}$ of Fmoc 
Pro with activation via $1.2 \mathrm{mmol}$ HATU and $1.8 \mathrm{mmol}$ DIEA in DMF. Subsequent residues, Leu, Asp(OtBu) and Alloc-Cys(o NBn) were coupled similarly using HBTU in place of HATU. The peptidoresin was protected from light after incorporation of the Alloc-Cys(o-NBn) residue. The Alloc protective group was removed by adding $\left(\mathrm{PPh}_{3}\right)_{4} \mathrm{Pd}(0)$ with 1,3-dimethylbarbituric acid (scavenger) to the peptide under neutral conditions. The final residue was incorporated using Boc-His(Trt)-OH.

After chain assembly, the resin was gently agitated with 2 mmol of pnitrophenylchloroformate in DCM for $1 \mathrm{~h}$ to convert the resin to the $\mathrm{N}$ acylbenzimidazolinone $(\mathrm{Nbz})$ form, which was then washed with DCM. The resin was agitated with 0.5 M DIEA in DMF for two 30 min treatments, then rinsed with the same solution until no further yellow coloration (from p-nitrophenol release) was observed. The peptidoresin was washed with DMF, MeOH, DCM then dried overnight in vacuo. The peptide was cleaved from the resin with trifluoroacetic acid/water/triisopropylsilane (90:5:5, $25 \mathrm{~mL}, 3 \mathrm{~h}$ ) then precipitated in ice-cold ether. The crude product was purified by reverse phase HPLC to yield the final product (120 mg).

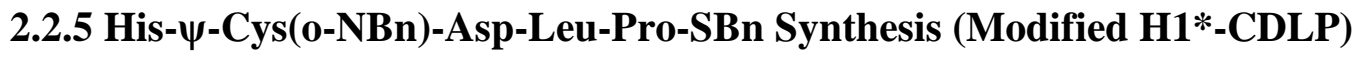

\subsubsection{Boc-His( $\mathbf{N}^{\pi}$-Adom)-H Synthesis}

Protected histidinal, Boc-His( $\mathrm{N}^{\pi}$-Adom)-H, was prepared by first synthesizing Boc-His( $\mathrm{N}^{\pi}$-Adom)-OMe. This was accomplished by reacting 2-adamantyloxymethyl chloride with Boc-His $\left(\mathrm{N}^{\pi}\right.$-Boc)-OMe as described by Okada et al. ${ }^{17}$ The product (BocHis( $\mathrm{N}^{\pi}$-Adom)-OMe) was then converted to Boc-His( $\mathrm{N}^{\pi}$-Adom)-ol by first dissolving 10 mmol Boc-His( $\mathrm{N}^{\pi}$-Adom)-OMe in $100 \mathrm{~mL}$ THF containing 60 mmol sodium 
borohydride. Methanol $(16 \mathrm{~mL})$ was then added dropwise followed by heating the solution at $40{ }^{\circ} \mathrm{C}$. The progress of the reaction was monitored by HPLC on a C18 column. When the reaction was completed, excess sodium borohydride was removed by the addition of an aqueous solution of citric acid. The resulting solution was concentrated until most of the organic solvent had been evaporated. The $\mathrm{pH}$ was then adjusted to 9 using potassium carbonate and the product (Boc-His( $\mathrm{N}^{\pi}$-Adom)-ol) was extracted using dichloromethane. The product was obtained as white foam (3.4 g) with 98\% purity (HPLC).

The alcohol (Boc-His( $\mathrm{N}^{\pi}$-Adom)-ol) was then converted to the aldehyde, BocHis( $\mathrm{N}^{\pi}$-Adom)-H. This was done by dissolving $3.6 \mathrm{mmol}$ Boc-His( $\mathrm{N}^{\pi}$-Adom)-ol in 100 $\mathrm{mL}$ dichloromethane followed by dropwise addition of 1.7 eq Dess-Martin reagent. The progress of the reaction was monitored by HPLC and when the reaction was completed, the solution was treated with $10 \mathrm{mmol}$ thiosulfate in $25 \mathrm{~mL} 10 \%$ bicarbonate buffer. The solution was concentrated until most of the organic solvent was removed and the material was used without any further purification.

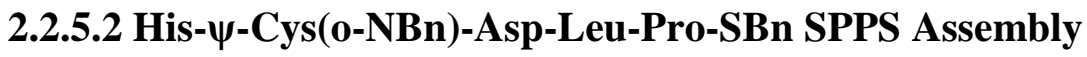

The pentapeptide benzylthioester, His- $\psi$-Cys(o-NBn)-Asp-Leu-Pro-SBn, was assembled by first synthesizing Alloc-Cys(o-NBn)-Asp(OtBu)-Leu-Pro by standard SPPS on 2-chlorotrityl resin. The cysteine N-terminal allyl chloroformate (Alloc) protective group was then removed as before (section 2.2.4.1). The resulting peptide, Cys(o-NBn)-Asp(OtBu)-Leu-Pro, was then cleaved from the resin using acetic acidtrifluoroethanol-dichloromethane (1:2:7, v/v). Reductive alkylation was then 
performed in solution to synthesize Boc-His( $\mathrm{N}^{\pi}$-Adom)- $\psi$-Cys(o-NBn)-Asp(OtBu)-LeuPro-OH. This was done by dissolving 1.7 mmol Cys(o-NBn)-Asp(OtBu)-Leu-Pro and 1.6 equiv of Boc-His( $\mathrm{N}^{\pi}$-Adom)-H in $30 \mathrm{~mL}$ methanol containing $0.3 \mathrm{~mL}$ acetic acid. The resulting solution was then treated with 4 eq sodium cyanoborohydride in portions. The reaction went to $90 \%$ completion (HPLC) after which methanol and acetic acid were then removed by evaporation under vacuum. The product, (Boc-His( $\mathrm{N}^{\pi}$-Adom)- $\psi$-Cys(o$\mathrm{NBn})-\mathrm{Asp}(\mathrm{OtBu})-\mathrm{Leu}-\mathrm{Pro}-\mathrm{OH})$, was then suspended in citric acid solution and extracted with dichloromethane, and then concentrated without further purification.

To the crude 1.68 mmol Boc-His( $\mathrm{N}^{\pi}$-Adom)- $\psi$-Cys(o-NBn)-Asp(OtBu)-Leu-ProOH solution, 9 mmol benzyl mercaptan was added together with 0.2 mmol DMAP hydrochloride and 0.26 eq DMAP in $30 \mathrm{~mL}$ dichloromethane. The resulting solution was treated with $2.14 \mathrm{mmol}$ EDC for $1 \mathrm{~h}$, after which the reaction was quenched with phosphate buffer at $\mathrm{pH}$ 6. The solution was then concentrated and the excess benzyl mercaptan was removed by washing the residue with heptane. The remaining material was then dissolved in dichloromethane and washed with phosphate buffer. The crude peptide was further purified using FC silica gel yielding 0.94 g material with $~ 80 \%$ purity. Treatment of the product with TFA/water (95:5) for an hour cleanly removed acid sensitive protecting groups, Boc, tBu, and Adom. The target peptide was finally purified on reverse phase column in TFA-containing gradient of water and acetonitrile and then lyophilized. 


\subsubsection{Native Chemical Ligation (NCL) and Product Purification}

The native chemical ligation was performed by combining $6 \mathrm{mM}$ pentapeptide and $3 \mathrm{mM} \mathrm{N} \Delta 5$-NiSOD in $100 \mathrm{mM}$ phosphate buffer with $6 \mathrm{M}$ guanidine hydrochloride, $15 \mathrm{mM}$ TCEP and $250 \mathrm{mM}$ 4-mercaptophenylacetic acid (MPAA) at $\mathrm{pH}=7.00$ for $24 \mathrm{~h}$ at room temperature in an anaerobic chamber (Coy Laboratories Inc., Grass Lake, MI). The ligation product is a mixture of properly ligated $\mathrm{H} 1 *$-NiSOD as well as $\mathrm{N} \Delta 5$-NiSOD oxidized at the N-terminal Cys residue, and N $\Delta 5$-NiSOD that had been desulfurized by reaction with TCEP ${ }^{18}$ (Figure 2.5A). The properly ligated protein was purified from the oxidized and desulfurized N $\Delta 5$-NiSOD, which both lack a thiol group, by using activated thiol sepharose affinity column chromatography. First, the NCL buffer was exchanged

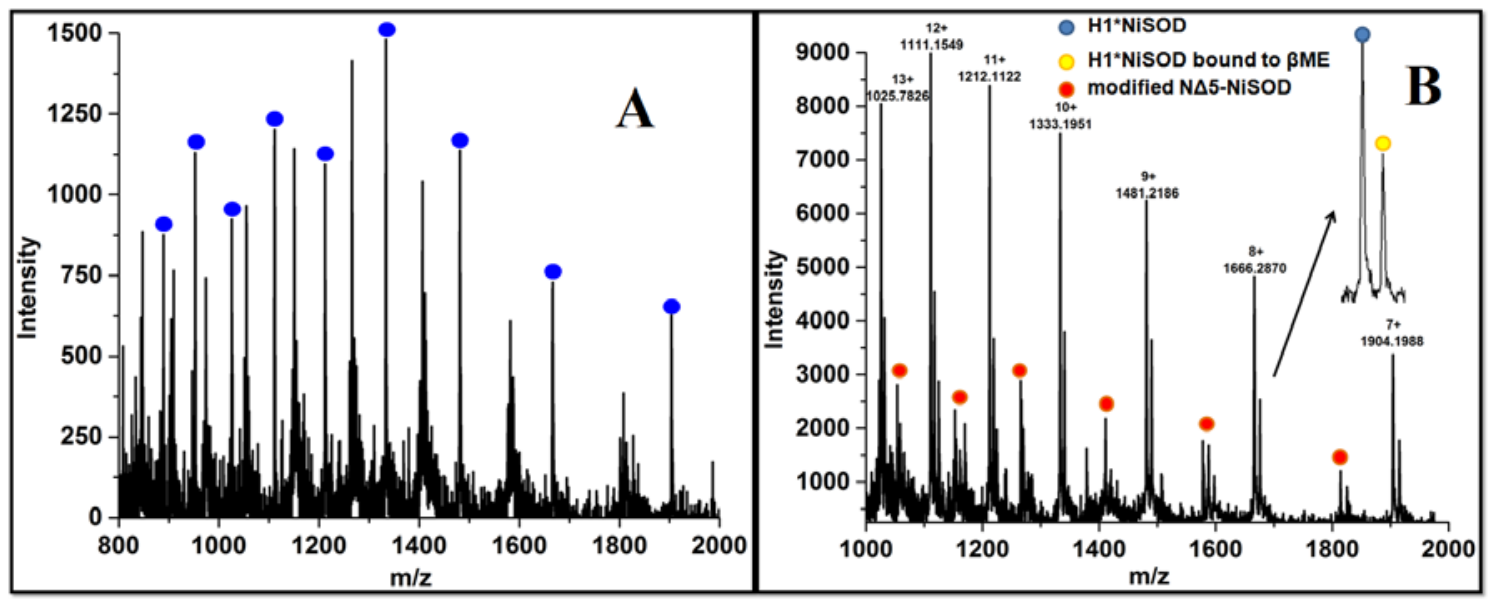

Figure 2.5. A. ESI-MS of $\mathrm{H} 1{ }^{*}$-NiSOD after $\mathrm{N} \Delta 5$ and $\mathrm{H}^{*}$ CDLP-thioester NCL. The peaks under the blue dots are the peaks that correspond to the charge states for $\mathrm{H} 1 *_{\text {- }}$ NiSOD. Unlabeled peaks correspond to the charge states of oxidized and desulfurized N $\triangle 5$-NiSOD. (Reprinted with permission from reference 11. Copyright (2015) American Chemical Society.)

with a binding buffer consisting of $100 \mathrm{mM}$ Tris, 8 M guanidine hydrochloride, $500 \mathrm{mM}$ $\mathrm{NaCl}$, and $1 \mathrm{mM}$ EDTA at $\mathrm{pH}=7.50$. This step also removes the excess MPAA that might interfere with the purification process. Next, the protein was loaded on to a column 
containing $5 \mathrm{~mL}$ of activated thiol sepharose resin and incubated at room temperature for at least $2 \mathrm{~h}$. The column was then washed with $30 \mathrm{~mL}$ of the binding buffer to remove unbound proteins. The bound protein was then eluted with $10 \mathrm{mM}$ Tris containing 50 $\mathrm{mM} \beta$-mercaptoethanol at $\mathrm{pH}=7.50$ (Figure 2.5B).

\subsubsection{Cys2 Protective Group Removal, Folding and Metalation}

To remove the 2-nitrobenzyl protecting group, $50 \mu \mathrm{M}$ protein in a buffer consisting of $100 \mathrm{mM}$ sodium acetate, $6 \mathrm{M}$ guanidine $\mathrm{HCl}, 20 \mathrm{mM}$ TCEP, and $10 \mathrm{mM}$ semicarbazide at pH 5.80 was placed in an ice bath and irradiated with UV light at 365 $\mathrm{nm}$. The extent of the reaction was monitored by mass spectrometry, and the reaction is complete after $4 \mathrm{~h}$ of irradiation. The sample was then dialyzed at $4{ }^{\circ} \mathrm{C}$ against $20 \mathrm{mM}$ Tris buffer containing $5 \mathrm{mM}$ TCEP and $5 \mathrm{mM} \mathrm{NiCl}_{2}$ at $\mathrm{pH} 8.00$ overnight. The sample was then dialyzed at $4{ }^{\circ} \mathrm{C}$ against $20 \mathrm{mM}$ Tris at $\mathrm{pH} 8.00$ for $12 \mathrm{~h}$, twice. Finally, the sample was treated with Chelex to remove any unbound nickel by adding a small amount of chelex resin and incubated at room temperature for $30 \mathrm{~min}$ and agitated occasionally. The Ni:protein ratio was determined by analyzing the nickel and sulfur content of the sample by ICP-OES. The ICP-OES determination of the enzyme concentration was done by first making a standard curve using 2, 5, 10, 20, and $50 \mathrm{ppm}$ sulfur standards prepared from a $1000 \mathrm{ppm}$ sulfur ICP standard (Sigma-Aldrich). The concentration of sulfur in each sample was then determined using the standard curve (machine automated determination). The protein concentration was calculated by dividing the sulfur concentration by 3 (since NiSOD has two cysteines and one methionine). Yield: $600 \mu \mathrm{g}$ protein from $10 \mathrm{mg}$ prior to native chemical ligation. 


\subsection{Results and Discussion}

A semisynthetic approach (Figure 2.6) was used to produce a variant of NiSOD in which the backbone amidate ligand provided by Cys2 is altered to a secondary amine. The semisynthesis of WT-NiSOD was carried out as a control using NCL to couple a

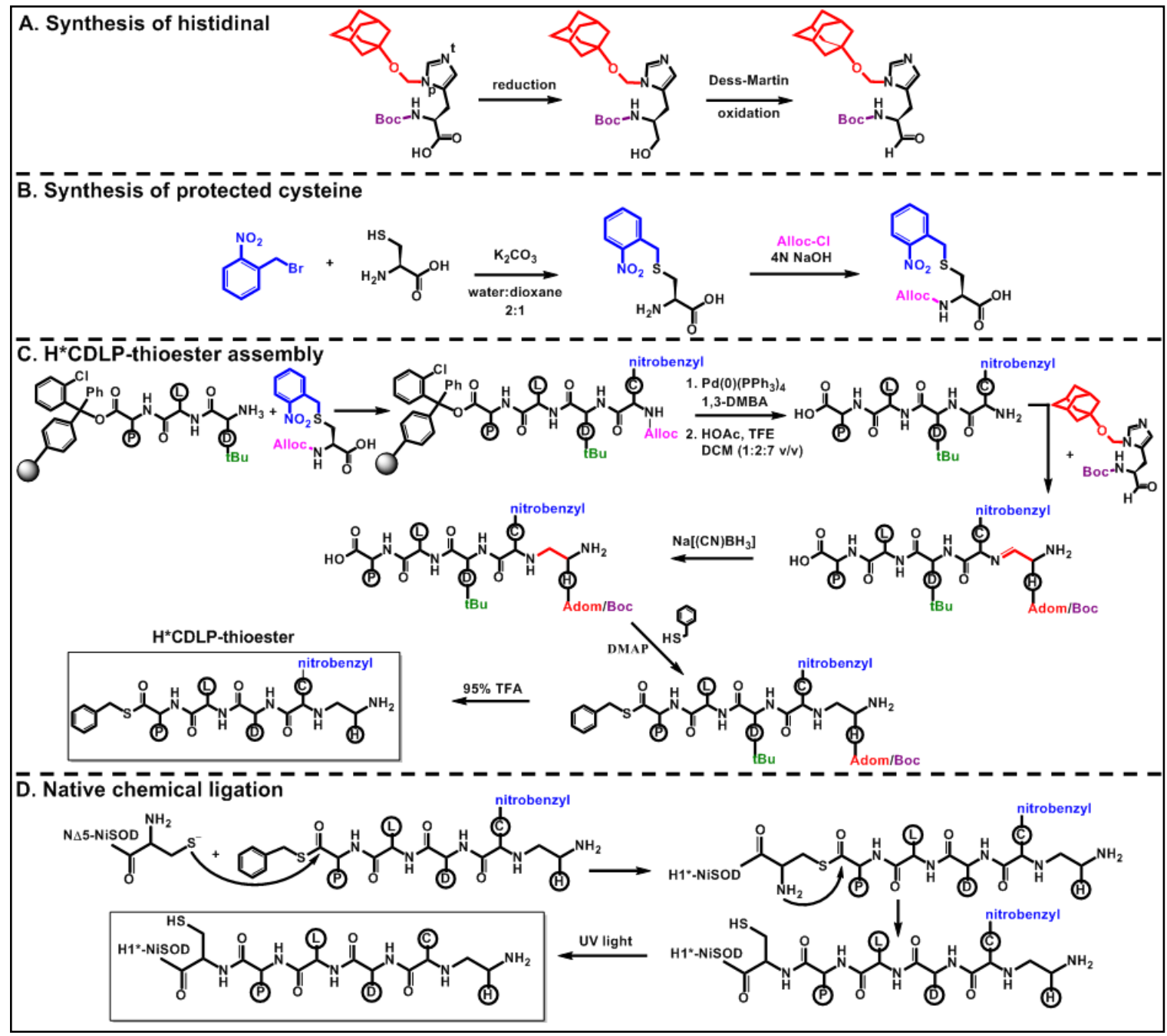

Figure 2.6. Semisynthetic approach for constructing H1*-NiSOD. (Reprinted with permission from reference 11. Copyright (2015) American Chemical Society.)

pentapeptide comprising the five N-terminal amino acids to a truncated NiSOD with an N-terminal Cys residue, N $\Delta 5$-NiSOD, which was produced recombinantly. A key feature of the approach is the use of a photolabile thiol protecting group (2-nitrobenzyl) that was 
used to protect Cys2 in order to keep it protected during NCL after acid deprotection of other residues, and also distinguish it from the N-terminal Cys of N $\Delta 5$-NiSOD. Following NCL and purification of the product, the 2-nitrobenzyl protecting group was removed photochemically by exposing the sample with UV light at $365 \mathrm{~nm}$. The production of the semisynthetic WT-NiSOD protein was confirmed by ESI-MS performed under denaturing conditions (Figure 2.7A). The sample was then folded and nickelated. Nickel and protein (sulfur) content were determined by ICP-OES and gave a nickel loading of $84 \%$. The resulting enzyme was found to be a fully active catalyst (vide infra) and was hexameric according to size exclusion chromatography (Figure 2.8).

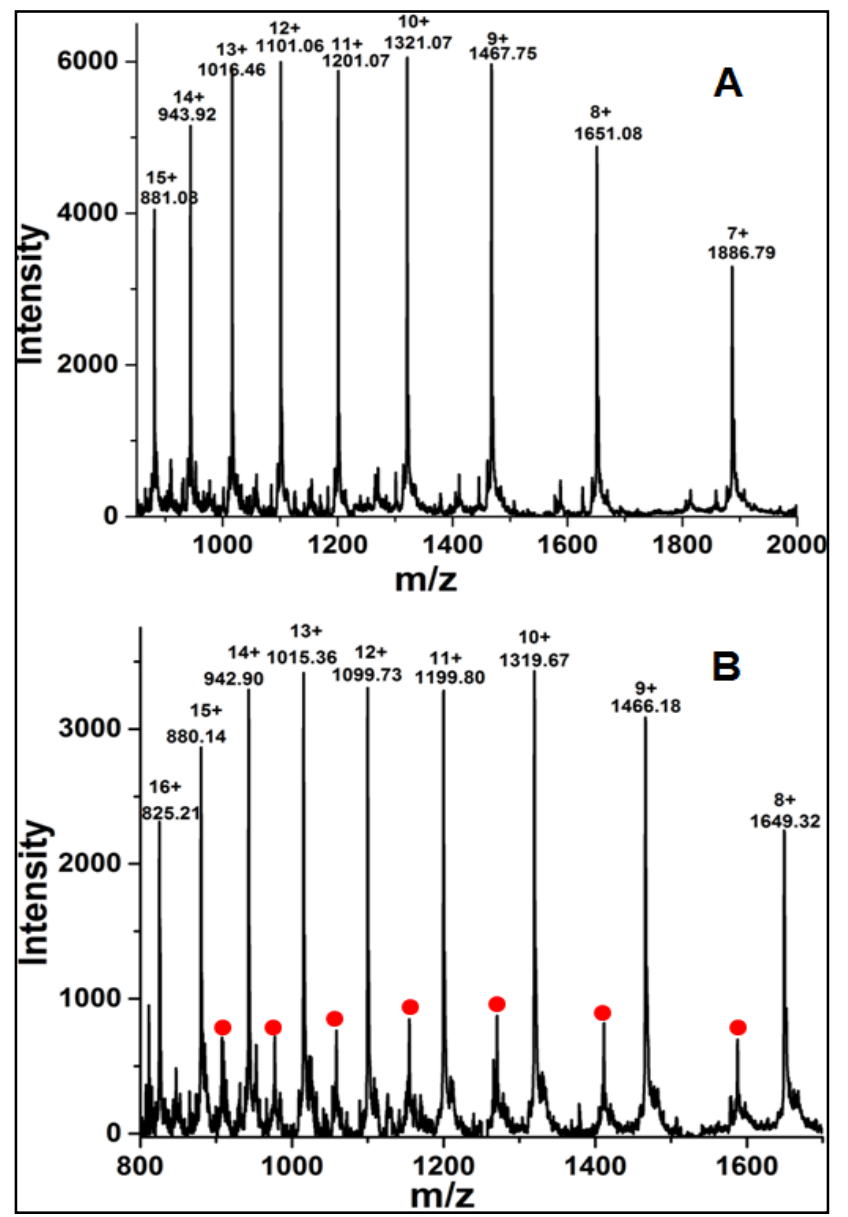

Figure 2.7. ESI-mass spectra of the semisynthetic WT-NiSOD (A) and H1*-NiSOD (B) after the removal of the 2-nitrobenzyl Cys2 protective group by UV irradiation. Peaks under the red dots in figure $\mathrm{B}$ correspond to a modified $\mathrm{N} \Delta 5-\mathrm{NiSOD}$ that does not contain a high-affinity nickel binding site. (Reprinted with permission from reference 11. Copyright (2015) American Chemical Society.)

The synthesis of the H1*-NiSOD variant was accomplished in an analogous manner to the semisynthesis of WT-NiSOD. The pentapeptide benzylthioester was prepared using SPPS and Alloc-S-o-nitrobenzyl cysteine, as before. The desired amide $\rightarrow$ 
amine modification was introduced in solution after cleavage of the tetrapeptide (CDLP) from the resin by using the aldehyde, histidinal, instead of the natural amino acid histidine to produce an imine linkage that was then converted to secondary amine by reduction with $\mathrm{Na}\left[(\mathrm{CN}) \mathrm{BH}_{3}\right]$ (Figure 2.6C). The synthesis of $\delta$-N-adamantyl-O- and Bocprotected histidinal from the corresponding protected histidine was achieved by reduction of the amino acid to the alcohol followed by Dess-Martin oxidation (Figure 2.6A). ${ }^{19}$ The synthesis of high purity histidinal in significant quantities and in a form suitable for peptide synthesis is reported here for the first time and was a significant component of the research. It was achieved by protecting the imidazole amine with an adamantyl group prior to reduction of the amino acid and oxidation of the alcohol. Following the removal of the acid-labile protecting groups, NCL was performed as for the semisynthetic WTNiSOD, except starting with the benzylthioester of the modified pentapeptide. The use of the poorer SBz leaving group compared with NBz used for the WT-NiSOD, ${ }^{20,21}$ led to extensive oxidation or desulfurization of the $\mathrm{N} \Delta 5$-NiSOD $\mathrm{N}$-terminal cysteine when large excesses of TCEP were used ${ }^{18}$ (Figure 2.5A), necessitating separation of the desired protein from the impurities that do not contain a thiol by chromatography on activated thiol sepharose. The resulting H1*-NiSOD is $\sim 70 \%$ pure by mass spectral deconvolution. The only remaining impurity is an N-terminally modified $\mathrm{N} \Delta 5$-NiSOD that does not undergo NCL (Figure 2.5B). This species does not affect the characterization of the enzyme because it lacks the high-affinity nickel binding site.

Following photochemical deprotection of Cys2, the resulting product was analyzed by ESI-MS under denaturing conditions, which confirmed the expected MW for the protein (Figure 2.7B). The sample was then folded, metalated, and analyzed for $\mathrm{Ni}$ 
content, as described for semisynthetic WT-NiSOD. The sample after chelex treatment was found to be $62 \%$ nickel loaded, after taking into account the sample purity. Like the WT enzyme, H1*-NiSOD was also found to be hexameric by size exclusion chromatography (Figure 2.8).

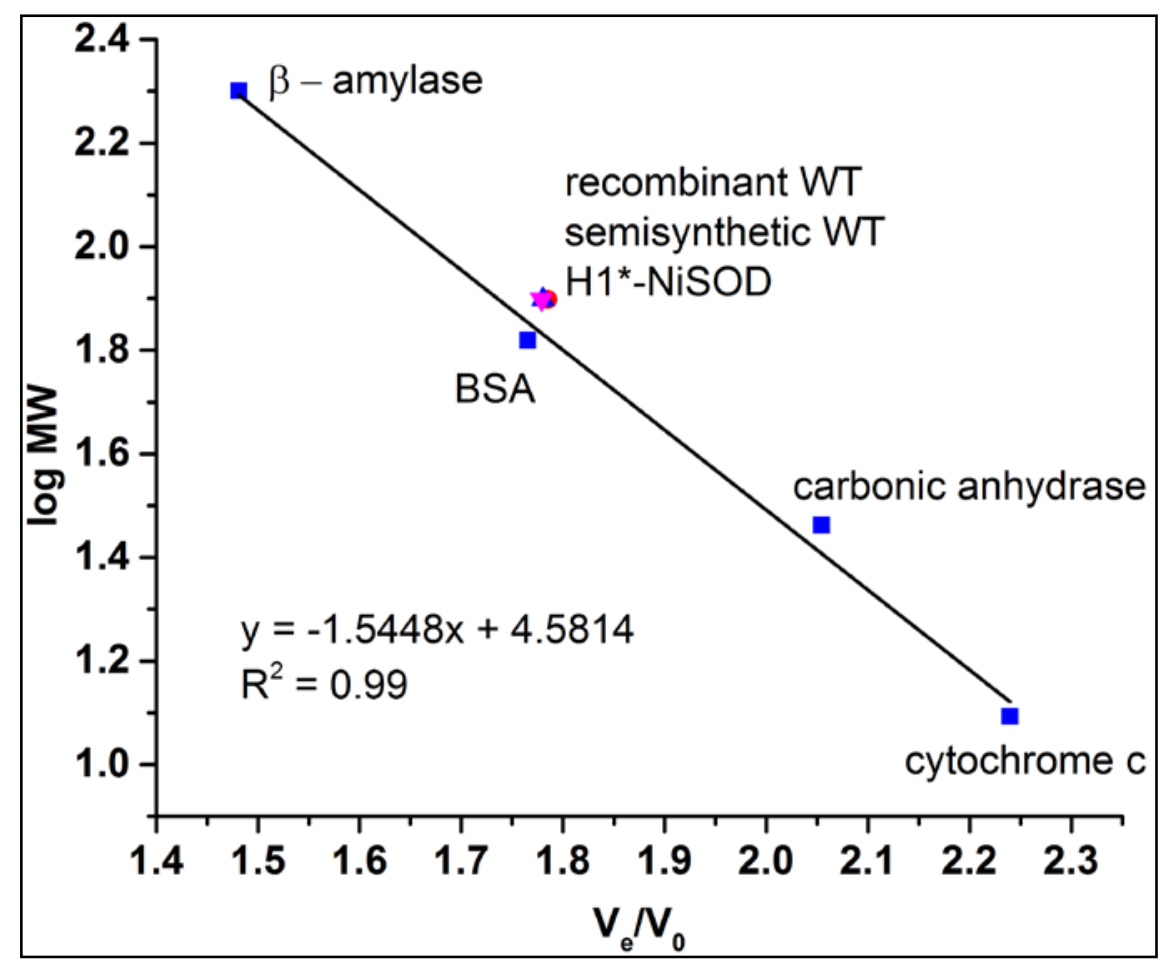

Figure 2.8. Size exclusion chromatography on the NiSOD variants. The apparent MW determined for all variants is approximately $73 \mathrm{kDa}$ (Calculated: $79 \mathrm{kDa}$ ). (Reprinted with permission from reference 11. Copyright (2015) American Chemical Society.)

The synthetic strategy detailed above provides a method to alter any backbone amide to a secondary amine employing aldehydes derived from amino acids that can be adapted to solid phase peptide synthesis. This approach differs from previous backbone alterations reported in the literature in that it preserves the backbone $\mathrm{N}$ atom in the protein, while altering its chemical properties including deprotonation (charge) and ability to engage in $\pi$-bonding. Of the strategies for modifying backbone amides that have 
been employed to make proteins (rather than small peptides), this strategy is novel in that it preserves the $\mathrm{N}$-donor ligand as opposed to replacement with an ester $\mathrm{O}$ donor. The latter can be achieved in several ways including the use of preactivated (L)-lactic acid or (S) hydroxymethylbutyric acid in solid phase peptide synthesis or the use of $\alpha$ hydroxyacids in tRNA suppression strategies. ${ }^{22-29}$ These amide $\rightarrow$ ester modifications enabled investigations probing the effect of altering hydrogen bonding interactions involving the amide, but are less applicable to amides that are metal ligands in metalloproteins, since ester $\mathrm{O}$ atoms are poor metal ligands. Although rare, metalloenzymes featuring active site metal amidate ligands include nitrile hydratase ${ }^{30}$ and thiocyanate hydrolase, ${ }^{31}$ in addition to NiSOD studied here. The use of histidinal to modify the peptide bond is specifically applicable to proteins that feature the amino terminal $\mathrm{Cu}(\mathrm{II})-$ and Ni(II)-binding (ATCUN) motif, ${ }^{32}$ which binds in a tetradentate planar fashion utilizing the $\mathrm{N}$-terminal amine, a histidine residue in position 3 , and two intervening amide $\mathrm{N}$ atoms. The ATCUN motif is a common feature of albumins, and $95 \%$ of serum Ni(II) is bound to albumin..$^{30}$ The ATCUN motif is also found in histatins, neuromedins $\mathrm{C}$ and $\mathrm{K}$, and human sperm protamine $\mathrm{P} 2 \mathrm{a}$, and is also a component of proteins engineered for DNA cleavage. ${ }^{30,33-35} \mathrm{~N}$-terminal ATCUN-like binding sites are also features of a number of proteins involved in Ni trafficking, including $\mathrm{NmtR}^{36}$ RcnR,${ }^{37}$ and $\mathrm{HypA}^{38}{ }^{38}$ where the His residue is second residue and the resulting $\mathrm{Ni}(\mathrm{II})$ complexes are all six-coordinate.

\subsection{References}

1. Fiedler, A. T.; Bryngelson, P. A.; Maroney, M. J.; Brunold, T. C. Spectroscopic and computational studies of $\mathrm{Ni}$ superoxide dismutase: electronic structure contributions to enzymatic function. J. Am. Chem. Soc. 2005, 127, 5449-5462. 
2. Shearer, J.; Long, L. M. A nickel superoxide dismutase maquette that reproduces the spectroscopic and functional properties of the metalloenzyme. Inorg. Chem. 2006, 45, 2358-2360.

3. Neupane, K. P.; Shearer, J. The influence of amine/amide versus bisamide coordination in nickel superoxide dismutase. Inorg. Chem. 2006, 45, 10552-10566.

4. Mullins, C.; Grapperhaus, C.; Kozlowski, P. Density functional theory investigations of NiN2S2 reactivity as a function of nitrogen donor type and $\mathrm{N}-\mathrm{H} \cdots \mathrm{S}$ hydrogen bonding inspired by nickel-containing superoxide dismutase. JBIC Journal of Biological Inorganic Chemistry 2006, 11, 617-625.

5. Shearer, J.; Dehestani, A.; Abanda, F. Probing variable amine/amide ligation in NiIIN2S2 complexes using sulfur K-edge and nickel L-edge X-ray absorption spectroscopies: implications for the active site of nickel superoxide dismutase. Inorg. Chem. 2008, 47, 2649-2660.

6. Shearer, J.; Zhao, N. [Me4N](NiII (BEAAM)): A Synthetic Model for Nickel Superoxide Dismutase That Contains $\mathrm{Ni}$ in a Mixed Amine/Amide Coordination Environment. Inorg. Chem. 2006, 45, 9637-9639.

7. Grapperhaus, C. A.; Maguire, M. J.; Tuntulani, T.; Darensbourg, M. Y. Singlet Oxygen and the Production of Sulfur Oxygenates of Nickel (II) and Palladium (II) Thiolates. Inorg. Chem. 1997, 36, 1860-1866.

8. Mirza, S. A.; Pressler, M. A.; Kumar, M.; Day, R. O.; Maroney, M. J. Oxidation of nickel thiolate ligands by dioxygen. Inorg. Chem. 1993, 32, 977-987.

9. Grapperhaus, C. A.; Darensbourg, M. Y. Oxygen capture by sulfur in nickel thiolates. Acc. Chem. Res. 1998, 31, 451-459.

10. Kaasjager, V. E.; Bouwman, E.; Gorter, S.; Reedijk, J.; Grapperhaus, C. A.; Reibenspies, J. H.; Smee, J. J.; Darensbourg, M. Y.; Derecskei-Kovacs, A.; Thomson, L. M. Unique reactivity of a tetradentate N2S2 complex of nickel: Intermediates in the production of sulfur oxygenates. Inorg. Chem. 2002, 41, 1837-1844.

11. Campeciño, J. O.; Dudycz, L. W.; Tumelty, D.; Berg, V.; Cabelli, D. E.; Maroney, M. J. A Semisynthetic Strategy Leads to Alteration of the Backbone Amidate Ligand in the NiSOD Active Site. J. Am. Chem. Soc. 2015, 137, 9044-9052.

12. Barondeau, D. P.; Kassmann, C. J.; Bruns, C. K.; Tainer, J. A.; Getzoff, E. D. Nickel superoxide dismutase structure and mechanism. Biochemistry (N. Y. ) 2004, 43, 80388047. 
13. Bryngelson, P. A.; Arobo, S. E.; Pinkham, J. L.; Cabelli, D. E.; Maroney, M. J. Expression, Reconstitution, and Mutation of Recombinant Streptomyces c oelicolor NiSOD. J. Am. Chem. Soc. 2004, 126, 460-461.

14. Gentle, I. E.; De Souza, D. P.; Baca, M. Direct production of proteins with N-terminal cysteine for site-specific conjugation. Bioconjug. Chem. 2004, 15, 658-663.

15. Fauvet, B.; Fares, M. B.; Samuel, F.; Dikiy, I.; Tandon, A.; Eliezer, D.; Lashuel, H. A. Characterization of semisynthetic and naturally Nalpha-acetylated alpha-synuclein in vitro and in intact cells: implications for aggregation and cellular properties of alphasynuclein. J. Biol. Chem. 2012, 287, 28243-28262.

16. Stevens, C. M.; Watanabe, R. Amino Acid Derivatives. I. Carboallyloxy Derivatives of $\alpha$-Amino Acids1, 2. J. Am. Chem. Soc. 1950, 72, 725-727.

17. Okada, Y.; Wang, J.; Yamamoto, T.; YOKOI, T.; MU, Y. Amino acids and peptides.

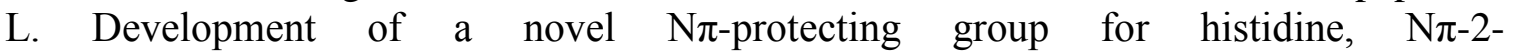
adamantyloxymethylhistidine, and its application to peptide synthesis. Chemical and pharmaceutical bulletin 1997, 45, 452-456.

18. Wang, Z.; Rejtar, T.; Zhou, Z. S.; Karger, B. L. Desulfurization of cysteinecontaining peptides resulting from sample preparation for protein characterization by mass spectrometry. Rapid Communications in Mass Spectrometry 2010, 24, 267-275.

19. Myers, A. G.; Zhong, B.; Movassaghi, M.; Kung, D. W.; Lanman, B. A.; Kwon, S. Synthesis of highly epimerizable $\mathrm{N}$-protected $\alpha$-amino aldehydes of high enantiomeric excess. Tetrahedron Lett. 2000, 41, 1359-1362.

20. Dawson, P. E.; Churchill, M. J.; Ghadiri, M. R.; Kent, S. B. Modulation of reactivity in native chemical ligation through the use of thiol additives. J. Am. Chem. Soc. 1997, 119, 4325-4329.

21. Blanco-Canosa, J. B.; Dawson, P. E. An Efficient Fmoc-SPPS Approach for the Generation of Thioester Peptide Precursors for Use in Native Chemical Ligation. Angewandte Chemie International Edition 2008, 47, 6851-6855.

22. Koh, J. T.; Cornish, V. W.; Schultz, P. G. An experimental approach to evaluating the role of backbone interactions in proteins using unnatural amino acid mutagenesis. Biochemistry (N. Y. ) 1997, 36, 11314-11322.

23. Shin, I.; Ting, A. Y.; Schultz, P. G. Analysis of backbone hydrogen bonding in a $\beta$ turn of staphylococcal nuclease. J. Am. Chem. Soc. 1997, 119, 12667-12668.

24. Low, D. W.; Hill, M. G. Backbone-engineered high-potential iron proteins: effects of active-site hydrogen bonding on reduction potential. J. Am. Chem. Soc. 2000, 122, 11039-11040. 
25. Jude, A. R.; Providence, L. L.; Schmutzer, S. E.; Shobana, S.; Greathouse, D. V.; Andersen, O. S.; Koeppe, R. E. Peptide backbone chemistry and membrane channel function: effects of a single amide-to-ester replacement on gramicidin channel structure and function. Biochemistry (N. Y. ) 2001, 40, 1460-1472.

26. Lu, W.; Qasim, M.; Laskowski, M.; Kent, S. B. Probing intermolecular main chain hydrogen bonding in serine proteinase-protein inhibitor complexes: chemical synthesis of backbone-engineered turkey ovomucoid third domain. Biochemistry (N. Y. ) 1997, 36, 673-679.

27. Eildal, J. N.; Hultqvist, G.; Balle, T.; Stuhr-Hansen, N.; Padrah, S.; Gianni, S.; Strømgaard, K.; Jemth, P. Probing the role of backbone hydrogen bonds in proteinpeptide interactions by amide-to-ester mutations. J. Am. Chem. Soc. 2013, 135, 1299813007.

28. Baca, M.; Kent, S. B. Protein backbone engineering through total chemical synthesis: new insight into the mechanism of HIV-1 protease catalysis. Tetrahedron 2000, 56, 9503-9513.

29. Bain, J.; Diala, E. S.; Glabe, C. G.; Wacker, D. A.; Lyttle, M. H.; Dix, T. A.; Chamberlin, A. R. Site-specific incorporation of nonnatural residues during in vitro protein biosynthesis with semi-synthetic aminoacyl-tRNAs. Biochemistry (N. Y. ) 1991, 30, 5411-5421.

30. Harrop, T. C.; Mascharak, P. K. Fe (III) and Co (III) centers with carboxamido nitrogen and modified sulfur coordination: lessons learned from nitrile hydratase. Acc. Chem. Res. 2004, 37, 253-260.

31. Arakawa, T.; Kawano, Y.; Kataoka, S.; Katayama, Y.; Kamiya, N.; Yohda, M.; Odaka, M. Structure of thiocyanate hydrolase: a new nitrile hydratase family protein with a novel five-coordinate cobalt (III) center. J. Mol. Biol. 2007, 366, 1497-1509.

32. Harford, C.; Sarkar, B. Amino terminal Cu (II)-and Ni (II)-binding (ATCUN) motif of proteins and peptides: metal binding, DNA cleavage, and other properties. Acc. Chem. Res. 1997, 30, 123-130.

33. Mack, D. P.; Iverson, B. L.; Dervan, P. B. Design and chemical synthesis of a sequence-specific DNA-cleaving protein. J. Am. Chem. Soc. 1988, 110, 7572-7574.

34. Mack, D. P.; Dervan, P. B. Nickel-mediated sequence-specific oxidative cleavage of DNA by a designed metalloprotein. J. Am. Chem. Soc. 1990, 112, 4604-4606.

35. Mack, D. P.; Dervan, P. B. Sequence-specific oxidative cleavage of DNA by a designed metalloprotein, nickel (II). cntdot. GGH (Hin139-190). Biochemistry (N. Y. ) 1992, 31, 9399-9405. 
36. Reyes-Caballero, H.; Lee, C. W.; Giedroc, D. P. Mycobacterium tuberculosis NmtR harbors a nickel sensing site with parallels to Escherichia coli RcnR. Biochemistry ( $N$. Y. ) 2011, 50, 7941-7952.

37. Iwig, J. S.; Leitch, S.; Herbst, R. W.; Maroney, M. J.; Chivers, P. T. Ni (II) and Co (II) sensing by Escherichia coli RcnR. J. Am. Chem. Soc. 2008, 130, 7592-7606.

38. Herbst, R. W.; Perovic, I.; Martin-Diaconescu, V.; O’Brien, K.; Chivers, P. T.; Pochapsky, S. S.; Pochapsky, T. C.; Maroney, M. J. Communication between the zinc and nickel sites in dimeric HypA: metal recognition and $\mathrm{pH}$ sensing. J. Am. Chem. Soc. 2010, 132, 10338-10351. 


\section{CHAPTER 3}

\section{REACTION KINETICS AND PHYSICAL CHARACTERIZATION OF H1*- NISOD}

\subsection{Introduction}

This chapter is dedicated to the kinetic and spectroscopic characterization of $\mathrm{H} 1 *_{-}$ NiSOD to understand the effects of the modification and draw conclusions regarding the functional role of the amidate ligand in NiSOD. The characterization of the mutant includes: kinetic studies using pulse radiolysis to produce $\mathrm{O}_{2}{ }^{-}$that were used to determine the catalytic rate; UV-Vis spectroscopy, to determine the electronic absorption characteristics; X-ray absorption spectroscopy, to determine structural features of the local environment of the Ni ion; and EPR spectroscopy, which is a useful probe of electronic structure and redox activity particularly in comparison with WT-NiSOD.

\subsection{Experimental}

\subsubsection{X-ray Absorption Spectroscopy}

A $50-\mu \mathrm{L}$ sample containing $3 \mathrm{mM}$ enzyme (per nickel basis) in $20 \mathrm{mM}$ Tris buffer at $\mathrm{pH}=8.00$ was treated with $10 \mu \mathrm{L}$ of $180 \mathrm{mM}$ dithionite for 1-2 min in a coy chamber (Coy Laboratory Products Inc., Grass Lake, MI). The sample was then added with $10 \mu \mathrm{L}$ of glycerol ( $\sim 15 \%$ final concentration) and loaded into a polycarbonate XAS holder wrapped in Kapton tape and slowly frozen in liquid nitrogen. Ni K-edge XAS data were collected as previously described ${ }^{1}$ at $10 \mathrm{~K}$ using a liquid helium cryostat (Oxford Instruments) on beamline 7-3 at the Stanford Synchrotron Radiation Laboratory (SSRL). The data were collected at $\sim 10 \mathrm{~K}$ using a liquid helium cryostat (Oxford Instruments) 
under ring conditions of $3 \mathrm{GeV}$ and 495-500 mA. Beamline optics consisted of a Si (220) double-crystal monochromator and a flat rhodium-coated mirror before the monochromator for harmonic rejection and vertical collimation. X-ray fluorescence was collected using a 30-element germanium detector (Canberra). Scattering was minimized by placing a set of Soller slits with a Z-1 element filter between the sample chamber and the detector. Internal energy calibration was performed by collecting spectra simultaneously in transition mode on nickel foil to determine the first inflection point on the edge, which was set to $8331.6 \mathrm{eV}$.

Sixpack software was used to remove signals from bad detectors, calibrate the edge energy of Ni foil, and finally to average the data. Athena software was used for data reduction and normalization using the Autobk algorithm. Data normalization was performed by setting the pre-edge range from -200 to $-30 \mathrm{eV}$ (WT: -200 to $-50 \mathrm{eV}$ ) relative to $\mathrm{E}_{0}$, and the post-edge was set from 200-896 eV (WT: 200-905 eV) relative to $\mathrm{E}_{0}$. Background removal was done by setting $\mathrm{E}_{0}=8340 \mathrm{eV}, \mathrm{R}_{\mathrm{bkg}}$ to 1.0 and a spline range from $\mathrm{k}=0 \AA$ to $\mathrm{k}=16.166 \AA$ (WT: $\mathrm{k}=0$ to $\mathrm{k}=16 \AA$ ).

Extended X-ray absorption fine structure (EXAFS) data were analyzed using Artemis software as previously described. ${ }^{2}$ The $k^{3}$-weighted data for the dithionitereduced WT-NiSOD was fitted using the X-ray reduced WT-NiSOD crystal structure (PDB: 1Q0G) as a model for calculating theoretical phases and amplitude parameters using FEFF 6.0, including multiple-scattering pathways for second coordination sphere C atoms from the five-membered chelate rings formed by His1 and Cys2. The FT window was set to 2.0-12.5 $\AA$ and fitting was performed over the range $r=1.0$ - $4.0 \AA$ in r-space with an $S_{0}$ value set to 0.9 . To assess the goodness of the fit, the fit parameters $\chi^{2}, \chi_{\mathrm{v}}{ }^{2}$, and 
$R$ factor were minimized. The $R$ factor generally improves with increasing number of adjustable parameters; whereas, $\chi_{\mathrm{v}}{ }^{2}$ may go through a minimum then increase, which indicates that the data is overfitted. ${ }^{2}$ The statistical parameters are defined as follows:

$$
\chi^{2}=\frac{N_{\text {idp }}}{N_{\text {pts }} \varepsilon^{2}} \sum_{t=1}^{N}\left\{\left[\operatorname{Re}\left(\chi_{\text {data }}\left(R_{i}\right)-\chi_{\text {theory }}\left(R_{i}\right)\right)\right]^{2}+\left[\operatorname{Im}\left(\chi_{\text {data }}\left(R_{i}\right)-\chi_{\text {theory }}\left(R_{i}\right)\right)\right]^{2}\right\},
$$

and

$$
\chi_{v}^{2}=\frac{\chi^{2}}{\left(N_{\text {idp }}-N_{\text {var }}\right)},
$$

"where $N_{\text {idp }}$ is the number of independent data points defined as $N_{\text {idp }}=(2 \Delta r \Delta k) / \pi, \Delta r$ is the fitting range in $r$-space, $\Delta k$ the fitting range in $k$-space, $N_{\text {pts }}$ is the number of points in the fitting range, $N_{\mathrm{var}}$ is the number of variables floating during the fit, $\varepsilon$ is the measurement uncertainty, $\operatorname{Re}()$ is the real part of the EXAFS Fourier-transformed data and theory functions, $\operatorname{Im}()$ is the imaginary part of the EXAFS Fourier-transformed data and theory functions, $\chi\left(R_{i}\right)$ is the Fourier-transformed data or theory function” (MartinDiaconescu 2012, p. 2) and

$$
R=\frac{\sum_{i=1}^{n}\left\{\left[\operatorname{Re}\left(\chi_{\text {data }}\left(R_{i}\right)-\chi_{\text {theory }}\left(R_{i}\right)\right)\right]^{2}+\left[\operatorname{Im}\left(\chi_{\text {data }}\left(R_{i}\right)-\chi_{\text {theory }}\left(R_{i}\right)\right)\right]^{2}\right\}}{\sum_{i=1}^{N}\left\{\left[\operatorname{Re}\left(\chi_{\text {data }_{i}}\left(R_{i}\right)\right)\right]^{2}+\left[\operatorname{Im}\left(\chi_{\text {data }}\left(R_{i}\right)\right)\right]^{2}\right\}} .
$$

Similarly, for dithionite-reduced $\mathrm{H} 1 *$-NiSOD, fits of first-coordination sphere scattering atoms were obtained using an FT window $=2.0-12.5 \AA, \mathrm{S}_{\mathrm{o}}=0.9$, and $\mathrm{r}=1.0$ to $2.3 \AA$ with the following combinations of first-shell scattering atoms: $4 \mathrm{~N} ; 3 \mathrm{~N}, 1 \mathrm{~S} ; 2 \mathrm{~N}$, $2 \mathrm{~S} ; 1 \mathrm{~N}, 3 \mathrm{~S}$; and $4 \mathrm{~S}$. The $2 \mathrm{~N}, 2 \mathrm{~S}$ combination afforded the best fit with the $2 \mathrm{~N}$-scattering and 2S-scattering atoms each averaged in single shells (Appendix, Table A.3). When it became apparent that the H1*- NiSOD active site is structurally similar to WT-NiSOD, judged by the minimum values of $R$ factor and $\chi_{v}{ }^{2}$, second shell carbon atoms were added 
to the fit using the X-ray reduced WT-NiSOD crystal structure (PDB: 1Q0G) as before, and the fitting range was extended to $r=1.25-4.5 \AA$.

X-ray absorption near edge structure (XANES) analysis was performed over the energy range from 8325 to $8340 \mathrm{eV}$ using an error function centered at $8340 \mathrm{eV}$ to fit a portion of the edge background, and Gaussian functions centered at $8331 \mathrm{eV}$ to fit the $1 \mathrm{~s}$ $\rightarrow 3 d$ transition and at $8336 \mathrm{eV}$ to fit the $1 \mathrm{~s} \rightarrow 4 \mathrm{p}_{\mathrm{z}}$ transition (Appendix, Figure A.1 and Table A.4).

\subsubsection{UV-Vis Spectroscopy}

UV-Vis absorption spectra of the recombinant WT-NiSOD, dithionite-reduced WT-NiSOD, semisynthetic WT-NiSOD, and H1*-NiSOD were obtained using a NanoDrop 2000c spectrophotometer. The absorption coefficients were calculated using the enzyme concentration determined based on the sulfur content of the sample as determined by ICP-OES (Chapter 2, section 2.2.7).

\subsubsection{Electron Paramagnetic Resonance Spectroscopy}

The EPR spectra were obtained using a Bruker Elexsys E500 cw-X-band EPR spectrometer. About $100 \mu \mathrm{L}$ of a $200-1000 \mu \mathrm{M}$ solution of each sample was loaded in EPR tubes and frozen using liquid nitrogen. The magnetic field is centered at $3200 \mathrm{G}$ with a sweep width set to $1500 \mathrm{G}$. The modulation frequency was set to $100 \mathrm{kHz}$, while the modulation amplitude was set to $2 \mathrm{G}$. The receiver gain of $60 \mathrm{~dB}$ and attenuation of $10 \mathrm{db}$ were applied and a time constant and conversion time of 0.64 and $655 \mathrm{~ms}$ were used, respectively. Spectral smoothing and baseline correction were performed using SpinCount software (M. Hendrich). Spin integration of the EPR signal from H1*-NiSOD 
was performed by comparing the double integration of the first derivative signal vs a $\mathrm{Cu}(\mathrm{II})$ standard $\left(1.0 \mathrm{mM} \mathrm{CuSO}_{4}\right.$ in $2 \mathrm{M} \mathrm{NaClO}_{4}$ and $\left.10 \mathrm{mM} \mathrm{HCl}\right)$, where the $\mathrm{Cu}$ content was determined by ICP-OES.

\subsubsection{Pulse Radiolysis}

The catalytic activities of the semisynthetic WT-NiSOD and H1*-NiSOD were determined by kinetics studies that employed pulse radiolysis using a $2.0 \mathrm{MeV}$ van de Graaff accelerator at Brookhaven National Laboratory, as previously described. ${ }^{3}$ Micromolar concentrations of the semisynthetic enzymes were exposed to short pulses (100-600 ns) of highly accelerated electrons producing 2-10 $\mu \mathrm{M}$ of superoxide radical. The catalytic activity was measured by monitoring the rate of disappearance of superoxide radical absorption at $260 \mathrm{~nm}$ in a buffered solution containing $2 \mu \mathrm{M}$ protein (per nickel basis), $10 \mathrm{mM}$ phosphate, $30 \mathrm{mM}$ formate, and $5 \mu \mathrm{M}$ EDTA at $\mathrm{pH}$ 7.50. Rates

of reaction are reported on a per $\mathrm{Ni}$ basis and assumed that all of the $\mathrm{Ni}$ in the sample is catalytically active. All quoted rates represent the average of at least three individual measurements and the system error is approximately $10 \%$.

\subsection{Results}

\subsubsection{Structural Characterization of the Ni Site in H1*-NiSOD}

XAS analysis was used to characterize the structure of the Ni site in $\mathrm{H} 1{ }^{*}$-NiSOD and WT-NiSOD (Figure 3.1). For H1*-NiSOD, the XANES spectrum shows a resolved maximum near $8336 \mathrm{eV}$ that is associated with a $1 \mathrm{~s} \rightarrow 4 \mathrm{p}_{\mathrm{z}}$ electronic transition that is diagnostic for four coordinate planar coordination, and is also observed for dithionite- 
reduced WT-NiSOD. ${ }^{4,5}$ In contrast to WT-NiSOD, the expected peak associated with a $1 \mathrm{~s}$ $\rightarrow$ 3d transition for $\mathrm{H}^{*}$-NiSOD was not observed; however, it has very low intensity in many 4-coordinate planar complexes, including some where it is not detected. ${ }^{5}$ The $\mathrm{H} 1{ }^{*}$ NiSOD EXAFS arising from first-coordination sphere scattering atoms was best fitted with 2 N-donor atoms @ 1.970(7) A and 2 S-donor atoms @ 2.17(2) Å (Table 3.1). The $\mathrm{N}$-donor atoms in H1*-NiSOD were not resolved by the data (resolution $=\frac{\pi}{2 k}=0.15 \AA$ ), which is distinct from the results for WT-NSOD, where the two shells are resolved (1.88, 2.09 §) (Table 3.2). This may reflect the fact that in WT-NiSOD, one N-donor atom is an amidate and the other is an amine, whereas in H1*-NiSOD, both N-donors are amines. The $\mathrm{N}$ and $\mathrm{S}$ distances in both $\mathrm{H} 1{ }^{*}$ - and WT-NiSOD are similar to the distances found in planar $\mathrm{NiN}_{2} \mathrm{~S}_{2}$ complexes $(\mathrm{Ni}-\mathrm{N}=1.84-1.99 \AA$; Ni-S = 2.14-2.20 $\AA){ }^{6-8}$
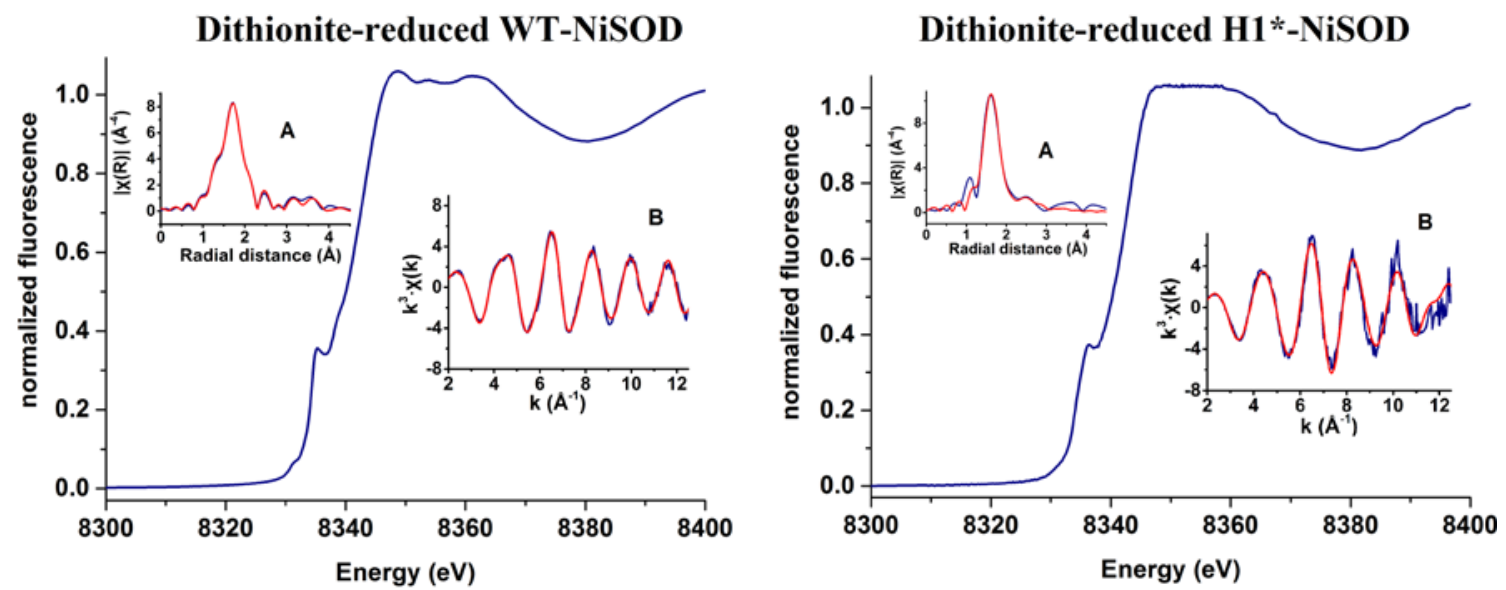

Figure 3.1. Ni K-edge XANES spectra for dithionite-reduced WT-NiSOD and dithionite reduced H1*-NiSOD. Figure insets: (A) Fourier-transformed $\left(k=2-12.5 \AA^{-1}\right)$ EXAFS (blue) and fit (red). (B) $k^{3}$-weighted EXAFS data (blue) and fit (red). (Reprinted with permission from reference 9. Copyright (2015) American Chemical Society.) 
Table 3.1. H1*-NiSOD first- and second-coordination sphere EXAFS fit results showing $\mathrm{Ni}-\mathrm{N},-\mathrm{S}$ and $-\mathrm{C}$ distances, $\mathrm{r}$; threshold energy shift, $\mathrm{E}_{0}$; Debye-Waller factor, $\sigma^{2}$; and statistical parameters. (Reprinted with permission from reference 9. Copyright (2015) American Chemical Society.)

\begin{tabular}{|c|c|c|c|c|c|c|}
\hline Shells & $\mathrm{r}(\AA \grave{)})$ & $\mathrm{E}_{0}(\mathrm{eV})$ & $\sigma^{2}\left(\mathrm{x} 10^{-3} \dot{\AA}^{-2}\right)$ & $\chi^{2}$ & $\chi_{v}^{2}$ & $\% \mathrm{R}$ \\
\hline $2 \mathrm{~N}$ & $1.970(7)$ & \multirow{5}{*}{-1.94} & $0.2(0.9)$ & \multirow{5}{*}{312.07} & \multirow{5}{*}{33.09} & \multirow{5}{*}{0.79} \\
\hline $2 \mathrm{~S}$ & $2.17(2)$ & & $7(1)$ & & & \\
\hline $1 \mathrm{C}$ & $2.43(3)$ & & $1(1)$ & & & \\
\hline $1 \mathrm{C}$ & 2.69(3) & & $1(1)$ & & & \\
\hline $2 \mathrm{C}$ & $2.90(2)$ & & $1(1)$ & & & \\
\hline
\end{tabular}

Table 3.2. WT-NiSOD first- and second-coordination sphere EXAFS fit results showing $\mathrm{Ni}-\mathrm{N}$, -S and -C distances, $\mathrm{r}$; threshold energy shift, $\mathrm{E}_{0}$; Debye-Waller factor, $\sigma^{2}$; and statistical parameters.

\begin{tabular}{|c|c|c|c|c|c|c|}
\hline Shells & $\mathrm{r}(\AA)$ & $\mathrm{E}_{0}(\mathrm{eV})$ & $\sigma^{2}\left(\mathrm{x} 10^{-3} \dot{\AA}^{-2}\right)$ & $\chi^{2}$ & $\chi_{v}^{2}$ & $\% \mathrm{R}$ \\
\hline $1 \mathrm{~N}$ & $1.88(1)$ & \multirow{5}{*}{-2.81} & $2(1)$ & \multirow{5}{*}{1348.60} & \multirow{5}{*}{198.39} & \multirow{5}{*}{0.32} \\
\hline $1 \mathrm{~N}$ & $2.09(2)$ & & $2(1)$ & & & \\
\hline $2 \mathrm{~S}$ & $2.157(4)$ & & $3(1)$ & & & \\
\hline $1 \mathrm{C}$ & $2.61(6)$ & & $11(4)$ & & & \\
\hline $3 C$ & $2.87(3)$ & & $11(4)$ & & & \\
\hline
\end{tabular}

\subsubsection{UV-Vis Spectroscopy}

UV-Vis absorption spectra of the H1*-NiSOD and semisynthetic WT-NiSOD are compared to spectra obtained for recombinant WT-NiSOD (Figure 3.2). The semisynthetic WT-NiSOD spectrum closely matches that of the recombinant WT-NiSOD and features the transition near $380 \mathrm{~nm}$ that has been assigned to CysS $\rightarrow \mathrm{Ni}(\mathrm{III})$ ligandto-metal charge transfer (LMCT) ${ }^{10}$ This LMCT transition is absent in the spectrum for H1*-NiSOD, which resembles the spectrum obtained for reduced recombinant WTNiSOD, consistent with the sample being mostly reduced, i.e., Ni(II). Spin integration of the EPR spectra obtained on an as-isolated sample of $\mathrm{H} 1{ }^{*}$-NiSOD (section 3.3.3) accounts for $\sim 11 \%$ of the nickel in the sample. Thus, the resting sample in air contains 
both $\mathrm{Ni}(\mathrm{II})$ and $\mathrm{Ni}(\mathrm{III})$ centers, but at a lower $\mathrm{Ni}(\mathrm{III}) / \mathrm{Ni}(\mathrm{II})$ ratio than the recombinant WT enzyme where $50 \%$ of the $\mathrm{Ni}$ in the aerobic resting enzyme is $\mathrm{Ni}(\mathrm{III}){ }^{3}$

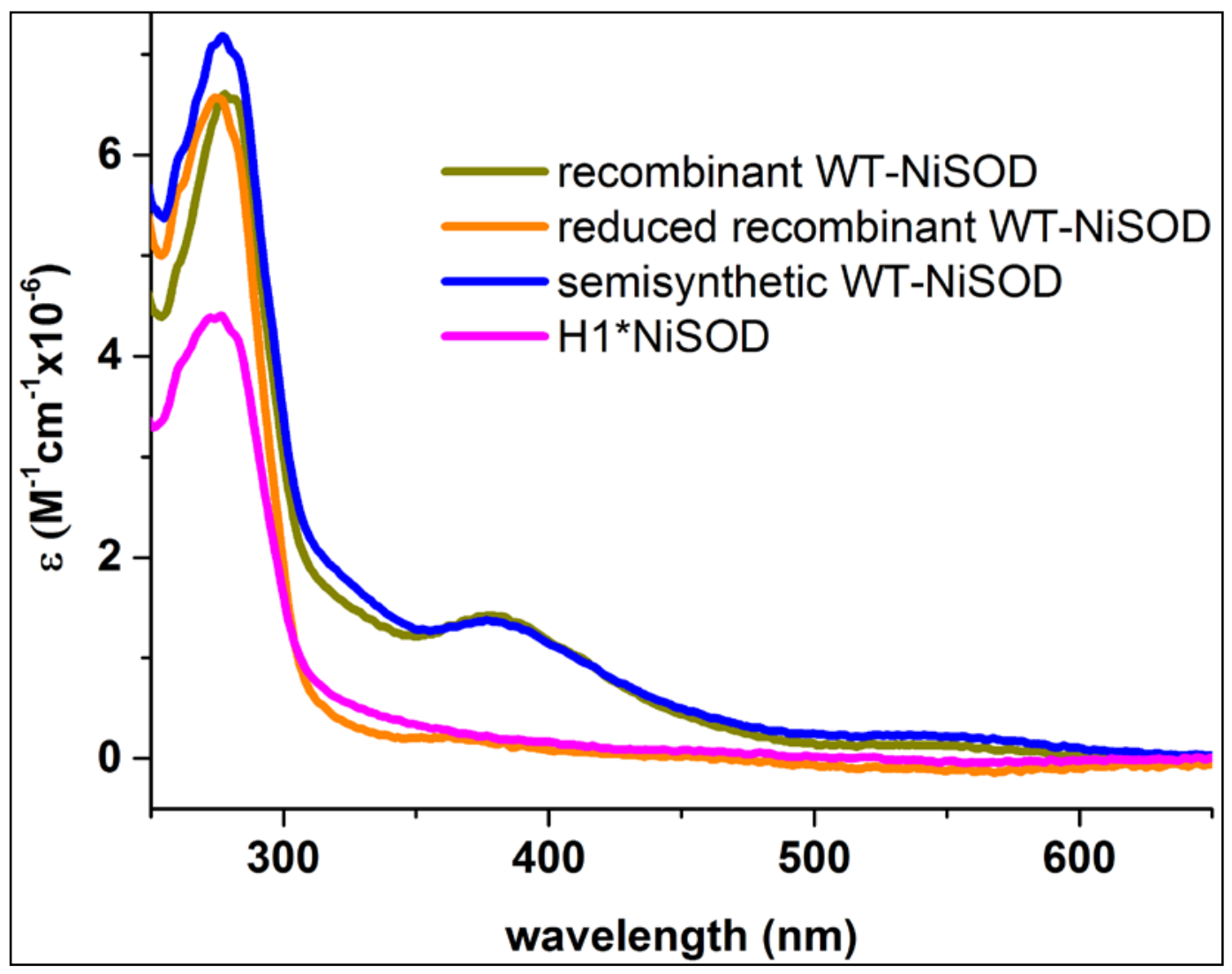

Figure 3.2. UV-Vis absorption spectra of the NiSOD variants. (Adapted with permission from reference 9. Copyright (2015) American Chemical Society.)

\subsubsection{Electron Paramagnetic Resonance Spectroscopy}

The EPR for H1*-NiSOD is consistent with a low spin $\mathrm{d}_{\mathrm{z}}{ }^{2}$ ground state $\mathrm{Ni}(\mathrm{III})$ species in a five-coordinate pyramidal geometry. The signal has $g_{x}=2.27, g_{y}=2.22$, and $\mathrm{g}_{\mathrm{z}}=2.02$, with hyperfine attributed to the apical His1 imidazole N-donor ligand resolved on $\mathrm{g}_{\mathrm{z}}, \mathrm{A}_{\mathrm{zz}}=24.2 \mathrm{G}$ (Figure 3.3). This signal is more axial compared to the rhombic spectrum observed for recombinant WT-NiSOD and semisynthetic WT-NiSOD (g-values $\left.=2.30,2.23,2.01 ; \mathrm{A}_{\mathrm{zz}}=24.9 \mathrm{G}\right) .^{3}$ 


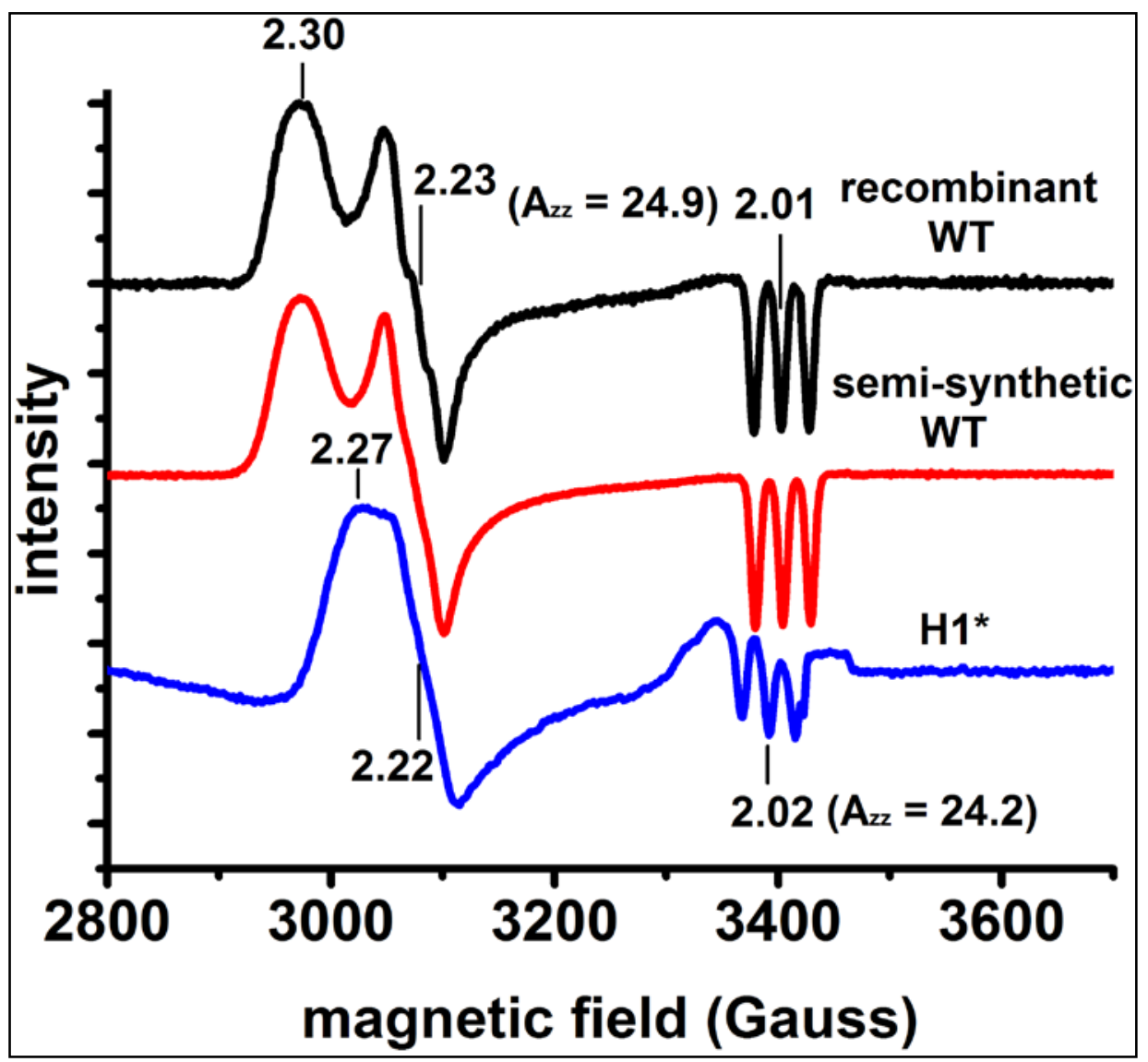

Figure 3.3. EPR spectra of recombinant WT-NiSOD, semisynthetic WT-NiSOD and H1*-NiSOD. (Adapted with permission from reference 9. Copyright (2015) American Chemical Society.)

\subsubsection{Redox Catalysis}

In contrast to the relatively small structural and electronic perturbations, the effect of substitution of the backbone amidate ligand by a secondary amine on redox catalysis is dramatic. Using pulse-radiolytically generated superoxide, the catalytic rate constant determined by monitoring the disappearance of the superoxide radical at $260 \mathrm{~nm}$ was only $\sim 1 \%$ of that observed for the recombinant WT-NiSOD. The semisynthetic WTNiSOD has a catalytic rate constant $k_{\text {cat }}=9.4 \pm 1.6 \times 10^{8} \mathrm{M}^{-1} \mathrm{~s}^{-1}$ at $\mathrm{pH}=7.5$ and a $\mathrm{pH}$ dependence that is experimentally indistinguishable from the catalytic rate constant 
observed for recombinant WT-NiSOD (Figure 3.4). ${ }^{3,11}$ In contrast, H1*-NiSOD has a catalytic rate constant $k_{\text {cat }}=5.6 \pm 0.5 \times 10^{6} \mathrm{M}^{-1} \mathrm{~s}^{-1}$ at $\mathrm{pH}=7.5$. Nonetheless, this residual activity is due to enzyme catalysis, and not the uncatalyzed bimolecular disproportionation reaction, since doubling the concentration of H1*-NiSOD doubled the rate of reaction (Appendix, Table A.1).

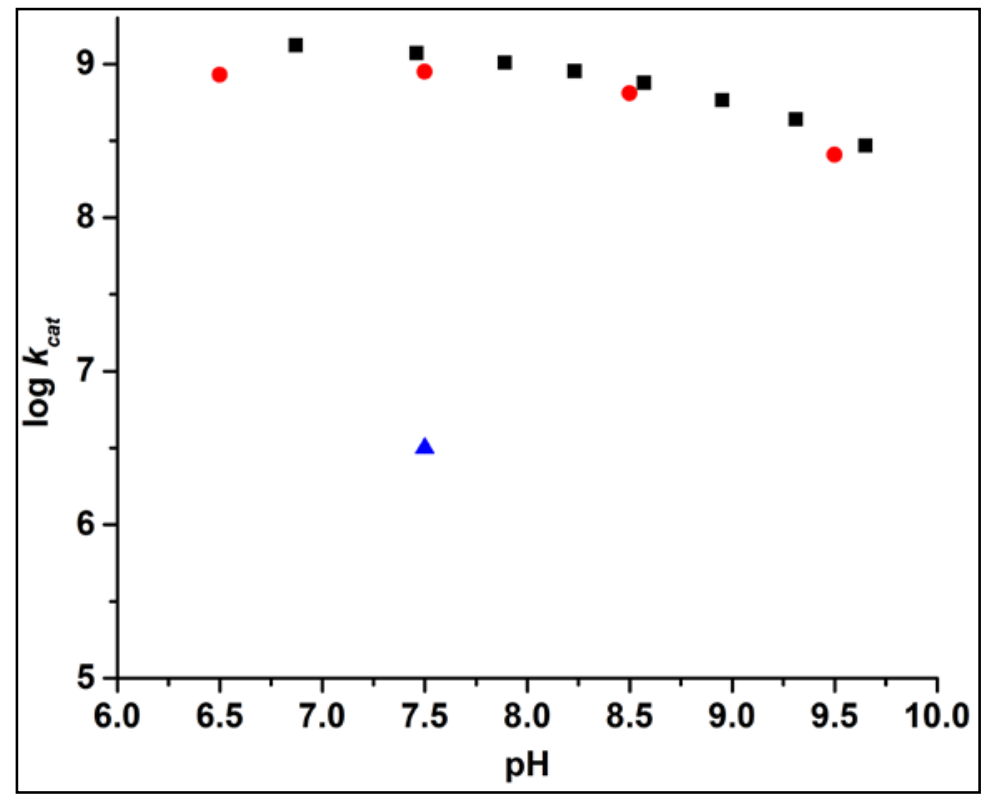

Figure 3.4. Catalytic activity $\mathrm{pH}$ dependence of recombinant WT-NiSOD (black square) ${ }^{11}$ compared with that of semi-synthetic WT-NiSOD (red circle). The catalytic activity of $\mathrm{H} 1 *-\mathrm{NiSOD}$ at $\mathrm{pH}=7.50$ is shown as a blue triangle. (Reprinted with permission from reference 9. Copyright (2015) American Chemical Society.)

\subsection{Discussion}

The Ni-dependent superoxide dismutases are a large class of superoxide dismutases that are encoded by the $\operatorname{sodN}$ gene. The $\operatorname{sod} N$ gene encodes a highly conserved (HCXXPCXXY) N-terminal "nickel hook” motif that binds Ni using the Nterminal amine and the side chain imidazole of His1, the amide $\mathrm{N}$ atom and side chain thiolate of Cys2, and the side chain of Cys6 (Figure 3.5). The N-terminal location of the 
binding site made synthesis of model peptides an approach that has been extensively exploited for studying the NiSOD active site, ${ }^{12-15}$ and the role of the Cys6 residue as the only ligand not derived from His1 or Cys2 makes semisynthesis of the protein employing NCL very attractive, particularly for a study modifying the backbone amidate ligand, for which no point mutation is possible. Using the synthetic strategy detailed in Chapter 2, histidinal was incorporated into a synthetic pentapeptide in order to produce a variant nickel hook motif, where the amidate ligand of the nickel center in WT-NiSOD was altered to a secondary amine. NCL was then employed to ligate the peptide to the remainder of the enzyme that was produced recombinantly and featured an N-terminal Cys residue.

Taken together, the spectroscopic characterization of H1*- NiSOD suggests that the nickel site in the variant is structurally very similar to those in WT-NiSOD. The $\mathrm{Ni}(\mathrm{II})$ sites are four coordinate and planar with a $\mathrm{N}_{2} \mathrm{~S}_{2}$ ligand donor-atom set, and the $\mathrm{Ni}(\mathrm{III})$ sites are five coordinate and pyramidal with the addition of an apical imidazole ligand from His1. Even the electronic structure of the site seems little perturbed in the H1*-NiSOD variant. The EPR spectrum of H1*-NiSOD $\left(g_{x}=2.27, g_{y}=2.22\right.$ and $g_{z}=$ 2.02, $A_{z z}=24.2$ G, Figure 3.3) is consistent with a low-spin $d^{7}$ electronic structure with the unpaired electron residing in a $\mathrm{d}_{\mathrm{z}}{ }^{2}$ orbital, similar to WT-NiSOD, but has a more axial signal than the rhombic signal observed for WT-enzyme. This arises mostly from a shift of $g_{x}$ from 2.30 to 2.27 in the variant. This can be rationalized in terms of the interaction of the $\mathrm{N}$-donors with $\pi$-symmetry orbitals on the $\mathrm{Ni(III)}$ center. An amidate $\mathrm{N}$-donor is expected to raise the energy of a $\pi$-symmetry $\mathrm{Ni} 3 \mathrm{~d}$ orbital through a filled $\pi-\pi$ interaction that is not present for an amine N-donor (Figure 3.5). ${ }^{10}$ Thus, asymmetric 
amidate-amine ligation would affect interactions with $d_{x z}$ and $d_{y z}$ differently, and is reflected in a rhombic EPR signal.

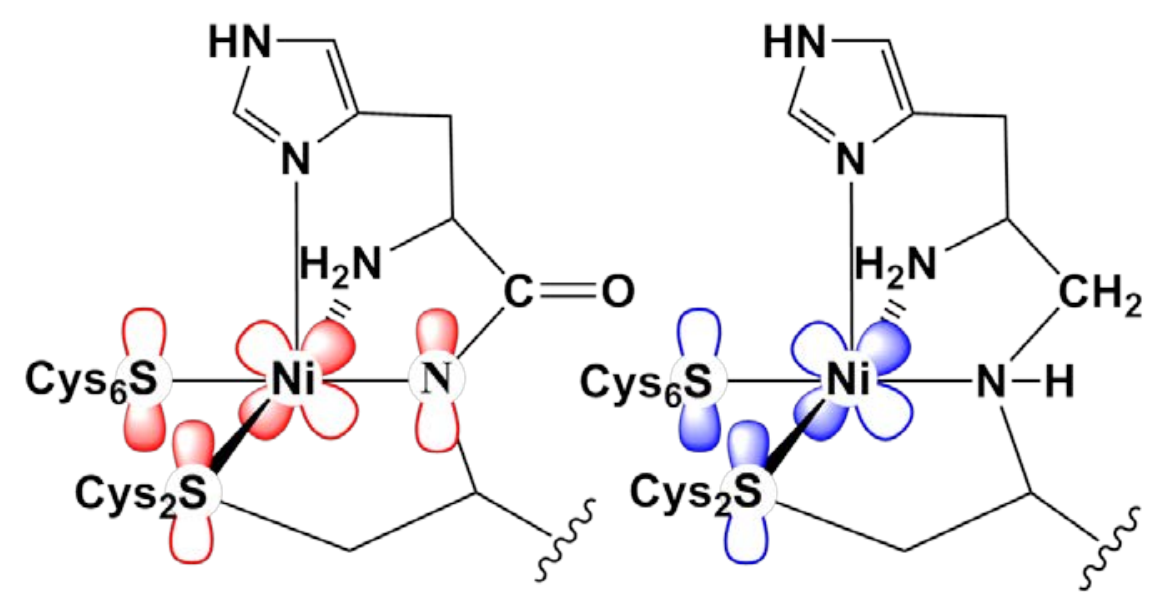

Figure 3.5. NiSOD active site diagrams illustrating the different interactions between the $\mathrm{N}$-donor ligands and a Ni $\pi$-symmetry $3 \mathrm{~d}$ orbital in WT-NiSOD with a Cys2 amidate ligand (left), and in $\mathrm{H} 1{ }^{*}$-NiSOD with a Cys2 $2^{\circ}$ amine (right). (Reprinted with permission from reference 9. Copyright (2015) American Chemical Society.)

Despite the minor structural and electronic perturbations, the alteration of the Cys2 amidate ligand to a secondary amine in $\mathrm{H} 1 *$-NiSOD has a dramatic effect on the redox catalytic properties of the active site. Alteration of the amidate ligand found in WT-NiSOD to a secondary amine apparently results in raising the redox potential of the nickel site to a value that is less accessible to air oxidation, resulting in lower amounts of $\mathrm{Ni}(\mathrm{III})$ in as-isolated samples of $\mathrm{H} 1{ }^{*}$-NiSOD $(\sim 11 \%)$ relative to recombinant WTNiSOD (50\%) and is accompanied by lower catalytic activity. The higher redox potential for $\mathrm{H} 1 *$-NiSOD would be expected to greatly decrease the catalytic activity, in line with the observed activity of $1 \%$ of WT-NiSOD. In addition, the trend for increased redox potentials in amine complexes relative to complexes with amidate ligands has been noted. ${ }^{16,17}$ The increased redox potential makes Ni(III) harder to access and thus inhibits 
the reduction of $\mathrm{O}_{2}{ }^{-}$to $\mathrm{H}_{2} \mathrm{O}_{2}$. Thus, the single amidate ligand present in the WT-NiSOD plays a critical role in the redox tuning of the catalytic site.

\subsection{Future Direction}

The most important contribution from this dissertation is the synthesis of $\mathrm{H} 1{ }^{*}$ NiSOD, where the amidate ligand in WT-NiSOD was converted to amine. From this amide $\rightarrow$ amine modification, we learned that the amidate ligation present in WT-NiSOD is crucial in tuning the redox potential of the nickel active site. This work will provide foundation for future studies to characterize the molecular and electronic structural perturbation arising from this modification. We also hope to learn about the spin distribution of oxidized $\mathrm{H} 1{ }^{*}$-NiSOD and compare it to the spin distribution of oxidized WT-NiSOD and validate the prior DFT calculation which suggest that oxidation of mixed amine/amide complexes are Ni-centered whereas bisamine complexes are S-centered.

A crystal structure of $\mathrm{H} 1{ }^{*}-\mathrm{NiSOD}$ will be obtained to establish the minor structural perturbations caused by the amide $\rightarrow$ amine modification while MCD and DFT calculation of the nickel active site will be done to provide a detailed picture of the electronic structure of the oxidized H1*-NiSOD. DFT calculation can be used to determine the spin distribution among the $\mathrm{Ni}$ ion and the ligands and ENDOR spectroscopy will be done to experimentally validate the DFT prediction. Since the naturally occurring sulfur and nickel isotopes are NMR-silent, for ENDOR experiments

${ }^{33} \mathrm{~S}$ and ${ }^{61} \mathrm{Ni}$ will be used. In case a ${ }^{14} \mathrm{~N}$ Larmor frequency is detected, the $\mathrm{N}$-donor ligands can be sequentially labeled with ${ }^{15} \mathrm{~N}$ to pinpoint the origin of that frequency. Solvent exchangeable protons hyperfine-coupled to a nucleus of interest can be labeled 
with ${ }^{2} \mathrm{H}$ by $\mathrm{H} / \mathrm{D}$ exchange. Overall these future studies will confirm what has already been established in $\mathrm{NiN}_{2} \mathrm{~S}_{2}$ complexes (i.e., the presence of an amidate ligation tunes the redox potential of the complex to be Ni-centered) in enzymatic system.

\subsection{References}

1. Leitch, S.; Bradley, M. J.; Rowe, J. L.; Chivers, P. T.; Maroney, M. J. Nickel-specific response in the transcriptional regulator, Escherichia coli NikR. J. Am. Chem. Soc. 2007, 129, 5085-5095.

2. Martin-Diaconescu, V.; Bellucci, M.; Musiani, F.; Ciurli, S.; Maroney, M. J. Unraveling the Helicobacter pylori UreG zinc binding site using X-ray absorption spectroscopy (XAS) and structural modeling. JBIC Journal of Biological Inorganic Chemistry 2012, 17, 353-361.

3. Herbst, R. W.; Guce, A.; Bryngelson, P. A.; Higgins, K. A.; Ryan, K. C.; Cabelli, D. E.; Garman, S. C.; Maroney, M. J. Role of Conserved Tyrosine Residues in NiSOD Catalysis: A Case of Convergent Evolution†. Biochemistry (N. Y. ) 2009, 48, 3354-3369.

4. Choudhury, S. B.; Lee, J.; Davidson, G.; Yim, Y.; Bose, K.; Sharma, M. L.; Kang, S.; Cabelli, D. E.; Maroney, M. J. Examination of the nickel site structure and reaction mechanism in Streptomyces seoulensis superoxide dismutase. Biochemistry (N. Y. ) 1999, 38, 3744-3752.

5. Colpas, G. J.; Maroney, M. J.; Bagyinka, C.; Kumar, M.; Willis, W. S.; Suib, S. L.; Mascharak, P. K.; Baidya, N. X-ray spectroscopic studies of nickel complexes, with application to the structure of nickel sites in hydrogenases. Inorg. Chem. 1991, 30, 920928.

6. Smee, J. J.; Miller, M. L.; Grapperhaus, C. A.; Reibenspies, J. H.; Darensbourg, M. Y. Subtle bite-angle influences on N2S2Ni complexes. Inorg. Chem. 2001, 40, 3601-3605.

7. Grapperhaus, C. A.; Mullins, C. S.; Mashuta, M. S. Structural comparison of alkylated derivatives of (bmmp-dmed) Ni and (bmmp-dmed) Zn. Inorg. Chim. Acta 2005, 358, 623-632.

8. Green, K. N.; Brothers, S. M.; Jenkins, R. M.; Carson, C. E.; Grapperhaus, C. A.; Darensbourg, M. Y. An experimental and computational study of sulfur-modified nucleophilicity in a dianionic NiN2S2 complex. Inorg. Chem. 2007, 46, 7536-7544.

9. Campeciño, J. O.; Dudycz, L. W.; Tumelty, D.; Berg, V.; Cabelli, D. E.; Maroney, M. J. A Semisynthetic Strategy Leads to Alteration of the Backbone Amidate Ligand in the NiSOD Active Site. J. Am. Chem. Soc. 2015, 137, 9044-9052. 
10. Fiedler, A. T.; Bryngelson, P. A.; Maroney, M. J.; Brunold, T. C. Spectroscopic and computational studies of Ni superoxide dismutase: electronic structure contributions to enzymatic function. J. Am. Chem. Soc. 2005, 127, 5449-5462.

11. Ryan, K. C.; Johnson, O. E.; Cabelli, D. E.; Brunold, T. C.; Maroney, M. J. Nickel superoxide dismutase: structural and functional roles of Cys2 and Cys6. JBIC Journal of Biological Inorganic Chemistry 2010, 15, 795-807.

12. Shearer, J.; Long, L. M. A nickel superoxide dismutase maquette that reproduces the spectroscopic and functional properties of the metalloenzyme. Inorg. Chem. 2006, 45, 2358-2360.

13. Neupane, K. P.; Shearer, J. The influence of amine/amide versus bisamide coordination in nickel superoxide dismutase. Inorg. Chem. 2006, 45, 10552-10566.

14. Shearer, J.; Neupane, K. P.; Callan, P. E. Metallopeptide based mimics with substituted histidines approximate a key hydrogen bonding network in the metalloenzyme nickel superoxide dismutase. Inorg. Chem. 2009, 48, 10560-10571.

15. Neupane, K. P.; Gearty, K.; Francis, A.; Shearer, J. Probing variable axial ligation in nickel superoxide dismutase utilizing metallopeptide-based models: insight into the superoxide disproportionation mechanism. J. Am. Chem. Soc. 2007, 129, 14605-14618.

16. Mathrubootham, V.; Thomas, J.; Staples, R.; McCraken, J.; Shearer, J.; Hegg, E. L. Bisamidate and Mixed Amine/Amidate NiN2S2 Complexes as Models for NickelContaining Acetyl Coenzyme A Synthase and Superoxide Dismutase: An Experimental and Computational Study. Inorg. Chem. 2010, 49, 5393-5406.

17. Shearer, J.; Zhao, N. [Me4N](NiII (BEAAM)): A Synthetic Model for Nickel Superoxide Dismutase That Contains $\mathrm{Ni}$ in a Mixed Amine/Amide Coordination Environment. Inorg. Chem. 2006, 45, 9637-9639. 


\section{APPENDIX}

\section{SUPPORTING INFORMATION}

Table A.1. Rates of reactions and [SOD] dependence for H1*-NiSOD.

\begin{tabular}{|c|c|c|c|}
\hline \multicolumn{4}{|c|}{ H1*-NiSOD $^{*}$} \\
\hline $\begin{array}{c}\mathrm{O}_{2}{ }^{-} \text {total dose } \\
(\mu \mathrm{M})\end{array}$ & $\begin{array}{c}\text { rate reaction } \\
(\mathrm{M} / \mathrm{s})\end{array}$ & $\begin{array}{c}\mathrm{O}_{2}{ }^{-} \text {total dose } \\
(\mu \mathrm{M})\end{array}$ & $\begin{array}{c}\text { rate reaction } \\
(\mathrm{M} / \mathrm{s})\end{array}$ \\
\hline 2.27 & 11.80 & 1.46 & 23.00 \\
\hline 2.71 & 11.10 & 3.57 & 20.40 \\
\hline 4.39 & 12.70 & 5.01 & 19.90 \\
\hline 5.09 & 12.00 & 8.64 & 18.90 \\
\hline 5.78 & 11.70 & 10.20 & 22.40 \\
\hline 6.88 & 9.03 & 12.60 & 19.80 \\
\hline 7.59 & 10.80 & 14.50 & 18.30 \\
\hline 8.80 & 10.20 & 16.20 & 20.50 \\
\hline 11.00 & 12.30 & 18.00 & 18.80 \\
\hline
\end{tabular}

Table A.2. $\mathrm{pH}$ dependent activity assay of semisynthetic WT-NiSOD at $2 \mu \mathrm{M}$ concentration.

\begin{tabular}{|c|c|c|c|c|c|c|c|}
\hline \multicolumn{2}{|c|}{$\mathrm{pH} 6.50$} & \multicolumn{2}{c|}{$\mathrm{pH} 7.50$} & \multicolumn{2}{c|}{$\mathrm{pH} 8.50$} & \multicolumn{2}{c|}{$\mathrm{pH} 9.50$} \\
\hline $\begin{array}{c}\mathrm{O}_{2}{ }^{-} \text {total } \\
\text { dose } \\
(\mu \mathrm{M})\end{array}$ & $\begin{array}{c}\text { rate } \\
\text { reaction } \\
(\mathrm{M} / \mathrm{s})\end{array}$ & $\begin{array}{c}\mathrm{O}_{2}^{-} \text {total } \\
\text { dose } \\
(\mu \mathrm{M})\end{array}$ & $\begin{array}{c}\text { rate } \\
\text { reaction } \\
(\mathrm{M} / \mathrm{s})\end{array}$ & $\begin{array}{c}\mathrm{O}_{2}{ }^{-} \text {total } \\
\text { dose } \\
(\mu \mathrm{M})\end{array}$ & $\begin{array}{c}\text { rate } \\
\text { reaction } \\
(\mathrm{M} / \mathrm{s})\end{array}$ & $\begin{array}{c}\mathrm{O}_{2}{ }^{-} \text {total } \\
\text { dose } \\
(\mu \mathrm{M})\end{array}$ & $\begin{array}{c}\text { rate } \\
\text { reaction } \\
(\mathrm{M} / \mathrm{s})\end{array}$ \\
\hline 1.29 & 1500 & 1.34 & 2060 & 1.38 & 1200 & 0.92 & 370 \\
\hline 1.94 & 1620 & 1.79 & 2210 & 1.83 & 1450 & 1.36 & 473 \\
\hline 3.03 & 1740 & 2.50 & 1800 & 2.27 & 1470 & 2.02 & 454 \\
\hline 4.56 & 1710 & 4.96 & 1800 & 2.71 & 1420 & 3.61 & 484 \\
\hline 6.52 & 1700 & 7.11 & 1610 & 3.39 & 1340 & 5.65 & 485 \\
\hline 8.04 & 1720 & 10.3 & 1540 & 4.07 & 1210 & 6.31 & 702 \\
\hline 9.13 & 1670 & 11.0 & 2170 & 5.23 & 1210 & 6.97 & 576 \\
\hline 9.78 & 1730 & N/A & N/A & 6.86 & 1200 & 7.64 & 640 \\
\hline N/A & N/A & N/A & N/A & 7.53 & 1330 & N/A & N/A \\
\hline
\end{tabular}


Table A.3. EXAFS first shell fit results showing Ni-N, -S and -C distances, r; threshold energy shift, $\mathrm{E}_{0}$; Debye-Waller factor, $\sigma^{2}$; and statistical parameters. Fit highlighted in yellow is the best fit.

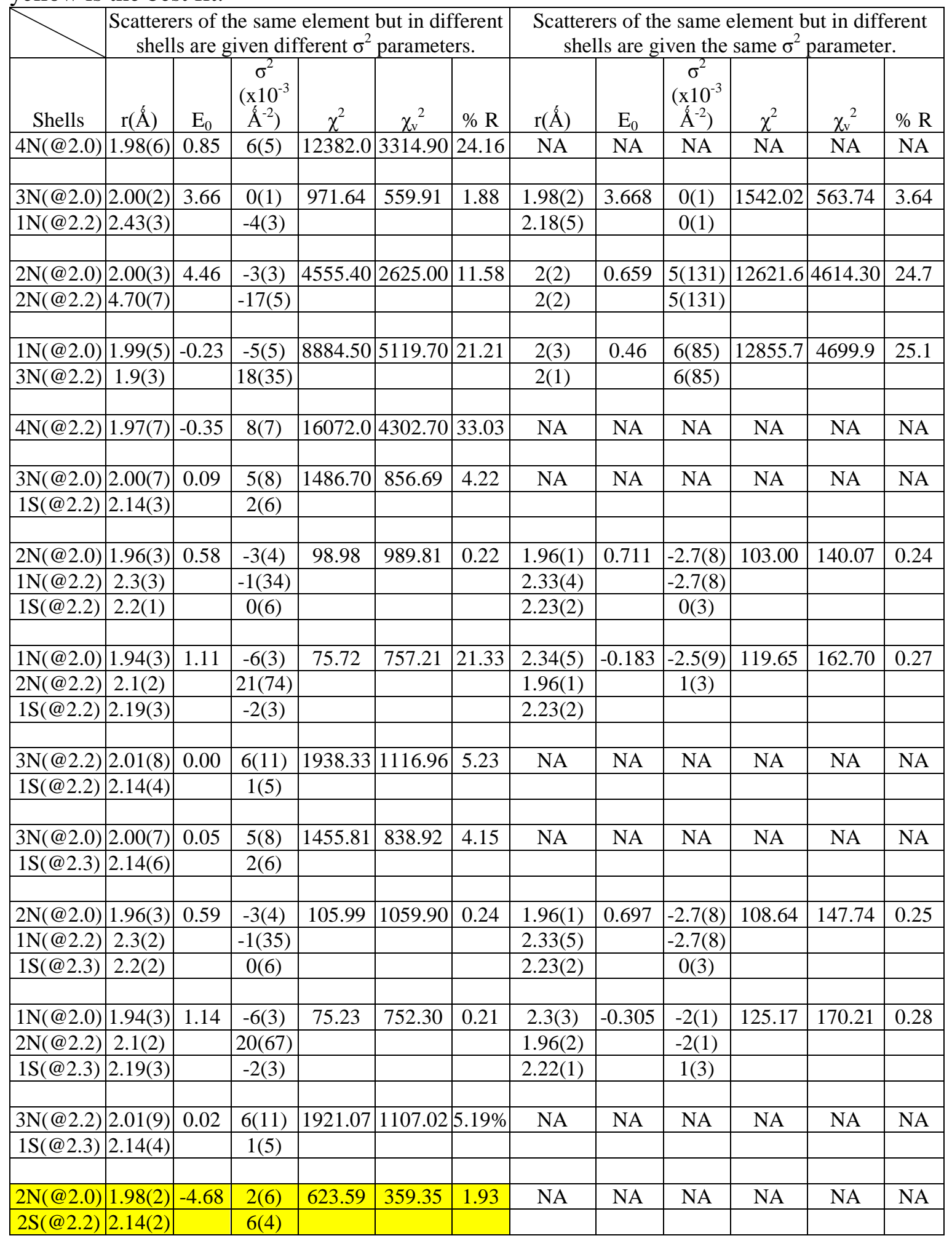




\begin{tabular}{|c|c|c|c|c|c|c|c|c|c|c|c|c|}
\hline 1N(@2.0) & $193(8)$ & |-311 & -6(21) & \begin{tabular}{|l|l|}
31748 \\
\end{tabular} & 317477 & 063 & $193(2)$ & 3091 & $-6(4)$ & 31765 & 42107 & 061 \\
\hline 1N(@2.2) & $2.1(2)$ & & $-6(26)$ & & & & $2.07(4)$ & & $-6(4)$ & & & \\
\hline 2S(@2.2) & $2.07(8)$ & & $6(28)$ & & & & $2.13(2)$ & & $7(7)$ & & & \\
\hline & & & & & & & & & & & & \\
\hline 2N(@2.2) & $1.99(2)$ & -4.72 & $3(6)$ & 645.43 & 371.93 & 2.04 & NA & NA & NA & NA & NA & NA \\
\hline 2S(@2.2) & $2.14(2)$ & & $6(5)$ & & & & & & & & & \\
\hline & & & & & & & & & & & & \\
\hline 2N(@2.0) & $1.9(1)$ & \begin{tabular}{|l|}
-5.39 \\
\end{tabular} & $-4(12)$ & \begin{tabular}{|l|}
183.52 \\
\end{tabular} & 1835.17 & 0.34 & $1.8(2)$ & -11.07 & $41(18)$ & 120.10 & 163.33 & 0.28 \\
\hline 1S(@2.2) & $2.0(2)$ & & $5(66)$ & & & & $2.19(2)$ & & -4.6(9) & & & \\
\hline 1S(@2.3) & $2.19(7)$ & & $-3(11)$ & & & & $2.05(2)$ & & & & & \\
\hline & & & & & & & & & & & & \\
\hline 2N(@2.2) & $1.94(9)$ & \begin{tabular}{|l|}
-5.64 \\
\end{tabular} & $-4(11)$ & 156.00 & 1559.96 & 0.32 & $1.8(3)$ & -11.5 & 50(23) & 130.05 & 176.86 & 0.28 \\
\hline 1S(@2.2) & $2.0(1)$ & & $5(49)$ & & & & $2.06(2)$ & & $-4(1)$ & & & \\
\hline 1S(@2.3) & $2.19(5)$ & & $-3(10)$ & & & & $2.19(2)$ & & $-4(1)$ & & & \\
\hline & & & & & & & & & & & & \\
\hline 2N(@2.0) & $1.98(2)$ & -4.76 & 2(5) & 635.54 & 366.23 & 1.91 & NA & NA & NA & NA & NA & NA \\
\hline 2S(@2.3) & $2.14(2)$ & & $6(4)$ & & & & & & & & & \\
\hline & & & & & & & & & & & & \\
\hline 1N(@2.0) & $1.9(2)$ & -9.99 & $-1(11)$ & 405.24 & 4052.42 & 1.15 & $1.93(2)$ & -3.245 & $-6(4)$ & \begin{tabular}{|l|}
351.48 \\
\end{tabular} & 477.98 & 0.70 \\
\hline $1 \mathrm{~N}(@ 2.2)$ & $1.6(4)$ & & $-1(11)$ & & & & $2.07(4)$ & & $-6(4)$ & & & \\
\hline 2S(@2.3) & $2.14(4)$ & & $3(7)$ & & & & $2.14(2)$ & & $7(7)$ & & & \\
\hline & & & & & & & & & & & & \\
\hline 2N(@2.2) & $1.99(2)$ & -4.75 & 2(6) & 666.13 & 383.86 & 2.05 & NA & NA & NA & NA & NA & NA \\
\hline 2S(@2.3) & $2.13(2)$ & & $6(5)$ & & & & & & & & & \\
\hline $1 \mathrm{~N}(@ 2.0)$ & N/A & N/A & N/A & N/A & N/A & N/A & $1.93(7)$ & -3.111 & $-6(12)$ & \begin{tabular}{|l|}
355.21 \\
\end{tabular} & 3552.13 & 0.71 \\
\hline 1N(@2.2) & N/A & N/A & N/A & N/A & N/A & N/A & $2.1(1)$ & & $-6(12)$ & & & \\
\hline 1S(@2.2) & N/A & N/A & N/A & N/A & N/A & N/A & $2(18)$ & & 6(810) & & & \\
\hline 1S(@2.3) & N/A & N/A & N/A & N/A & N/A & N/A & $2(18)$ & & 6(810) & & & \\
\hline 4S(@2.2) & $2.11(2)$ & -13.41 & $9(2)$ & 2273.87 & 608.74 & 5.24 & NA & NA & NA & NA & NA & NA \\
\hline 3S(@2.2) & $2.12(2)$ & -11.26 & $5(1)$ & \begin{tabular}{|l|}
714.26 \\
\end{tabular} & 411.59 & 2.49 & $2.13(3)$ & $\mid-13.97$ & $7(10)$ & 2241.21 & 819.35 & 5.25 \\
\hline 1S(@2.3) & $2.4(2)$ & & $32(61)$ & & & & $2.0(2)$ & & $7(10)$ & & & \\
\hline & & & & & & & & & & & & \\
\hline 2S(@2.2) & 2.1(4) & -12.81 & 28(19) & $\mid 1139.11$ & \begin{tabular}{|l|}
656.41 \\
\end{tabular} & 3.77 & $2(2)$ & \begin{tabular}{|l|}
-13.63 \\
\end{tabular} & $8(93)$ & 2250.26 & 822.66 & 5.19 \\
\hline 2S(@2.3) & $2.11(2)$ & & $3(2)$ & & & & $2(2)$ & & $8(93)$ & & & \\
\hline $1 \mathrm{~S}(\Omega 27)$ & $19(2)$ & 1408 & $27(01)$ & |69811 & | & 270 & $27(7)$ & 1267 & $8(20)$ & 226972 & 87077 & 522 \\
\hline 3S(@2.3) & $2.11(2)$ & & $5(1)$ & & & & $2.10(2)$ & & & & & \\
\hline & & & & & & & & & & & & \\
\hline 4S(@2.3) & $2.11(2)$ & -13.82 & $8(2)$ & 2538.87 & \begin{tabular}{|l|}
679.69 \\
\end{tabular} & 5.77 & NA & NA & NA & NA & NA & NA \\
\hline 3S(@2.2) & $2.12(2)$ & $\mid-9.77$ & $7(4)$ & \begin{tabular}{|l|}
687.22 \\
\end{tabular} & 396.01 & 2.09 & NA & NA & NA & NA & NA & NA \\
\hline 1N(@2.0) & $1.98(6)$ & & $1(10)$ & & & & & & & & & \\
\hline & & & & & & & & & & & & \\
\hline 2S(@2.2) & $2.18(2)$ & \begin{tabular}{|l|}
-3.88 \\
\end{tabular} & $4(1)$ & 22.65 & \begin{tabular}{|l|}
226.47 \\
\end{tabular} & 0.08 & $2.14(2)$ & $\mid-11.54$ & $-8(2)$ & \begin{tabular}{|l|}
231.56 \\
\end{tabular} & 314.90 & 0.51 \\
\hline 1S(@2.3) & $2.51(1)$ & & 11(10) & & & & $1.94(2)$ & & $-1(2)$ & & & \\
\hline 1N(@2.0) & $1.94(2)$ & & $-3(2)$ & & & & 1.91(3) & & $-1(2)$ & & & \\
\hline & & & & & & & & & & & & \\
\hline 1S(@2.2) & $1.9(1)$ & -11.42 & $2(31)$ & \begin{tabular}{|l|}
208.10 \\
\end{tabular} & 2081.01 & 0.41 & $2.2(2)$ & $\mid-9.999$ & $2(41)$ & \begin{tabular}{|l|}
655.58 \\
\end{tabular} & 891.52 & 1.83 \\
\hline 2S(@2.3) & $2.15(5)$ & & $0(8)$ & & & & 2.1(3) & & $2(41)$ & & & \\
\hline
\end{tabular}




\begin{tabular}{|c|c|c|c|c|c|c|c|c|c|c|c|c|}
\hline 1N(@2.0) & $1.91(8)$ & & $-6(12)$ & & & & $2(2)$ & & $6(506)$ & & & \\
\hline \begin{tabular}{|l|}
$3 S(@ 2.3)$ \\
\end{tabular} & $2.12(2)$ & -10.05 & $7(4)$ & 730.53 & \begin{tabular}{|l|}
420.97 \\
\end{tabular} & 2.18 & NA & NA & NA & NA & NA & NA \\
\hline \begin{tabular}{|l}
$1 \mathrm{~N}(@ 2.0)$ \\
\end{tabular} & $1.99(6)$ & & $1(10)$ & & & & & & & & & \\
\hline 3S(@2.2) & $2.12(2)$ & $\mid-10,96$ & 1(1) & 529.23 & 304.97 & 076 & NA & NA & NA & $\overline{N A}$ & NA & $\mathrm{NA}$ \\
\hline 1N(@2.2) & $2.14(2)$ & & $-6(2)$ & & & & & & & & & \\
\hline & & & & & & & & & & & & \\
\hline 2S(@2.2) & $2.15(5)$ & -11.11 & $0(8)$ & 193.85 & 1938.47 & 0.39 & $2.08(2)$ & -13.68 & $3(6)$ & 570.39 & 775.67 & 1.81 \\
\hline 1S(@2.3) & $1.9(1)$ & & $3(31)$ & & & & $2.2(1)$ & & $3(6)$ & & & \\
\hline 1N(@2.2) & $1.91(7)$ & & $-6(11)$ & & & & $1.5(2)$ & & 20(77) & & & \\
\hline & & & & & & & & & & & & \\
\hline 1S(@2.2) & $2.0(2)$ & -10.30 & $-2(48)$ & 479.64 & 4796.37 & 0.95 & $2.2(1)$ & -9.962 & $2(18)$ & 655.37 & 891.24 & 1.84 \\
\hline 2S(@2.3) & $2.2(1)$ & & $1(63)$ & & & & $2.1(2)$ & & $2(18)$ & & & \\
\hline 1N(@2.2) & $2(1)$ & & $-2(294)$ & & & & $2(1)$ & & $5(311)$ & & & \\
\hline & & 16 & $5(1)$ & & & ح & $\mathrm{N}$ & NI & 1 & NA & No & TA \\
\hline$\frac{35(\omega 2.3)}{1 \mathrm{~N}(@ 2.2)}$ & $\frac{2.11(4)}{23(1)}$ & $\mid-13.16$ & \begin{tabular}{|c|}
$5(1)$ \\
$44(48)$
\end{tabular} & 00 & 454.42 & 2.43 & NA & NA & & NA & NA & NA \\
\hline
\end{tabular}

Table A.4. XANES analysis for H1*-NiSOD.

\begin{tabular}{|c|c|c|c|c|c|c|}
\hline line shape & $\mathrm{E}_{0}(\mathrm{eV})$ & $\begin{array}{c}\text { area }\left(\mathrm{x} 10^{-}\right. \\
\mathrm{eV})\end{array}$ & sigma & $\chi^{2}$ & $\chi_{v}^{2}$ & $\% \mathrm{R}$ \\
\hline Gaussian(1s->3d) & 8331.00 & -0.07 & $1.7(3)$ & \multirow{3}{*}{0.00099} & \multirow{3}{*}{0.0000141} & \multirow{3}{*}{0.02} \\
\hline Gaussian $\left(1 \mathrm{~s}->4 p_{\mathrm{z}}\right)$ & 8335.78 & 0.37 & $1.17(3)$ & & & \\
\hline error function & 8340.00 & - & - & & & \\
\hline
\end{tabular}




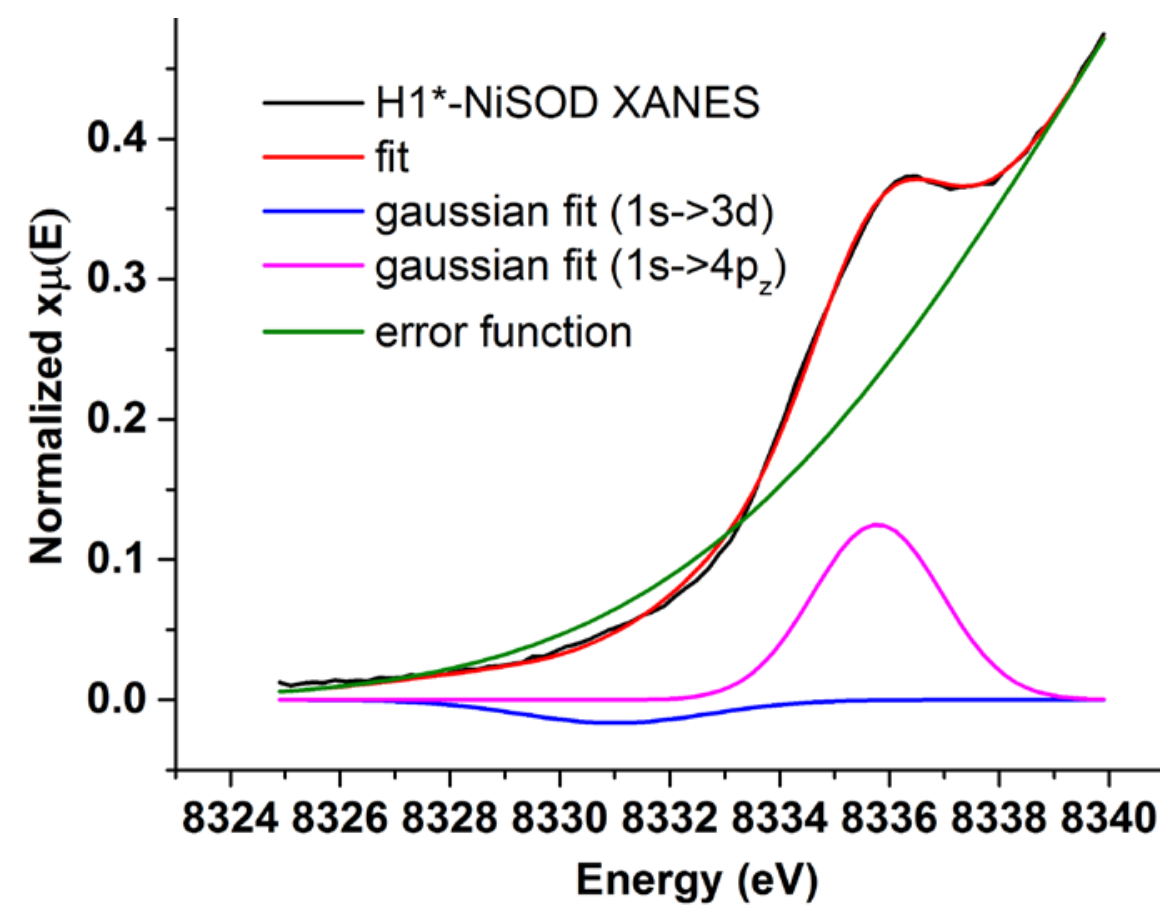

Figure A.1. XANES spectrum fitted with an error function and two gaussian functions. 


\section{BIBLIOGRAPHY}

Ahn, B.; Cha, J.; Lee, E.; Han, A.; Thompson, C. J.; Roe, J. Nur, a nickel-responsive regulator of the Fur family, regulates superoxide dismutases and nickel transport in Streptomyces coelicolor. Mol. Microbiol. 2006, 59, 1848-1858.

Allan, C. B.; Davidson, G.; Choudhury, S. B.; Gu, Z.; Bose, K.; Day, R. O.; Maroney, M. J. Protonation and alkylation of a dinuclear nickel thiolate complex. Inorg. Chem. 1998, 37, 4166-4167.

Arakawa, T.; Kawano, Y.; Kataoka, S.; Katayama, Y.; Kamiya, N.; Yohda, M.; Odaka, M. Structure of thiocyanate hydrolase: a new nitrile hydratase family protein with a novel five-coordinate cobalt (III) center. J. Mol. Biol. 2007, 366, 1497-1509.

Archibald, F. S.; Fridovich, I. Manganese and defenses against oxygen toxicity in Lactobacillus plantarum. J. Bacteriol. 1981, 145, 442-451.

Archibald, F. S.; Fridovich, I. Manganese, superoxide dismutase, and oxygen tolerance in some lactic acid bacteria. J. Bacteriol. 1981, 146, 928-936.

Baca, M.; Kent, S. B. Protein backbone engineering through total chemical synthesis: new insight into the mechanism of HIV-1 protease catalysis. Tetrahedron 2000, 56, 9503-9513.

Bain, J.; Diala, E. S.; Glabe, C. G.; Wacker, D. A.; Lyttle, M. H.; Dix, T. A.; Chamberlin, A. R. Site-specific incorporation of nonnatural residues during in vitro protein biosynthesis with semi-synthetic aminoacyl-tRNAs. Biochemistry (N. Y. ) 1991, 30, 5411-5421.

Barondeau, D. P.; Kassmann, C. J.; Bruns, C. K.; Tainer, J. A.; Getzoff, E. D. Nickel superoxide dismutase structure and mechanism. Biochemistry (N. Y. ) 2004, 43, 80388047.

Benov, L. How superoxide radical damages the cell. Protoplasma 2001, 217, 33-36.

Bhagavan, N. V. Medical biochemistry; Academic press: 2002; .

Bielski, B. H.; Cabelli, D. E.; Arudi, R. L.; Ross, A. B. Reactivity of HO2/O- 2 radicals in aqueous solution. Journal of Physical and Chemical Reference Data 1985, 14, 10411100.

Blanco-Canosa, J. B.; Dawson, P. E. An Efficient Fmoc-SPPS Approach for the Generation of Thioester Peptide Precursors for Use in Native Chemical Ligation. Angewandte Chemie International Edition 2008, 47, 6851-6855. 
Blum, J.; Fridovich, I. Inactivation of glutathione peroxidase by superoxide radical. Arch. Biochem. Biophys. 1985, 240, 500-508.

Boll, M.; Fuchs, G.; Tilley, G.; Armstrong, F. A.; Lowe, D. J. Unusual spectroscopic and electrochemical properties of the 2 [4Fe-4S] ferredoxin of Thauera aromatica. Biochemistry (N. Y. ) 2000, 39, 4929-4938.

Brawn, K.; Fridovich, I. Superoxide radical and superoxide dismutases: threat and defense; Springer: 1980; .

Bryngelson, P. A.; Arobo, S. E.; Pinkham, J. L.; Cabelli, D. E.; Maroney, M. J. Expression, Reconstitution, and Mutation of Recombinant Streptomyces c oelicolor NiSOD. J. Am. Chem. Soc. 2004, 126, 460-461.

Bryngelson, P. A.; Maroney, M. J. Nickel superoxide dismutase. Nickel and its Surprising Impact in Nature.John Wiley and Sons 2007, 417-444.

Cadenas, E.; Davies, K. J. Mitochondrial free radical generation, oxidative stress, and aging. Free Radical Biology and Medicine 2000, 29, 222-230.

Campeciño, J. O.; Dudycz, L. W.; Tumelty, D.; Berg, V.; Cabelli, D. E.; Maroney, M. J. A Semisynthetic Strategy Leads to Alteration of the Backbone Amidate Ligand in the NiSOD Active Site. J. Am. Chem. Soc. 2015, 137, 9044-9052.

Choudhury, S. B.; Lee, J.; Davidson, G.; Yim, Y.; Bose, K.; Sharma, M. L.; Kang, S.; Cabelli, D. E.; Maroney, M. J. Examination of the nickel site structure and reaction mechanism in Streptomyces seoulensis superoxide dismutase. Biochemistry (N. Y. ) 1999, 38, 3744-3752.

Colpas, G. J.; Maroney, M. J.; Bagyinka, C.; Kumar, M.; Willis, W. S.; Suib, S. L.; Mascharak, P. K.; Baidya, N. X-ray spectroscopic studies of nickel complexes, with application to the structure of nickel sites in hydrogenases. Inorg. Chem. 1991, 30, 920928.

Dawson, P. E.; Churchill, M. J.; Ghadiri, M. R.; Kent, S. B. Modulation of reactivity in native chemical ligation through the use of thiol additives. J. Am. Chem. Soc. 1997, 119, 4325-4329.

Diekert, G. B.; Graf, E. G.; Thauer, R. K. Nickel requirement for carbon monoxide dehydrogenase formation in Clostridium pasteurianum. Arch. Microbiol. 1979, 122, 117120.

Dupont, C.; Neupane, K.; Shearer, J.; Palenik, B. Diversity, function and evolution of genes coding for putative Ni-containing superoxide dismutases. Environ. Microbiol. 2008, 10, 1831-1843. 
Dupont, C. L.; Barbeau, K.; Palenik, B. Ni uptake and limitation in marine Synechococcus strains. Appl. Environ. Microbiol. 2008, 74, 23-31.

Eildal, J. N.; Hultqvist, G.; Balle, T.; Stuhr-Hansen, N.; Padrah, S.; Gianni, S.; Strømgaard, K.; Jemth, P. Probing the role of backbone hydrogen bonds in proteinpeptide interactions by amide-to-ester mutations. J. Am. Chem. Soc. 2013, 135, 1299813007.

Eitinger, T. In vivo production of active nickel superoxide dismutase from Prochlorococcus marinus MIT9313 is dependent on its cognate peptidase. J. Bacteriol. 2004, 186, 7821-7825.

Fauvet, B.; Fares, M. B.; Samuel, F.; Dikiy, I.; Tandon, A.; Eliezer, D.; Lashuel, H. A. Characterization of semisynthetic and naturally Nalpha-acetylated alpha-synuclein in vitro and in intact cells: implications for aggregation and cellular properties of alphasynuclein. J. Biol. Chem. 2012, 287, 28243-28262.

Fee, J. A. Is superoxide toxic. Dev.Biochem 1980, 11, 41-48.

Fiedler, A. T.; Bryngelson, P. A.; Maroney, M. J.; Brunold, T. C. Spectroscopic and computational studies of Ni superoxide dismutase: electronic structure contributions to enzymatic function. J. Am. Chem. Soc. 2005, 127, 5449-5462.

Fridovich, I. Superoxide radical and superoxide dismutases. Annu. Rev. Biochem. 1995, 64, 97-112.

Fridovich, I. Superoxide dismutases. Adv. Enzymol. Relat. Areas Mol. Biol. 1986, 58, 6197.

Fridovich, I. Superoxide radical: an endogenous toxicant. Annu. Rev. Pharmacol. Toxicol. 1983, 23, 239-257.

Fridovich, I. Superoxide radicals, superoxide dismutases and the aerobic lifestyle. Photochem. Photobiol. 1978, 28, 733-741.

Fridovich, I. Oxygen toxicity: a radical explanation. J. Exp. Biol. 1998, 201, 1203-1209.

Gale, E. M.; Narendrapurapu, B. S.; Simmonett, A. C.; Schaefer III, H. F.; Harrop, T. C. Exploring the effects of H-bonding in synthetic analogues of nickel superoxide dismutase (Ni-SOD): experimental and theoretical implications for protection of the $\mathrm{Ni}-\mathrm{SCys}$ bond. Inorg. Chem. 2010, 49, 7080-7096.

Genova, M. L.; Pich, M. M.; Bernacchia, A.; Bianchi, C.; Biondi, A.; Bovina, C.; Falasca, A. I.; Formiggini, G.; Castelli, G. P.; Lenaz, G. The mitochondrial production of reactive oxygen species in relation to aging and pathology. Ann. N. Y. Acad. Sci. 2004, 1011, 86-100. 
Gentle, I. E.; De Souza, D. P.; Baca, M. Direct production of proteins with N-terminal cysteine for site-specific conjugation. Bioconjug. Chem. 2004, 15, 658-663.

Goris, T.; Wait, A. F.; Saggu, M.; Fritsch, J.; Heidary, N.; Stein, M.; Zebger, I.; Lendzian, F.; Armstrong, F. A.; Friedrich, B. A unique iron-sulfur cluster is crucial for oxygen tolerance of a [NiFe]-hydrogenase. Nature chemical biology 2011, 7, 310-318.

Grapperhaus, C. A.; Darensbourg, M. Y. Oxygen capture by sulfur in nickel thiolates. Acc. Chem. Res. 1998, 31, 451-459.

Grapperhaus, C. A.; Maguire, M. J.; Tuntulani, T.; Darensbourg, M. Y. Singlet Oxygen and the Production of Sulfur Oxygenates of Nickel (II) and Palladium (II) Thiolates. Inorg. Chem. 1997, 36, 1860-1866.

Grapperhaus, C. A.; Mullins, C. S.; Mashuta, M. S. Structural comparison of alkylated derivatives of (bmmp-dmed) Ni and (bmmp-dmed) Zn. Inorg. Chim. Acta 2005, 358, 623-632.

Green, K. N.; Brothers, S. M.; Jenkins, R. M.; Carson, C. E.; Grapperhaus, C. A.; Darensbourg, M. Y. An experimental and computational study of sulfur-modified nucleophilicity in a dianionic $\mathrm{NiN}_{2} \mathrm{~S}_{2}$ complex. Inorg. Chem. 2007, 46, 7536-7544.

Guan, Y.; Hickey, M. J.; Borgstahl, G. E.; Hallewell, R. A.; Lepock, J. R.; O'Connor, D.; Hsieh, Y.; Nick, H. S.; Silverman, D. N.; Tainer, J. A. Crystal structure of Y34F mutant human mitochondrial manganese superoxide dismutase and the functional role of tyrosine 34. Biochemistry (N. Y. ) 1998, 37, 4722-4730.

Harford, C.; Sarkar, B. Amino terminal Cu (II)-and Ni (II)-binding (ATCUN) motif of proteins and peptides: metal binding, DNA cleavage, and other properties. Acc. Chem. Res. 1997, 30, 123-130.

Harrop, T. C.; Mascharak, P. K. Fe (III) and Co (III) centers with carboxamido nitrogen and modified sulfur coordination: lessons learned from nitrile hydratase. Acc. Chem. Res. 2004, 37, 253-260.

Hassan, H. Cytotoxicity of oxyradicals and the evolution of superoxide dismutases. LUNG BIOLOGY IN HEALTH AND DISEASE 1997, 105, 27-48.

Hayaishi, O. Molecular mechanisms of oxygen activation; Elsevier: 2012; .

Herbst, R. W.; Guce, A.; Bryngelson, P. A.; Higgins, K. A.; Ryan, K. C.; Cabelli, D. E.; Garman, S. C.; Maroney, M. J. Role of Conserved Tyrosine Residues in NiSOD Catalysis: A Case of Convergent Evolution†. Biochemistry (N. Y. ) 2009, 48, 3354-3369.

Herbst, R. W.; Perovic, I.; Martin-Diaconescu, V.; O’Brien, K.; Chivers, P. T.; Pochapsky, S. S.; Pochapsky, T. C.; Maroney, M. J. Communication between the zinc 
and nickel sites in dimeric HypA: metal recognition and $\mathrm{pH}$ sensing. J. Am. Chem. Soc. 2010, 132, 10338-10351.

Hewitt, J.; Morris, J. Superoxide dismutase in some obligately anaerobic bacteria. FEBS Lett. 1975, 50, 315-318.

Hunter, T.; Ikebukuro, K.; Bannister, W. H.; Bannister, J. V.; Hunter, G. J. The conserved residue tyrosine 34 is essential for maximal activity of iron-superoxide dismutase from Escherichia coli. Biochemistry (N. Y. ) 1997, 36, 4925-4933.

Imlay, J. A.; Fridovich, I. Assay of metabolic superoxide production in Escherichia coli. J. Biol. Chem. 1991, 266, 6957-6965.

Iwig, J. S.; Leitch, S.; Herbst, R. W.; Maroney, M. J.; Chivers, P. T. Ni (II) and Co (II) sensing by Escherichia coli RcnR. J. Am. Chem. Soc. 2008, 130, 7592-7606.

Jeuken, L. J.; van Vliet, P.; Verbeet, M. P.; Camba, R.; McEvoy, J. P.; Armstrong, F. A.; Canters, G. W. Role of the surface-exposed and copper-coordinating histidine in blue copper proteins: The electron-transfer and redox-coupled ligand binding properties of His117Gly azurin. J. Am. Chem. Soc. 2000, 122, 12186-12194.

Jude, A. R.; Providence, L. L.; Schmutzer, S. E.; Shobana, S.; Greathouse, D. V.; Andersen, O. S.; Koeppe, R. E. Peptide backbone chemistry and membrane channel function: effects of a single amide-to-ester replacement on gramicidin channel structure and function. Biochemistry (N. Y. ) 2001, 40, 1460-1472.

Kaasjager, V. E.; Bouwman, E.; Gorter, S.; Reedijk, J.; Grapperhaus, C. A.; Reibenspies, J. H.; Smee, J. J.; Darensbourg, M. Y.; Derecskei-Kovacs, A.; Thomson, L. M. Unique reactivity of a tetradentate $\mathrm{N}_{2} \mathrm{~S}_{2}$ complex of nickel: Intermediates in the production of sulfur oxygenates. Inorg. Chem. 2002, 41, 1837-1844.

Keele, B. B.,Jr; McCord, J. M.; Fridovich, I. Superoxide dismutase from escherichia coli B. A new manganese-containing enzyme. J. Biol. Chem. 1970, 245, 6176-6181.

Kim, E.; Chung, H.; Suh, B.; Hah, Y. C.; Roe, J. Transcriptional and post-transcriptional regulation by nickel of sodN gene encoding nickel-containing superoxide dismutase from Streptomyces coelicolor Müller. Mol. Microbiol. 1998, 27, 187-195.

Kim, H. M.; Shin, J. H.; Cho, Y. B.; Roe, J. H. Inverse regulation of Fe- and Nicontaining SOD genes by a Fur family regulator Nur through small RNA processed from 3'UTR of the sodF mRNA. Nucleic Acids Res. 2014, 42, 2003-2014.

Kirschvink, J. L.; Gaidos, E. J.; Bertani, L. E.; Beukes, N. J.; Gutzmer, J.; Maepa, L. N.; Steinberger, R. E. Paleoproterozoic snowball earth: extreme climatic and geochemical global change and its biological consequences. Proc. Natl. Acad. Sci. U. S. A. 2000, 97, 1400-1405. 
Koh, J. T.; Cornish, V. W.; Schultz, P. G. An experimental approach to evaluating the role of backbone interactions in proteins using unnatural amino acid mutagenesis. Biochemistry (N. Y. ) 1997, 36, 11314-11322.

Kono, Y.; Fridovich, I. Superoxide radical inhibits catalase. J. Biol. Chem. 1982, 257, 5751-5754.

Leclere, V.; Boiron, P.; Blondeau, R. Diversity of superoxide-dismutases among clinical and soil isolates of Streptomyces species. Curr. Microbiol. 1999, 39, 365-368.

Lee, H.; Lee, J.; Yang, T.; Kang, S.; Hoffman, B. M. ENDOR and ESEEM investigation of the Ni-containing superoxide dismutase. JBIC Journal of Biological Inorganic Chemistry 2010, 15, 175-182.

Leitch, S.; Bradley, M. J.; Rowe, J. L.; Chivers, P. T.; Maroney, M. J. Nickel-specific response in the transcriptional regulator, Escherichia coli NikR. J. Am. Chem. Soc. 2007, 129, 5085-5095.

Low, D. W.; Hill, M. G. Backbone-engineered high-potential iron proteins: effects of active-site hydrogen bonding on reduction potential. J. Am. Chem. Soc. 2000, 122, 11039-11040.

Lu, W.; Qasim, M.; Laskowski, M.; Kent, S. B. Probing intermolecular main chain hydrogen bonding in serine proteinase-protein inhibitor complexes: chemical synthesis of backbone-engineered turkey ovomucoid third domain. Biochemistry (N. Y. ) 1997, 36, 673-679.

Mack, D. P.; Dervan, P. B. Sequence-specific oxidative cleavage of DNA by a designed metalloprotein, nickel (II). cntdot. GGH (Hin139-190). Biochemistry (N. Y. ) 1992, 31, 9399-9405.

Mack, D. P.; Dervan, P. B. Nickel-mediated sequence-specific oxidative cleavage of DNA by a designed metalloprotein. J. Am. Chem. Soc. 1990, 112, 4604-4606.

Mack, D. P.; Iverson, B. L.; Dervan, P. B. Design and chemical synthesis of a sequencespecific DNA-cleaving protein. J. Am. Chem. Soc. 1988, 110, 7572-7574.

Mann, T.; Keilin, D. Haemocuprein and hepatocuprein, copper-protein compounds of blood and liver in mammals. Proceedings of the Royal Society of London.Series B, Biological Sciences 1938, 126, 303-315.

Maroney, M. J. Structure/function relationships in nickel metallobiochemistry. Curr. Opin. Chem. Biol. 1999, 3, 188-199.

Martin-Diaconescu, V.; Bellucci, M.; Musiani, F.; Ciurli, S.; Maroney, M. J. Unraveling the Helicobacter pylori UreG zinc binding site using X-ray absorption spectroscopy 
(XAS) and structural modeling. JBIC Journal of Biological Inorganic Chemistry 2012, $17,353-361$.

Mathrubootham, V.; Thomas, J.; Staples, R.; McCraken, J.; Shearer, J.; Hegg, E. L. Bisamidate and Mixed Amine/Amidate $\mathrm{NiN}_{2} \mathrm{~S}_{2}$ Complexes as Models for NickelContaining Acetyl Coenzyme A Synthase and Superoxide Dismutase: An Experimental and Computational Study. Inorg. Chem. 2010, 49, 5393-5406.

McCord, J. M. The evolution of free radicals and oxidative stress. Am. J. Med. 2000, 108, 652-659.

McCord, J. M.; Fridovich, I. Superoxide dismutase. An enzymic function for erythrocuprein (hemocuprein). J. Biol. Chem. 1969, 244, 6049-6055.

Miller, A. Superoxide dismutases: ancient enzymes and new insights. FEBS Lett. 2012, 586, 585-595.

Miquel, J.; Economos, A.; Fleming, J.; Johnson Jr, J. Mitochondrial role in cell aging. Exp. Gerontol. 1980, 15, 575-591.

Mirza, S. A.; Pressler, M. A.; Kumar, M.; Day, R. O.; Maroney, M. J. Oxidation of nickel thiolate ligands by dioxygen. Inorg. Chem. 1993, 32, 977-987.

Mullins, C.; Grapperhaus, C.; Kozlowski, P. Density functional theory investigations of $\mathrm{NiN}_{2} \mathrm{~S}_{2}$ reactivity as a function of nitrogen donor type and $\mathrm{N}-\mathrm{H} \cdots \mathrm{S}$ hydrogen bonding inspired by nickel-containing superoxide dismutase. JBIC Journal of Biological Inorganic Chemistry 2006, 11, 617-625.

Murphy, L. M.; Strange, R. W.; Hasnain, S. S. A critical assessment of the evidence from XAFS and crystallography for the breakage of the imidazolate bridge during catalysis in CuZn superoxide dismutase. Structure 1997, 5, 371-379.

Myers, A. G.; Zhong, B.; Movassaghi, M.; Kung, D. W.; Lanman, B. A.; Kwon, S. Synthesis of highly epimerizable $\mathrm{N}$-protected $\alpha$-amino aldehydes of high enantiomeric excess. Tetrahedron Lett. 2000, 41, 1359-1362.

Neupane, K. P.; Gearty, K.; Francis, A.; Shearer, J. Probing variable axial ligation in nickel superoxide dismutase utilizing metallopeptide-based models: insight into the superoxide disproportionation mechanism. J. Am. Chem. Soc. 2007, 129, 14605-14618.

Neupane, K. P.; Shearer, J. The influence of amine/amide versus bisamide coordination in nickel superoxide dismutase. Inorg. Chem. 2006, 45, 10552-10566.

Okada, Y.; Wang, J.; Yamamoto, T.; YOKOI, T.; MU, Y. Amino acids and peptides. L. Development of a novel N $\pi$-protecting group for histidine, $N \pi$-2- 
adamantyloxymethylhistidine, and its application to peptide synthesis. Chemical and pharmaceutical bulletin 1997, 45, 452-456.

Palenik, B.; Brahamsha, B.; Larimer, F.; Land, M.; Hauser, L.; Chain, P.; Lamerdin, J.; Regala, W.; Allen, E.; McCarren, J. The genome of a motile marine Synechococcus. Nature 2003, 424, 1037-1042.

Pelmenschikov, V.; Siegbahn, P. E. Nickel superoxide dismutase reaction mechanism studied by hybrid density functional methods. J. Am. Chem. Soc. 2006, 128, 7466-7475.

Prabhakar, R.; Morokuma, K.; Musaev, D. G. A DFT study of the mechanism of Ni superoxide dismutase (NiSOD): Role of the active site cysteine-6 residue in the oxidative half-reaction. Journal of computational chemistry 2006, 27, 1438-1445.

Reyes-Caballero, H.; Lee, C. W.; Giedroc, D. P. Mycobacterium tuberculosis NmtR harbors a nickel sensing site with parallels to Escherichia coli RcnR. Biochemistry (N. Y. ) 2011, 50, 7941-7952.

Ringe, D.; Petsko, G. A.; Yamakura, F.; Suzuki, K.; Ohmori, D. Structure of iron superoxide dismutase from Pseudomonas ovalis at 2.9-A resolution. Proc. Natl. Acad. Sci. U. S. A. 1983, 80, 3879-3883.

Ryan, K. C.; Guce, A. I.; Johnson, O. E.; Brunold, T. C.; Cabelli, D. E.; Garman, S. C.; Maroney, M. J. Nickel Superoxide Dismutase: Structural and Functional Roles of His1 and its H-bonding Network. Biochemistry (N. Y. ) 2015, 54, 1016-1027.

Ryan, K. C.; Johnson, O. E.; Cabelli, D. E.; Brunold, T. C.; Maroney, M. J. Nickel superoxide dismutase: structural and functional roles of Cys2 and Cys6. JBIC Journal of Biological Inorganic Chemistry 2010, 15, 795-807.

Sawyer, D. T.; Valentine, J. S. How super is superoxide? Acc. Chem. Res. 1981, 14, 393400.

Shearer, J. Use of a Metallopeptide-Based Mimic Provides Evidence for a Proton-Coupled Electron-Transfer Mechanism for Superoxide Reduction by Nickel-Containing Superoxide Dismutase. Angewandte Chemie International Edition 2013, 52, 2569-2572.

Shearer, J. Dioxygen and superoxide stability of metallopeptide based mimics of nickel containing superoxide dismutase: The influence of amine/amidate vs. bis-amidate ligation. J. Inorg. Biochem. 2013, 129, 145-149.

Shearer, J.; Dehestani, A.; Abanda, F. Probing variable amine/amide ligation in $\mathrm{NiIIN}_{2} \mathrm{~S}_{2}$ complexes using sulfur K-edge and nickel L-edge X-ray absorption spectroscopies: implications for the active site of nickel superoxide dismutase. Inorg. Chem. 2008, 47, 2649-2660. 
Shearer, J.; Long, L. M. A nickel superoxide dismutase maquette that reproduces the spectroscopic and functional properties of the metalloenzyme. Inorg. Chem. 2006, 45, 2358-2360.

Shearer, J.; Neupane, K. P.; Callan, P. E. Metallopeptide based mimics with substituted histidines approximate a key hydrogen bonding network in the metalloenzyme nickel superoxide dismutase. Inorg. Chem. 2009, 48, 10560-10571.

Shearer, J.; Peck, K. L.; Schmitt, J. C.; Neupane, K. P. Cysteinate Protonation and Water Hydrogen Bonding at the Active-Site of a Nickel Superoxide Dismutase MetallopeptideBased Mimic: Implications for the Mechanism of Superoxide Reduction. J. Am. Chem. Soc. 2014, 136, 16009-16022.

Shearer, J.; Zhao, N. [Me4N](NiII (BEAAM)): A Synthetic Model for Nickel Superoxide Dismutase That Contains Ni in a Mixed Amine/Amide Coordination Environment. Inorg. Chem. 2006, 45, 9637-9639.

Sheng, Y.; Abreu, I. A.; Cabelli, D. E.; Maroney, M. J.; Miller, A.; Teixeira, M.; Valentine, J. S. Superoxide Dismutases and Superoxide Reductases. Chem. Rev. 2014, 114, 3854-3918.

Shin, I.; Ting, A. Y.; Schultz, P. G. Analysis of backbone hydrogen bonding in a $\beta$-turn of staphylococcal nuclease. J. Am. Chem. Soc. 1997, 119, 12667-12668.

Smee, J. J.; Miller, M. L.; Grapperhaus, C. A.; Reibenspies, J. H.; Darensbourg, M. Y. Subtle bite-angle influences on $\mathrm{N}_{2} \mathrm{~S}_{2} \mathrm{Ni}$ complexes. Inorg. Chem. 2001, 40, 3601-3605.

Stans, M. H. Bond dissociation energies in simple molecules. NIST Special Publication 1970, 1, 58.

Starai, V.; Escalante-Semerena, J. Acetyl-coenzyme A synthetase (AMP forming). Cellular and Molecular Life Sciences CMLS 2004, 61, 2020-2030.

Stevens, C. M.; Watanabe, R. Amino Acid Derivatives. I. Carboallyloxy Derivatives of a-Amino Acids1, 2. J. Am. Chem. Soc. 1950, 72, 725-727.

Szilagyi, R. K.; Bryngelson, P. A.; Maroney, M. J.; Hedman, B.; Hodgson, K. O.; Solomon, E. I. S K-edge X-ray absorption spectroscopic investigation of the $\mathrm{Ni}$ containing superoxide dismutase active site: New structural insight into the mechanism. J. Am. Chem. Soc. 2004, 126, 3018-3019.

Tainer, J. A.; Getzoff, E. D.; Beem, K. M.; Richardson, J. S.; Richardson, D. C. Determination and analysis of the $2 \AA$ structure of copper, zinc superoxide dismutase. $J$. Mol. Biol. 1982, 160, 181-217. 
Tietze, D.; Breitzke, H.; Imhof, D.; Kothe, E.; Weston, J.; Buntkowsky, G. New insight into the mode of action of nickel superoxide dismutase by investigating metallopeptide substrate models. Chemistry-A European Journal 2009, 15, 517-523.

Tietze, D.; Voigt, S.; Mollenhauer, D.; Tischler, M.; Imhof, D.; Gutmann, T.; González, L.; Ohlenschläger, O.; Breitzke, H.; Görlach, M. Revealing the position of the substrate in nickel superoxide dismutase: A model study. Angewandte Chemie International Edition 2011, 50, 2946-2950.

Tseng, H.; Srikhanta, Y.; McEwan, A. G.; Jennings, M. P. Accumulation of manganese in Neisseria gonorrhoeae correlates with resistance to oxidative killing by superoxide anion and is independent of superoxide dismutase activity. Mol. Microbiol. 2001, 40, 1175-1186.

Uudsemaa, M.; Tamm, T. Density-functional theory calculations of aqueous redox potentials of fourth-period transition metals. The Journal of Physical Chemistry A 2003, 107, 9997-10003.

Venter, J. C.; Remington, K.; Heidelberg, J. F.; Halpern, A. L.; Rusch, D.; Eisen, J. A.; Wu, D.; Paulsen, I.; Nelson, K. E.; Nelson, W.; Fouts, D. E.; Levy, S.; Knap, A. H.; Lomas, M. W.; Nealson, K.; White, O.; Peterson, J.; Hoffman, J.; Parsons, R.; BadenTillson, H.; Pfannkoch, C.; Rogers, Y. H.; Smith, H. O. Environmental genome shotgun sequencing of the Sargasso Sea. Science 2004, 304, 66-74.

Wagner, U. G.; Frolow, F.; Sussman, J. L.; Pattridge, K. A.; Ludwig, M. L.; Stallings, W. C.; Werber, M. M.; Oefner, C. Comparison of the crystal structures of genetically engineered human manganese superoxide dismutase and manganese superoxide dismutase from Thermus thermophilus: differences in dimer-dimer interaction. Protein Science 1993, 2, 814-825.

Wang, Z.; Rejtar, T.; Zhou, Z. S.; Karger, B. L. Desulfurization of cysteine-containing peptides resulting from sample preparation for protein characterization by mass spectrometry. Rapid Communications in Mass Spectrometry 2010, 24, 267-275.

Woyke, T.; Teeling, H.; Ivanova, N. N.; Huntemann, M.; Richter, M.; Gloeckner, F. O.; Boffelli, D.; Anderson, I. J.; Barry, K. W.; Shapiro, H. J. Symbiosis insights through metagenomic analysis of a microbial consortium. Nature 2006, 443, 950-955.

Wuerges, J.; Lee, J. W.; Yim, Y. I.; Yim, H. S.; Kang, S. O.; Djinovic Carugo, K. Crystal structure of nickel-containing superoxide dismutase reveals another type of active site. Proc. Natl. Acad. Sci. U. S. A. 2004, 101, 8569-8574.

Yost, F. J.,Jr; Fridovich, I. An iron-containing superoxide dismutase from Escherichia coli. J. Biol. Chem. 1973, 248, 4905-4908. 
Youn, H.; Kim, E.; Roe, J.; Hah, Y.; Kang, S. A novel nickel-containing superoxide dismutase from Streptomyces spp. Biochem. J. 1996, 318, 889-896.

Youn, H.; Youn, H.; Lee, J.; Yim, Y.; Lee, J. K.; Hah, Y. C.; Kang, S. Unique Isozymes of Superoxide Dismutase inStreptomyces griseus. Arch. Biochem. Biophys. 1996, 334, 341-348. 